\title{
ELECTROMAGNETIC PULSE RESEARCH ON ELECTRIC POWER SYSTEMS: PROGRAM SUMMARY AND RECOMMENDATIONS
}

P. R. Barnes

B. W. McConnell

J. W. Van Dyke

Energy Division

Oak Ridge National Laboratory

Oak Ridge, Tennessee

F. M. Tesche

Consultant

Dallas, Texas

E. F. Vance

Consultant

Fort Worth, Texas

January 1993

Prepared by the

OAK RIDGE NATIONAL LABORATORY

Oak Ridge, Tennessee 37831-6285

managed by

MARTIN MARIETTA ENERGY SYSTEMS, INC.

for the

U.S. DEPARTMENT OF ENERGY

under contract DE-AC05-84OR21400 
TABLE OF CONTENTS

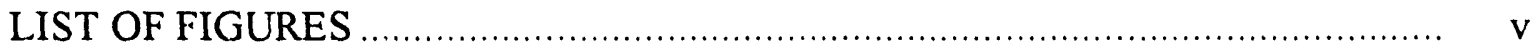

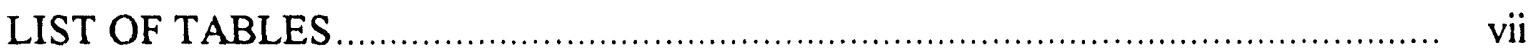

ABBREVIATIONS AND ACRONYMS …............................................. ix

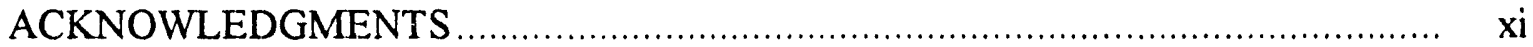

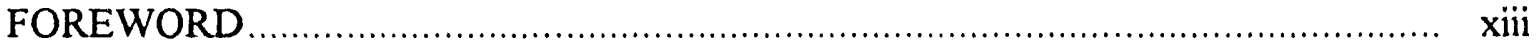

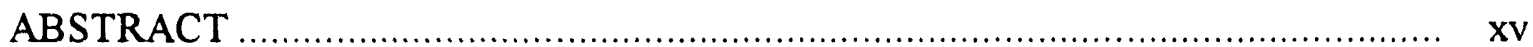

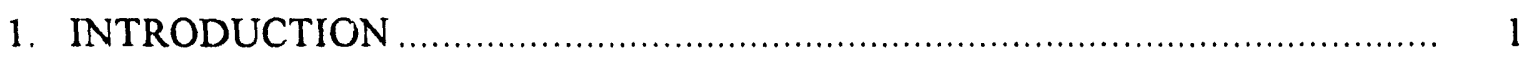

1.1 SECTION REFERENCES ..................................................... 2

2. THE HIGH-ALTITUDE ELECTROMAGNETIC PULSE

ENVIRONMENT …................................................................................ 4

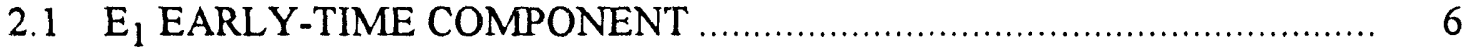

$2.2 \quad E_{2}$ INTERMEDIATE-TIME COMPONENT …................................. 7

$2.3 \quad E_{3}$ LATE-TIME COMPONENT .................................................. 7

2.4 SECTION REFERENCES ...................................................... 11

3. ASSESSMENT METHODOLOGY ................................................... 12

3.1 GENERAL DESCRIPTION .................................................... 12

3.2 STATISTICAL CONSIDERATIONS IN THE ASSESSMENT .............. 14

3.3 PRACTICAL LIMITATIONS IN THE IMPLEMENTATION OF THE ASSESSMENT .............................................................. 16

3.4 SECTION REFERENCES ....................................................... 17

4. ANALYTICAL MODELING ......................................................... 18

4.1 OVERVIEW OF HIGH-ALTITUDE ELECTROMAGNETIC PULSE ANALYSIS ............................................................ 18

4.2 HIGH-ALTITUDE ELECTROMAGNETIC PULSE

ENVIRONMENT

DEFINITION

4.3 HIGH-ALTITUDE ELECTROMAGNETIC PULSE INTERACTION WITH THE EARTH …......................................................... 19

4.4 BASIC ELECTROMAGNETIC COUPLING ANALYSIS ..................... 19

4.5 ANALYSIS VALIDATION .................................................... 20

4.6 SYSTEM-LEVEL ANALYSIS ................................................ 20

4.7 EXPERIMENT DESIGN ....................................................... 21

4.8 SECTION REFERENCES .................................................... 21

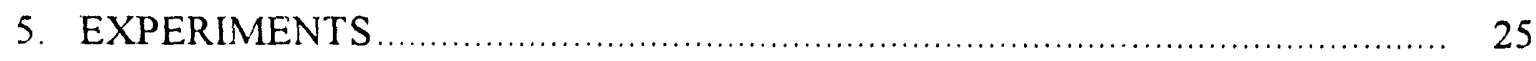

5.1 TEST OBJECTIVES AND OVERVIEW ….................................. 25

5.2 TEST DESCRIPTION ........................................................... 26

5.2.1 Distribution Transformers ................................................ 26

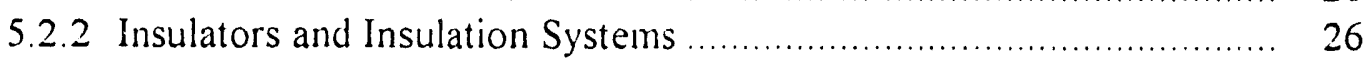

5.2.3 Power Line Filters ....................................................... 27 
5.2.4 Underground Distribution Cables................................................ 27

5.2 .5 Corona Testing ....................................................................... 27

5.2.6 Protective Relay Equipment................................................... 27

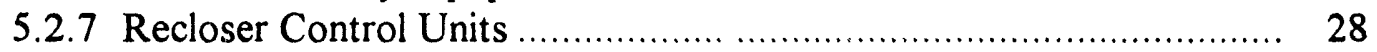

5.2.8 Power Plant Instrumentation...................................................... 28

5.3 SUMMARY OF TEST RESULTS ………............................................. 28

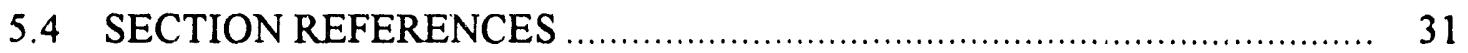

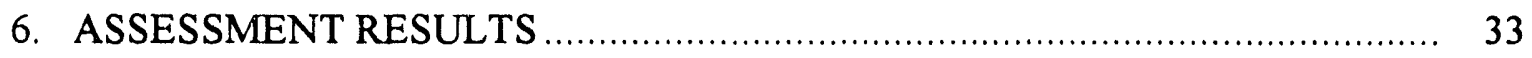

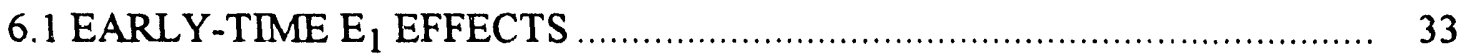

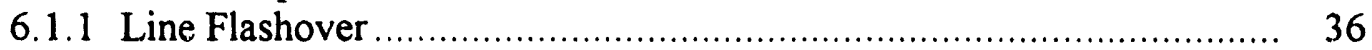

6.1.2 Loss of Load Due to Flashovers ................................................. 37

6.1.3 Loss of Load Due to Secondary Voltage Transients........................ 39

6.1.4 High-Altitude Electromagnetic Pulse-Induced Damage On Power System Components ................................................................. 39

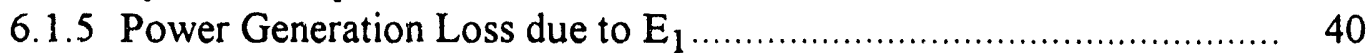

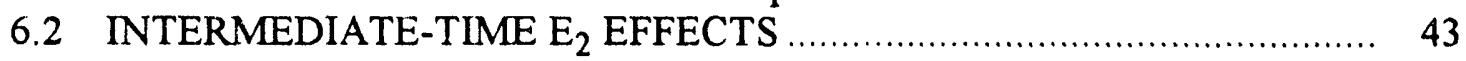

6.3 MAGNETOHYDRODYNAMIC ELECTROMAGNETIC PULSE

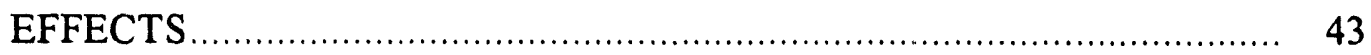

6.3.1 Direct Damage ……............................................................... 44

6.3.2 Faulty Operation of Power System Components ............................ 44

6.3.3 System-Wide Magnetohydrodynamic Electromagnetic Pulse Effects.. 45

6.4 POWER SYSTEM RESPONSE TO THE COMBINED HIGH-

ALTITUDE ELECTROMAGNETIC PULSE ENVIRONMENTS ............. 46

6.5 EFFECTS OF MULTIPLE BURSTS ON POWER SYSTEMS ................. 47

6.5.1 Multipıe $E_{1}$ Effects on the Power System Load............................... 47

6.5.2 Multiple $E_{1}$ Effects on Arresters .................................................. 48

6.5.3 Multiple $\mathrm{E}_{1}$ Effects on Generation .............................................. 48

6.5.4 Multiple Magnetohydrodynamic Electromagnetic Pulse Events ......... 49

6.5.5 Other Assessments................................................................ 49

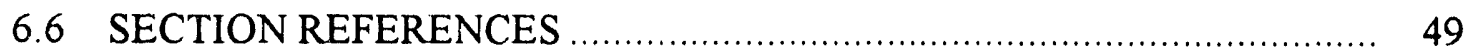

7. SOCIOECONOMIC IMPACTS OF HIGH-ALTITUDE

ELECTROMAGNETIC PULSE …......................................................... 52

7.1 COMPONENTS OF SOCIOECONOMIC COSTS OF

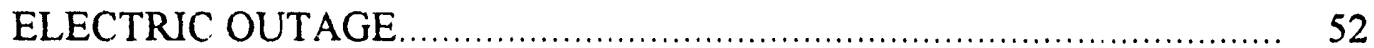

7.2 ESTIMATING COSTS OF ELECTRIC OUTAGE …............................. 53

7.3 OUTAGE SCENARIOS ............................................................... 56

7.4 HIGH-ALTITUDE ELECTROMAGNETIC PULSE OUTAGE COSTS

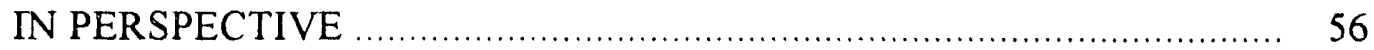

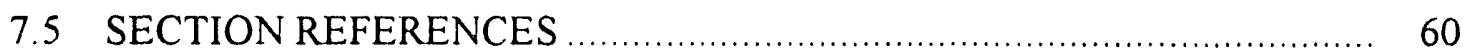

8. RECOMMENDATIONS FOR UTILITIES AND EMERGENCY

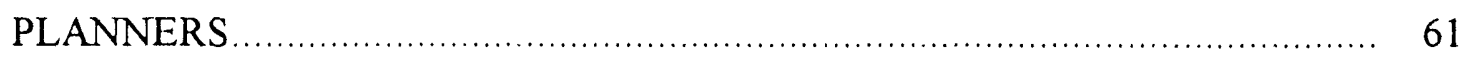

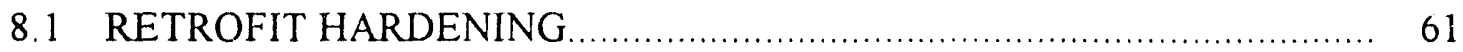

8.2 GOOD ENGINEERING DESIGN PRACTICES .................................. 61 
8.3 COMMUNICATION FACILITY DESIGN PRACTICES …....................... 63

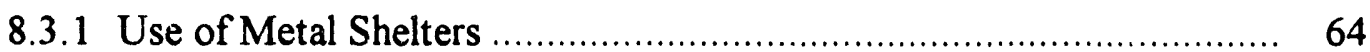

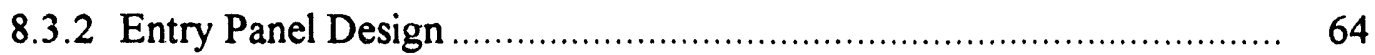

8.3.3 Treatment of Power Service ...................................................... 65

8.3.4 Coaxial Cable and Waveguide Treatment ....................................... 65

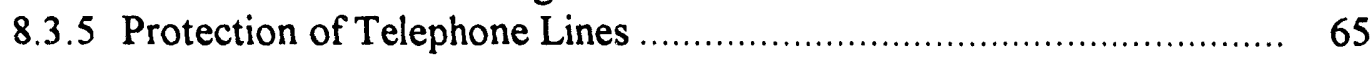

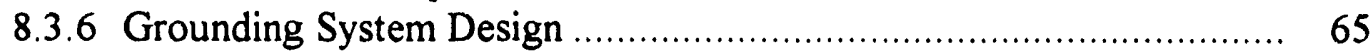

8.4 SPARES.

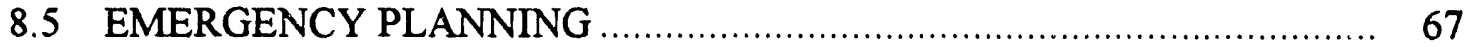

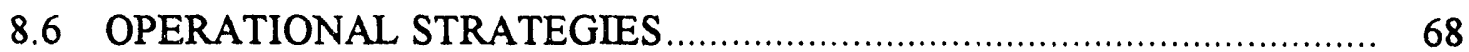

8.7 TRAINING AND PLANNING DEVELOPMENT ….............................. $\quad 70$

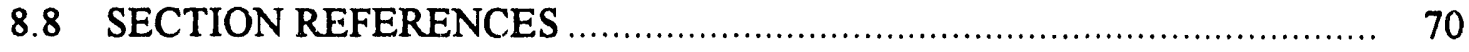

9. SUMMARY AND CONCLUSIONS .................................................... 72

APPENDIX A EMP RESEARCH PROGRAM REVIEW GROUPS ..................... 74

APPENDIX B BIBLIOGRAPHY OF ORNL-RELATED PUBLICATIONS …....... 75 


\section{LIST OF FIGURES}

1. Qualitative example of transient high-altitude electromagnetic pulse environments.

2. Characteristics of the $E_{1}$ environment. (a) Spatial variation of the peak $E_{1}$ fields (contours in kilovolts per meter), (b) transient $E_{1}$ waveforms to the west of ground zero.

3. Magnetohydrodymanic electromagnetic pulse environment for a 400 $\mathrm{km}$ burst over the central United States. (a) Normalized transient waveform for $E_{3}$, (b) electric field lines for early time, (c) electric field lines for late time.

4. Time sequence of events for the power system response to a single high-altitude burst.

5. Simplified flow diagram of the assessment methodology for $E_{1}$ and $\mathrm{E}_{3}$ assessments of electric power systems.

6. Flowchart of the process of stress-strength comparison.

7. Graphic representation of stress-strength comparisons.

8. Peak $\mathrm{V}_{\mathrm{\alpha c}}$ for a $15-\mathrm{kV}$ class power distribution line (contours in kilovolts per meter).

9. Cumulative probability distribution for $\mathrm{V}_{\mathrm{oc}}$ for different classes of transmission and distribution lines.

10. Regions of flashover for the $12.47-\mathrm{kV}$ power distribution line with grounded insulators.

11. Component levels in a typical distribution system

12. Illustration of entry panel into a partially shielded facility. 


\section{LIST OF TABLES}

1. Selected results of components tests

2. Selected results from steep-front short-duration impulse tests on

insulators, cables, and arresters

3. Percentage of line flashovers for several operating voltages and peak

$\mathrm{E}_{1}$ fields

4. Percentage of distribution class lines experiencing a flashover for various peak $\mathrm{E}_{1}$ field strengths.

5. Percentage of remote 480-V-motors failing when supplied by an unshielded, buried cable (for a $2200-\mathrm{km}$ radius area of illumination)

6. Percentage of generation loss based on 480-V-motor damage when supplied by unshielded buried cable $(2200-\mathrm{km}$ radius area of illumination)

7. Percentage of busses with a per-unit voltage level below the specified values as a result of the Arizona Public Service magnetohydrodynamic electromagnetic pulse analysis.

8. Some social and economic impacts of the New York city blackout

9. Scenario I: High-altitude electromagnetic pulse costs due to effects on electric system (costs in millions of 1988 dollars)

10. Scenario II: High-altitude electromagnetic pulse costs due to effects on electric system (costs in millions of 1988 dollars)

11. Scenario III: High-altitude electromagnetic pulse costs due to effectson electric system (costs in millions of 1988 dollars).

12. Scenario IV: High-altitude electromagnetic pulse costs due to effects on electric system (costs in millions of 1988 dollars).

13. Summary table: range of high-altitude electromagnetic pulse costs (billions of 1988 dollars).

14. Estimated costs of disasters 


\section{ABBREVIATIONS AND ACRONYMS}

ac

alternating current

APS

Arizona Public Service

BIL

CFO

basic insulation level

CT

critical flashover

dc

current transformer

DNA

direct current

DOD

Defense Nuclear Agency

DOE

EM

U.S. Department of Defense

U.S. Department of Energy

electromagnetic

EMF

electromotive force

EMP

electromagnetic pulse

EPRI

HEMP

Electric Power Research Institute

IEEE

$\mathrm{km}$

high-altitude electromagnetic pulse

LLNL

Institute of Electrical and Electronics Engineers

kilometer

MAIN

Lawrence Livermore National Laboratory

MHD-EMP

Mid-America Interconnected Network

MOV

MW

magnetohydrodynamic electromagnetic pulse

metal oxide varistor

NERC

megawatt

ORNL

PJM

North American Electric Reliability Council

Oak Ridge National Laboratory

PT

Pennsylvania-New Jersey-Maryland Interconnection

SFSD

T\&D

potential transformer

steep-front short-duration

TVSS

transmission and distribution

U.S.

transient voltage surge suppressers

UPS

United States

WSCC

uninterruptable power supply

Western States Coordinating Council 


\section{ACKNOWLEDGMENTS}

This research effort was sponsored by the Office of Energy Storage and Distribution of the United States Department of Energy (DOE) under Contract DE-AC05$840 R 21400$ with Martin Marietta Energy Systems, Inc., manager of the Oak Ridge National Laboratory (ORNL).

We wish to acknowledge and thank various individuals and organizations for their valuable assistance during the course of this research program. We thank Dr. Imre Gyuk of DOE and Mr. Ken Klein, formerly of DOE, for their support, guidance, and encouragement in this program. In addition, thanks are due to Dr. Steinar Dale and Mr. Paul Gnadt, formerly of ORNL, for their daily advice and assistance. Thanks are also due to the members of the Utility Advisory Group and the members of the Electromagnetic Pulse (EMP) Advisory Group for providing useful insights into many problem areas and in reviewing the research. A list of the Advisory Group members is provided in Appendix A. We also wish to acknowledge Dr. Mario Rabinowitz of the Electric Power Research Institute (EPR J) for providing suggestions associated with the flashover vulnerability analysis of distribution systems, and Mr. George Applegren of the Mid-America Interconnected Network (MAIN) for providing reviews and suggestions for various reports written under this effort. We would like to thank Arizona Public Service for the use of their system in the preliminary assessment studies, and Virginia Power Co., and Wisconsin Electriz Co., for providing equipment for impulse tests. The Public Service Company of New Mexico also assisted in providing transformers for component testing. Thanks also are extended to the Defense Nuclear Agency for providing HEMP simulator facilities for testing and to the Lawrence Livermore National Laboratory for useful discussions regarding HEMP environments and coupling. The North American Electric Reliability Council assisted in the restoration studies, and EPRI provided useful data and models associated with electromagnetic transients in substations.

This program could have not been possible without the assistance of various subcontractor organizations. These include BDM International; Kaman Sciences Corporation; LuTech, Inc.; Maxwell Laboratories; Cooper Power Systems; Mission Research Corporation; Pulse Sciences, Inc.; Rockwell International; SRI International; University of Florida; University of Mississippi; The University of Tennessee; and Westinghouse Electric Corp. (ABB Power Systems, Inc.). 


\section{FOREWORD}

The Office of Energy Management of the United States Department of Energy (DOE) has formulated a program for the research and development of technologies and systems for the assessment, operation, and control of electrical power systems when subjected to an electromagnetic pulse (EMP). The DOE EMP program plan is documented in a DOE report entitled Program Plan for Research and Development of Technologies and systems for Electric Power Systems Under the Influence of Nuclear Electromagnetic Pulses, DOE/NBB-003, May 1983. This report summarizes much of the important results of this research activity for the period 1983 to 1992 . The important elements of this work, such as system and component modeling, equipment testing, assessment methodology, etc., are described in the various sections of this report. Each section has its own references pertaining to the particular subject matter being discussed so that it can stand as a self-contained unit. At the end of the report, in Appendix B, a bibliography of ORNL-related publications resulting from this effort are presented. 


\begin{abstract}
A single nuclear detonation several hundred kilometers above the central United States will subject much of the nation to a high-altitude electromagnetic pulse (HEMP). This pulse consists of an intense steep-front, short-duration transient electromagnetic field, followed by a geomagnetic disturbance with tens of seconds duration. This latter environment is referred to as the magnetohydrodynanic electromagnetic pulse (MHDEMP). Both the early-time transient and the geomagnetic disturbance could impact the operation of the nation's power systems. Since 1983, the U.S. Department of Energy has been actively pursuing a research program to assess the potential impacts of one or more HEMP events on the nation's electric energy supply. This report summarizes the results of that program and provides recommendations for enhancing power system reliability under HEMP conditions. A nominal HEMP environment suitable for assessing geographically large systems was developed during the program and is briefly described in this report. This environment was used to provide a realistic indication of HEMP impacts on electric power systems. It was found that a single high-altitude burst, which could significantly disturb the geomagnetic field, may cause the interconnected power network to break up into utility islands with massive power failures in some areas. However, permanent damage vould be isolated, and restoration should be possible within a few hours. Multiple bursts would likely increase the blackout areas, component failures, and restoration time. However, a long-term blackout of many months is unlikely because major power system components, such as transformers, are not likely to be damaged by the nominal HEMP environment. Moreover, power system reliability, under both HEMP and normal operating conditions, can be enhanced by simple, and often low cost, modifications to current utility practices.
\end{abstract}




\section{INTRODUCTION}

On July 8,1962 , at 11:00 p.m. Hawaiian time, a nuclear detonation occurred at $400 \mathrm{~km}$ above Johnston Atoll in the Pacific Ocean. This high-altitude nuclear test was conducted by the United States under the code name "Starfish." Approximately $1300 \mathrm{~km}$ from ground zero on the Hawaiian island of Oahu, 30 strings of streetlights failed simultaneously at the time of the Starfish shot ${ }^{1}$. This streetlight incident was examined by Vittitoe, who concluded that the failure was caused by the high-altitude electromagnetic pulse (HEMP) generated by the high-altitude burst ${ }^{2}$. The peak HEMP electric field over Honolulu was estimated ${ }^{3}$ to be $5.6 \mathrm{kV} / \mathrm{m}$. Although the peak amplitude of the HEMP was relatively small, the orientation of the streetlight circuits with respect to the incident HEMP angle allowed a coherent buildup of surges that resulted in blown fuses ${ }^{2}$.

Modern weapons with higher gamma-ray yields and the higher geomagnetic fields over the central United States could produce HEMP signals with intense transient electromagnetic (EM) fields on the order of tens of kilovolts per meter. These higher fields, along with the introduction of modern solid-state and microprocessor-based control, instrumentation, and protection equipment in electric power systems, have caused concern in both government and civilian sectors that one or more nuclear weapons detonated in space above the continental United States could disrupt electric power during a period of national crisis. During the early 1980s, numerous newspaper and journal articles focused attention on the potential impacts of HEMP on the nation's electric energy supply ${ }^{4-12}$. A recent article on the research and development of new third-generation nuclear weapons, that can be designed to selectively produce gamma and EM radiation ${ }^{13}$, implies that nuclear-generated HEMP may become an even more important issue in the future.

In 1983, the Office of Energy Storage and Distribution of the U.S. Department of Energy (DOE) established a research program to assess the impacts of HEMP on electric power systems ${ }^{14,15}$. The primary goal of the program was to increase national security by assessing the impacts of HEMP on electric power systems and, if necessary, to enhance the reliability of electric power systems under the influence of HEMP. A secondary goal was to enhance the reliability of power systems under the influence of related EM disturbances, such as steep-front surges, lightning, and geomagnetic storms.

The research conducted under the DOE HEMP Program has been reviewed frequently by a group of experts in the HEMP and electric utility communities. These reviews help to ensure that the studies are realistic for electric power systems and that solutions are consistent with acceptable utility practice. To minimize duplication of work, the program also depends on cooperation and coordination with related U.S. Department of Defense (DOD), Electric Power Research Institute (EPRI), and European research. The program also works closely with the North American Electric Reliability Council (NERC) in areas related to reliability and restoration. 
The purpose of this report is to summarize the results of the DOE HEMP Program, with emphasis on HEMP effects on commercial electric power systems. Section 2 discusses the HEMP environments used in this study. Because of security considerations, only unclassified environments that are typical of those expected from an actual nuclear detonation are used, and these are referred to as "nominal" HEMP environments. The methodology for assessing the overall behavior of the power system in response to these HEMP environments is discussed in Section 3. The application of this methodology requires a knowledge of HEMP-induced voltage or current surges on power system conductors and the response of power system components to these surges. This required information was obtained by both analytical and experimental methods, which are described in Sections 4 and 5, respectively. Section 6 summarizes the results of this assessment for both single- and multi-burst scenarios. After this estimation of the power system responses to the HEMP environments, the estimated socioeconomic impact of HEMP is summarized in Section 7. Fi rally, in Section 8 various steps that utility companies and emergency planners can to to mitigate the HEMP effect on the power system are outlined. The summary and cunclu ions are presented in Section 9.

\subsection{SECTION REFERENCES}

1. S. Glasstone and P. J. Dolan, The Effects of Nuclear Weapons, U.S. Department of Energy, Washington, D.C., 1977.

2. C. N. Vittitoe, Did High-Altitude EMP Cause the Hawaiian Streetlights Incident? SAND88-0043C, Sandia National Laboratories, Albuquerque, N.M., 1988.

3. C. L. Longmire, "EMP on Honolulu from the Starfish Event," EMP Theoretical Note 353, Air Force Weapons Laboratory, Albuquerque, N.M., March 1985.

4. W. J. Broad, "Nuclear Pulse (I): Awakening to the Chaos Factor," Science 212, $1009-12,(1981)$.

5. W. J. Broad, "Nuclear Pulse (II): Ensuring Delivery of the Doomsday Signal," Science 212, 1116-20, (1981).

6. W. J. Broad, "Nuclear Pulse (III): Playing a Wild Card," Science 212, 1248-51, (1981).

7. E. J. Lerner, "Electromagnetic Pulses: Potential Crippler," IEEE Spectrum 18, 41-46, (May 1981).

8. E. J. Lerner, "EMP and Nuclear Power," IEEE Spectrum 18, 48-49, (June 1981).

9. J. Raloff, "EMP: A Sleeping Electronic Dragon," Scicnce News 119, 300--302, (1981).

10. J. Raloff, "EMP: Defensive Strategies," Science New 119, 314-315, (1981). 
11. E. Teller, "Mlectromagnetic Pulses from Nuclear Explosions," IEEE Spectrum 19 (10), 65, (October 1y82).

12. W. J. Broad, "The Chaos Factor," Science 83, 41-49, (January/February 1983).

13. T. B. Taylor, "Third-Generation Nuclear Weapons," Scientific American 256 (4), 34-39, (April 1987).

14. Program Plan for Research and Development of Technologies and Systems for Electrical Power Systems Under the Influence of Nuclear Electromagnetic Pulses, DOE/NBB-003, U.S. DOE, May 1983.

15. K. W. Klein, P. R. Barnes, and H. W. Zaininger, "Electromagnetic Pulse and the Electric Power Network," IEEE PAS Transactions PAS-104 (6), (June 1985). 


\section{THE HIGH-ALTITUDE ELECTROMAGNETIC PULSE ENVIRONMENT}

A nuclear detonation in or above the earth's atmosphere produces an intense electromagnetic pulse (EMP) ${ }^{1,2}$. The EMP produced by such a detonation is often referred to as a nuclear EMP (NEMP). The EM fields radiater from the blast vary greatly with weapon characteristics, yield, and detonation height. a targe portion of the EMP energy is contained in the radio frequency spectrum below $200 \mathrm{MHz}$. For bursts at altitudes above $40 \mathrm{~km}$, the EMP environment is referred to as a HEMP. For convenience, this $\mathrm{EM}$ disturbance is further subdivided into three components, denoted by $E_{1}, E_{2}$, and $E_{3}$, depending on the production mechanism and the observed time of the disturbance.

The early-time $\mathrm{E}_{1}$ component of HEMP is a steep-tront, short-duration pulse with a rise time of a few nanoseconds. This waveform rapidly decays away in about $1 \mu$ s or less. A single high-altitude nuclear burst at a height of about $400 \mathrm{~km}$ can subject much of the continental United States to an $\mathrm{E}_{1}$ HEMP electric field with a peak amplitude on the order of tens of kilovolts per meter.

Following the early-time HEMP environment, a more slowly varying and less intense EM field is observed on the ground. This is the intermediate-time $E_{2}$ environment, which has an electric field strength of several hundreds of volts per meter and a typical duration time of several hundred microseconds. This waveform component is followed by a very low amplitude, late-time signal that is on the order of tens of volts per kilometer. This late-time $\mathrm{E}_{3}$ signal results from geomagnetic perturbations caused by a high-altitude nuclear detonation and has a response time up to several hundreds of seconds. This latter component of the HEMP signal is often referred to as magnetohydrodynamic EMP (MHDEMP). MHD-EMP may affect power systems similarly to geomagnetic storms ${ }^{3}$.

As an illustration of these three environments, Fig. 1 presents a qualitative view of the E-field found in HEMP, with the various production mechanisms indicated. As noted previously, the various parts of this environment have different properties. Consequently, it is difficult to compare them on a quantitative basis.

To assess the effects of EMP on civilian electric power systems, it is necessary to have specifications of the $E_{1}, E_{2}$, and $E_{3}$ field components that excite the system. These excitation fields, together with a specification of the initial condition, or state, of the power system, are used to determine the probable respunse of the power network. Because a knowledgeable expert might derive significant information about the weapon design from detailed environmental information about the EMP characteristics, such detailed information cannot be used in this unclassified assessment. 


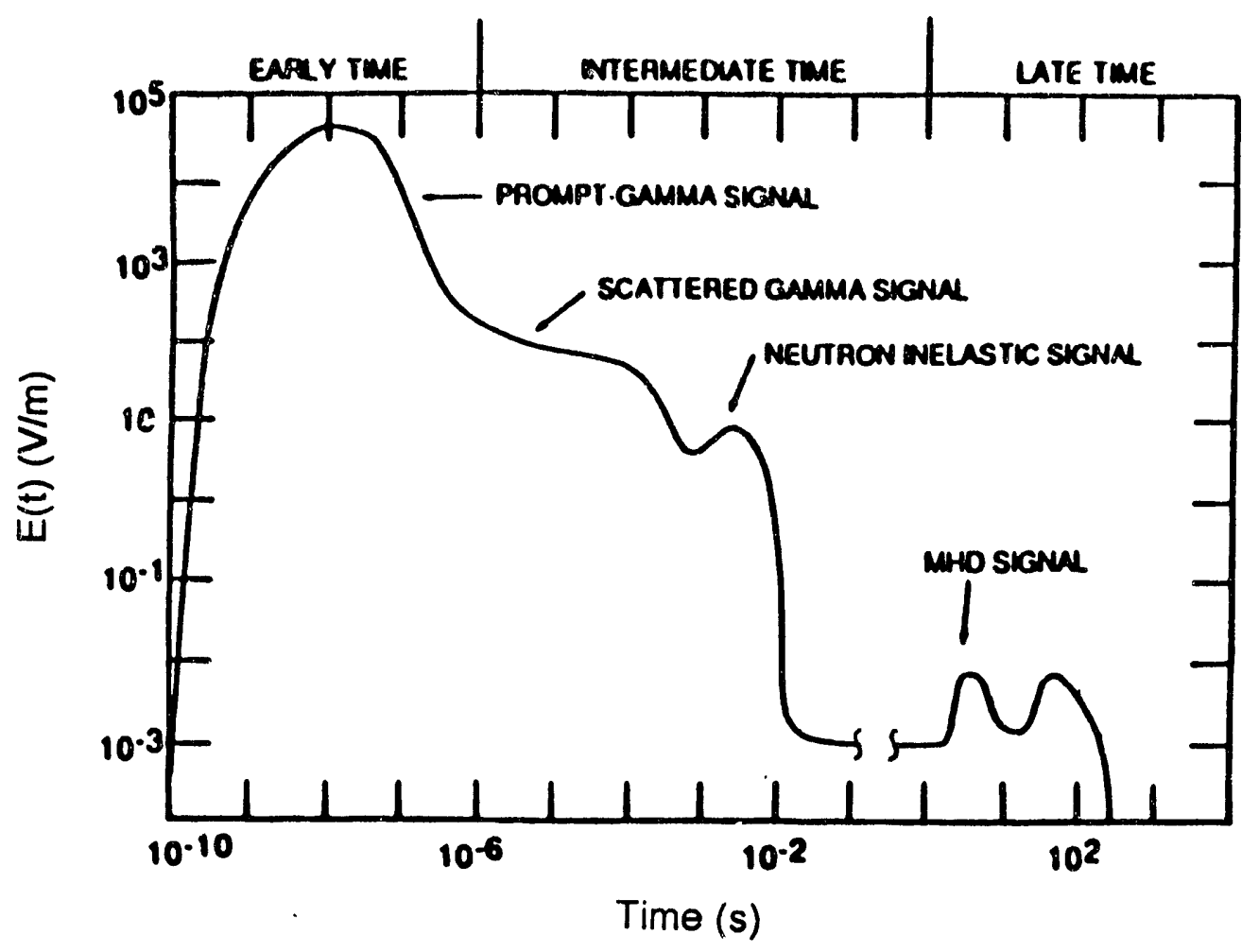

\section{Fig. 1. Qualitative example of transient high-altitude electromagnetic pulse environments.}

Various HEMP waveforms have been developed for analysis and used in the unclassified literature ${ }^{4-7}$. It is important to recognize that these generalized waveforms do not represent an actual HEMP. They are designed to incorporate the potentially damaging features of HEMP, such as a large-peak amplitude, a fast-rise time, and a long-fall time. Such an HEMP description is referred to as a "bounding" waveform and is used most effectively in designing a hardened military system when the system is small (on the order of several hundred meters in extent) and survivability is a key issue. Typically, this worstcase HEMP environment is applied with the angle of incidence and polarization chosen so that the induced system response is as large as possible. The HEMP hardening design then proceeds with this response as a criterion for the expected excitation of internal systems.

For performing a realistic assessment of the effects of HEMP on very large systems such as a power network, this worst-case definition of the environment is not warranted. An expected HEMP environment would vary considerably in pulse shape, amplitude, polarization, and angle of incidence at observation locations on the giound. This more realistic definition leads to system responses that can be much less than those for the bounding waveform. While such a bounding HEMP definition could be invoked in the assessment of the civilian electric power network, the significant geographic size of the power system and the nature of the network properties would provide unrealistically large 
estimates of the system responses. The resulting assessment $\mathrm{cf}$ the power system response would then be excessively pessimistic.

To provide a reasonable definition of the HEMP environment for power system assessments, a set of unclassified $E_{1}, E_{2}$, and $E_{3}$ fields has been developed under this assessment program. These nominal HEMP environments are based on both observed HEMP response data and on calculations of actual HEMP environments. These fields are summarized in the following sections.

\section{$2.1 \quad E_{1}$ EARLY-TIME COMPONENT}

The production of the early-time $\mathrm{E}_{1}$ HEMP environment has been studied intensively and is well understood. Theoretical models provide results that compare well with limited measurements taken from atmospheric nuclear tests. For example, ref. 8 illustrates measured data and calculated results for a high-altitude detonation that were computed using the CHAP Code 9 . This code accurately predicts the $\mathrm{E}_{1}$ fields on the earth due to a specified high-altitude nuclear burst. The theory for predicting this early-time pulse was developed during 1963-1964 ${ }^{8}$. Numerical computer codes, like CHAP, were developed during the 1960s and 1970s. Currently, the only improvements being introduced are refinements in the computer codes, with uncertainties in the pulse magnitude arising from the uncertainties in the weapon output and air chemistry parameters.

The fundamental mechanism responsible for the production of the $E_{1}$ pulse is the prompt gamma radiation from the detonation that is converted to EM energy by the Compton process. The highly energetic gamma particles interact with air molecules in the earth's atmosphere to produce a "source region" at an altitude of 30 to $40 \mathrm{~km}$. In this region, energetic electrons are produced by the Compton scattering process. These Compton electrons move in spiral paths under the influence of the local geomagnetic field and radiate EM energy. The rise time and peak of this early-time signal are dependent on the time history and energy spectrum of the gamma and X-ray outputs of the weapon. These, in turn, are dependent on the weapon design. These incident $E_{1}$ fields can cover a large portion of the earth's surface under the burst location.

For a system on the ground, the $E_{1}$ pulse appears to be a transient plane wave, arriving from the direction of the burst point. Either a vertically polarized field, a horizontally polarized field, or a combination of the two is possible, depending on geometrical considerations. This incident field is reflected from the earth, and the sum of the incident and reflected field components is the total field that excites the system.

To define the $E_{1}$ waveform properties for the power system assessments, an unclassified DOD-developed HEMP environment calculational code has been used 10,11 . This nominal HEMP environment has peak E-fields near the maximum that can be produced by a high-altitude nuclear explosion. However, this environment is suitable for the unclassified literature because it was calculated without using values of weapon output parameters that are classified by the Atomic Energy Act of 1954. This nominal HEMP 
environment has electric and magnetic field pulse characteristics and polarization that vary over the area of coverage; thus, it is suitable for assessments of geographically large sysıems.

The spatial variations of the peak $\mathrm{E}_{1}$ HEMP fields as calculated by this environmental code are shown in Fig. 2(a) for an assumed burst location over the central part of the United States. Examples of the calculated transient incident E-field waveforms are shown in Fig. 2(b) for different observation locations to the west of ground zero. In these calculations, details of the waveform polarization are also provided, although they are not presented here.

\section{$2.2 \quad E_{2}$ INTERMEDIATE-TIME COMPONENT}

The intermediate-time $E_{2}$ pulse has an electric field pulse amplitude of about 100 $\mathrm{V} / \mathrm{m}$. The physics of the production of this environment is more complex and less understood than that of $E_{1}$. Initially, this pulse is sustained by the interaction of the relaxing prompt gamma source and the scattered prompt gamma rays with the atmosphere

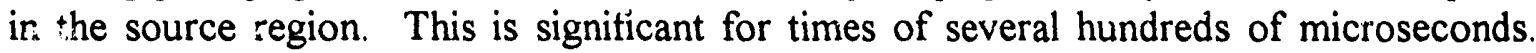
Later, gamma rays are produced by inelastic collisions between neutrons from the detonation and air molecules. Ultimately, these gammas begin to dominate the Compton source nrciuction and sustain the pulse into the millisecond regime. Thus, this part of the HEMP envic. ment depends on the total neutron output and spectrum of the weapon.

The first part of this intermediate-time pulse is characterized as an incident plane wave and thus can be considered an extension of the prompt $E_{1}$ pulse. The second part of this pulse more nearly resembles a static E-field that is predominantly vertical on the earth's surface. This field will interact with the earth to produce a total horizontal E-field component, which is dependent on the earth's conductivity.

For the purposes of the assessments in this DOE program, the $E_{2}$ environment was assumed to have the same polarization characteristics and angles of incidence as those for the $E_{1}$ field component. The time behavior of the $E_{2}$ field was modeled as a single exponential waveform of the form $E_{2}=100 \mathrm{e}^{-1000 t}$. This waveform was added to the early-time $E_{1}$ component to provide a composite HEMP waveform similar to that shown in Fig. 1.

\section{$2.3 \quad$ E $_{3}$ LATE-TIME COMPONENT}

The late-time MHD-EMP, or $\mathrm{E}_{3}$, environment is a result of the motion of the bomb debris and ionized air in the upper atmosphere that causes perturbations in the earth's magnetic field. For times less than about $10 \mathrm{~s}$, the expanding fireball from the explosion is highly conducting and tends to exclude the geomagnetic field as it expands and rises. Furthermore, a region below the burst point is ionized by the absorption of X-rays. This affects the magnetic field seen on the ground. At times greater than about $10 \mathrm{~s}$, the ionized 


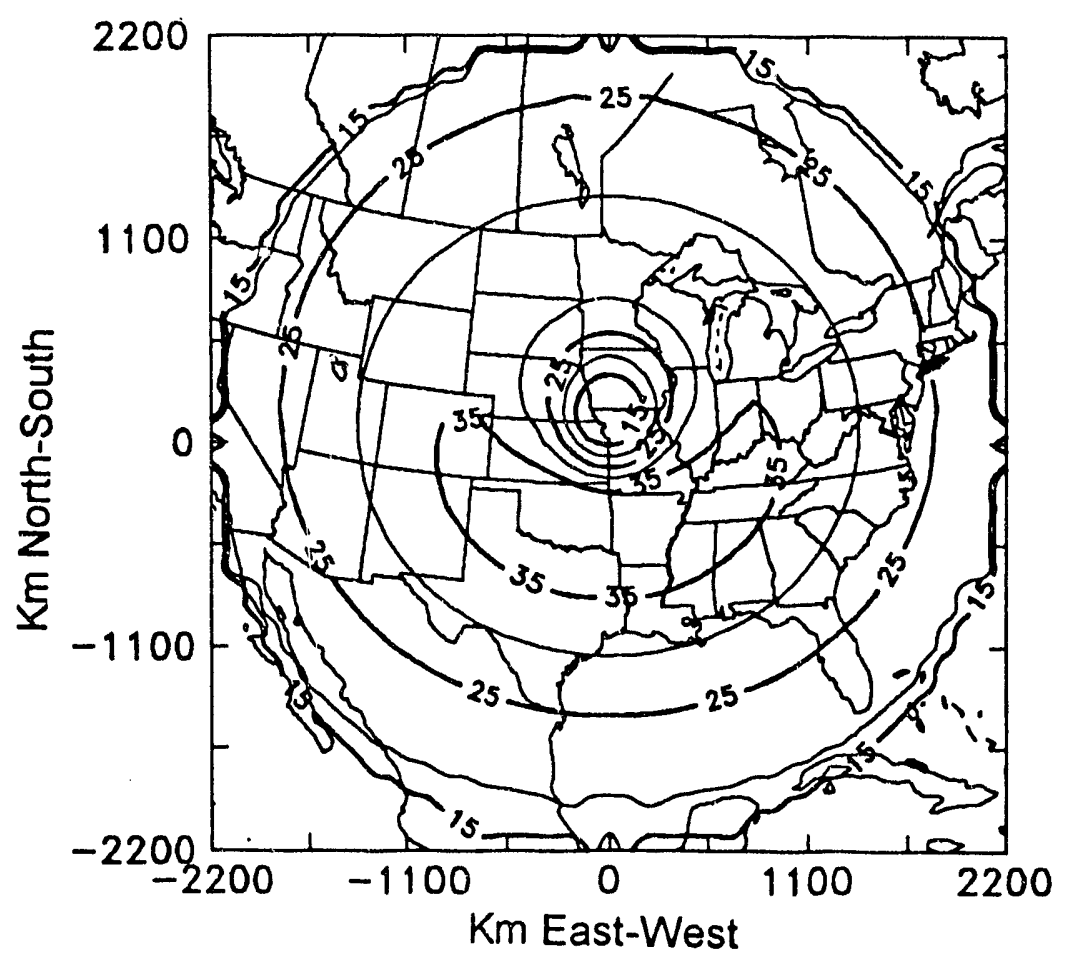

(a)

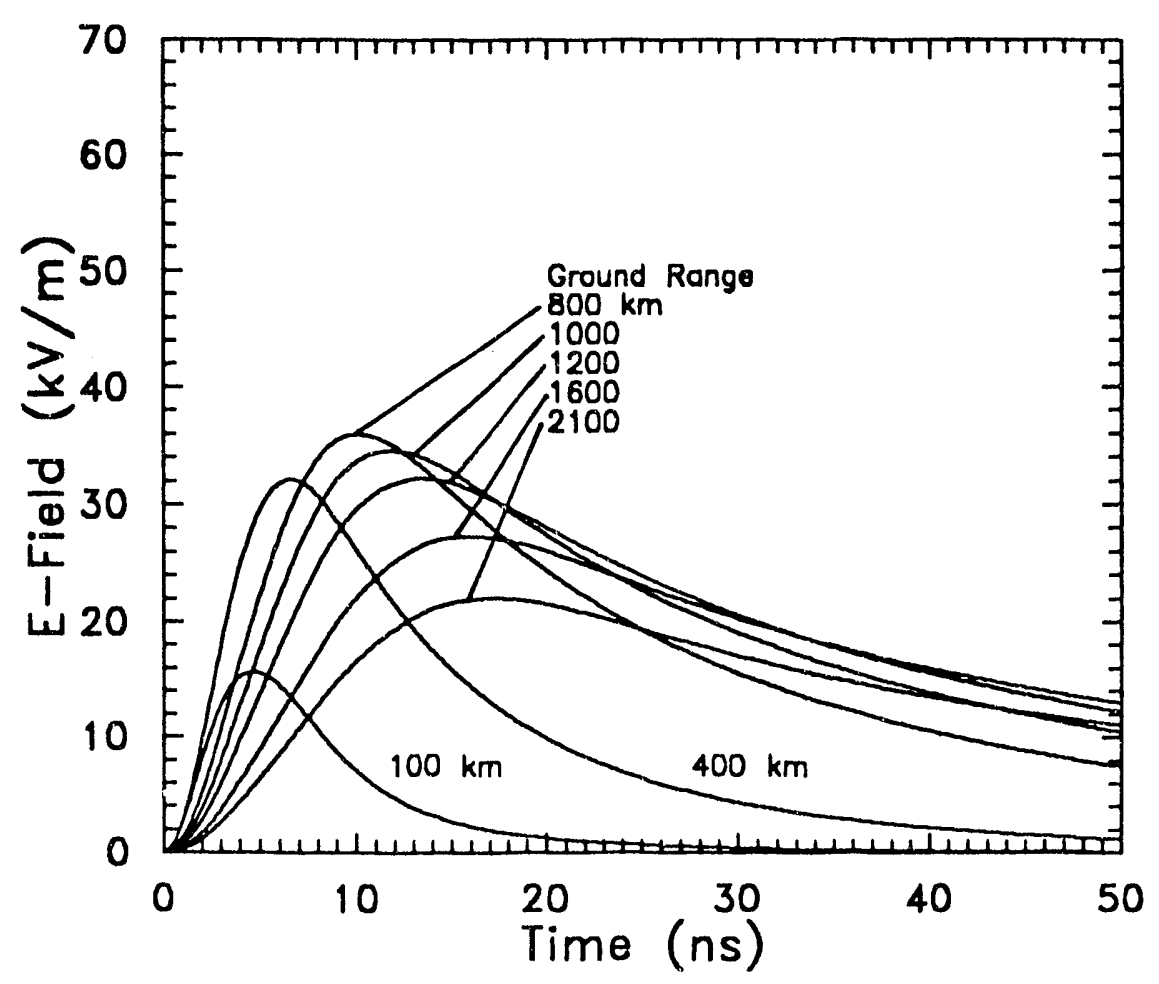

(b)

Fig. 2. Characteristics of the $\mathbf{E}_{1}$ environment. (a) Spatial variation of the peak $E_{1}$ fields (contours in kilovolts per meter), (b) transient $E_{1}$ waveforms to the west of ground zero. 
and expanding atmosphere interacts with the partially restored geomagnetic field. This produces ionospheric current sources that further affect the magnetic field on the earth. Because of the resulting time variation of the magnetic field, an electric field is induced in the finitely conducting earth. This E-field is orthogonal to the time varying magnetic field and is parallel to the earth surface. This is the $E_{3}$ field component, and it is on the order of several tens of volts per kilometer.

Early in the assessment program, the MHD-EMP environment described in ref. 12 was used. It is based on measured data from the Starfish high-altitude nuclear detonation and $\mathrm{MHD}$ atmospheric calculations ${ }^{13}$. For a burst over the central part of the United States, the maximum E-field for this environment was estimated to be about $24 \mathrm{~V} / \mathrm{km}$. This peak value, however, occurred only for a limited region on the ground. Later, as a result of ongoing research efforts into HEMP environments, a revised MHD-EMP environment was developed. Ref. 14 discusses this newer $E_{3}$ environment and compares it with that experienced in geomagnetic storms.

An example of the MHD-EMP environment for a burst $400 \mathrm{~km}$ over the central part of the United States is shown in Fig. 3. Part (a) presents a normalized $\mathrm{E}_{3}$ transient waveform, consisting of an early-time component lasting for about $10 \mathrm{~s}$, and a late-time component lasting hundreds of seconds. Parts (b) and (c) of the figure present examples of the directions of the E-field on the surface of the earth for each of these time regimes. For the early-time contribution in (b), a region under the burst has a more or less constant eastwest directed E-field. This is known as the X-ray patch. The distance between these contours provides a rough indication of the variation of the E-field strength: the closer contours indicate regions of more intense E-fields. For the case of the later-time waveform components, the field pattern has a more complex shape, as shown in part (c).

For the purposes of the assessment in this program, a peak value of $24 \mathrm{~V} / \mathrm{km}$ was used for the MHD-EMP waveform. This environment is based on an assumed earth conductivity of $\sigma=0.001 \mathrm{~S} / \mathrm{m}$. As discussed in ref. 11 , corrections to this environment are possible if the local earth conductivity is changed. 


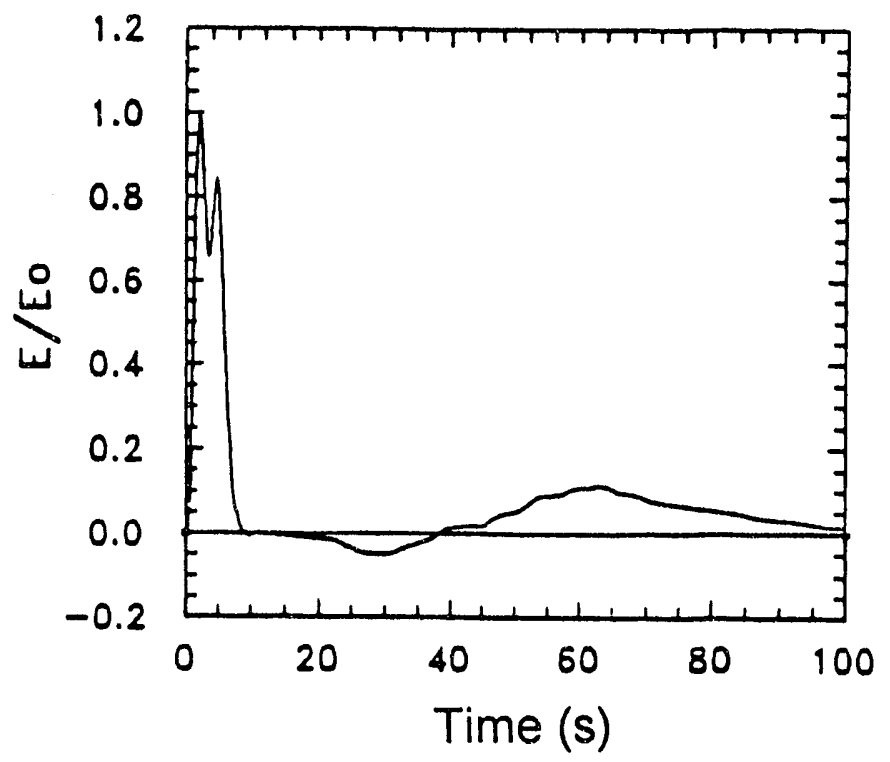

(a)

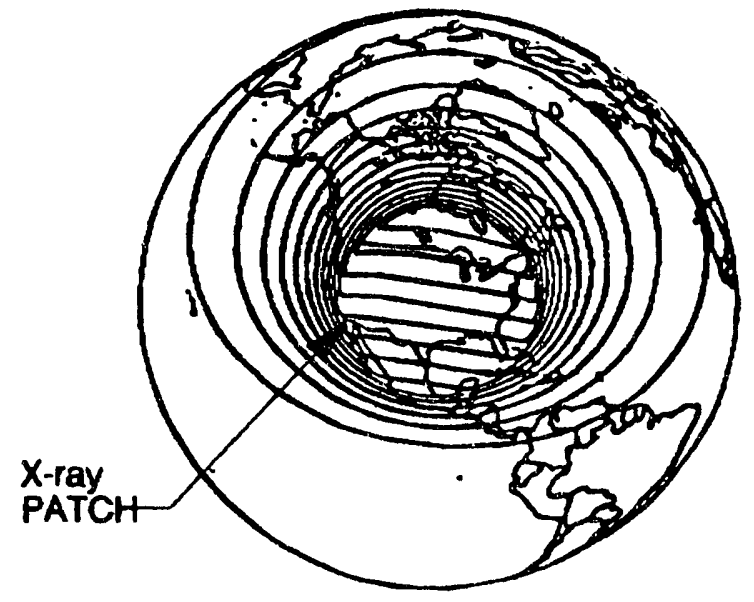

(b)

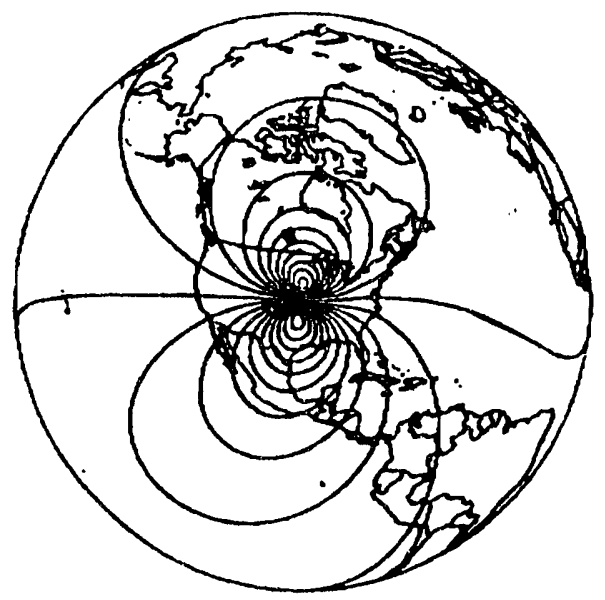

(c)

Fig. 3. Magnetohydrodynamic electromagnetic pulse environment for a 400 km burst over the central United States. (a) Normalized transient waveform for $\mathrm{E}_{3}$, (b) electric field lines for early time, (c) electric field lines for late time. 


\subsection{SECTION REFERENCES}

1. W. J. Karzas and R. Latter, "Electromagnetic Radiation from a Nuclear Explosion in Space," Physics Review 126 (6), 1919-26, (June 15, 1962).

2. C. L. Longmire, "On the Electromagnetic Pulse Produced by Nuclear Explosions," IEEE Transactions on Antennas and Propagation AP-26 (1), (January 1978).

3. J. R. Legro, N. C. Abi-Samra, and F. M. Tesche, Study to Assess the Effects of Magnetohydrodynamic Electromagnetic Pulse on Electric Power Systems, ORNL/Sub83/43374/1/V3, Martin Marietta Energy Systems, Inc., Oak Ridge National Laboratory, May 1985.

4. K. W. Klein, P. R. Barnes, and H. W. Zaininger, "Electromagnetic Pulse and the Electric Power Network," IEEE PAS Transactions PAS-104 (6), (June 1985).

5. P. R. Barnes, E. F. Vance, and H. W. Askins, Jr., Nuclear Electromagnetic Pulse (EMP) and Electric Power Systems, ORNL-6033, Martin Marietta Energy Systems, Inc., Oak Ridge National Laboratory, April 1984.

6. EMP Engineering and Design Principles, Bell Laboratories Publication, Whippany, NJ, 1975.

7. Interaction of Electromagnetic Pulse with Commercial Nuclear Power Plant Systems, NUREG/CR-3069, Sandia National Laboratories, February 1983.

8. K. S. H. Lee, ed., EMP Interaction: Principles, Techniques and Reference Data, AFWL-TR-80-402, Air Force Weapons Laboratory, 1981.

9. H. J. Longley and C. L. Longmire, Development of CHAP - A High-Altitude EMP Code, MRC-R-375, DNA 4521T, Mission Research Corp., January 1978.

10. C. L. Longmire, R. M. Hamilton, and J. M. Hahn, A Nominal Set of HighAltitude EMP Environments, ORNL/Sub/86-18417/1, Martin Marietta Energy Systems, Inc., Oak Ridge National Laboratory, February 1987.

11. F. M. Tesche and P. R. Barnes, "Development of a New High Altitude Electromagnetic Pulse (HEMP) Environment and Resulting Overhead Line Responses," Electromagnetics 8 (2-4), (1988).

12. J. R. Legro, et al., "A Methodology to Assess the Effects of Magnetohydrodynamic Electromagnetic Pulse (MHD-EMP) on Power Systems," IEEE Transactions on Power Deliver PWRD-1 (3), (July 1986).

13. S. Chavin, et al., MHD-EMP Code Simulation of Starfish, MRC-R-516, Mission Research Corporation, August 1979.

14. P. R. Barnes, et al., Electric Utility Industry Experience With Geomagnetic Disturbances, ORNL-6665, Martin Marietta Energy Systems, Inc., Oak Ridge National Laboratory, September 1991. 


\section{ASSESSMENT METHODOLOGY}

The analysis of the interaction of HEMP with electric power systems is a very complicated problem. The complications are primarily the result of the wide frequency spectrum and the large geographic area covered by the HEMP. A comprehensive HEMP assessment methodology for elactric power systems has been developed by the Advanced Systems Technology division of ASEA Brown Boveri Power Systems Inc., for the Oak Ridge National Laboratory (ORNL) ${ }^{1,2}$. This methodology includes the impacts of the early-time $\left(\mathrm{E}_{1}\right)$ HEMP and the late-time $\left(\mathrm{E}_{3}\right)$ MHD-EMP environments. A special assessment methodology for the effects of the intermediate-time $\operatorname{HEMP}\left(\mathrm{E}_{2}\right)$ is not necessary, since the $E_{2}$-induced surges on power lines are similar to small lightning and switching transients. Methods of assessing the impact of lightning and switching transients on electrical power systems are well known to the power engineering community. A brief and highly simplified description of the methodology is presented in this section.

\subsection{GENERAL DESCRIPTION}

The time sequence of events following a single high-altitude nuclear detonation is shown in Fig. 4. This figure graphically indicates the relationship between the $E_{1}$ component of the HEMP environment of such a burst in time and the system response to this environment. The $E_{1}$ transient wave has a duration of hundreds of nanoseconds, whereas induced surges resulting from this wave last as long as microseconds. Conversely, the subsequent response of power system components - ranging from solid-state device failure or upset to insulator flashovers and such subsystems response as relay actuations occur over a period of microseconds to milliseconds. Thus, the system response to the $\mathrm{E}_{1}$ stress is expected to occur over a period of several seconds. The power system next comes under the influence of the MHD-EMP environment, which lasts for a period of tens of seconds to hundreds of seconds. The power system response to MHD-EMP can occur over a period of a few seconds to a period comparable to the MHD-EMP excitation, depending on the nature of the system response.

A simplified flow diagram of the assessment methodology is shown in Fig. 5. The HEMP assessment methodology is based on the assumption that for an initial period of time when the HEMP $E_{1}$ component interacts with the system, each subsystem (such as a substation, etc.) and each functional group of circuits within subsystems can be assessed independently. The system states, which are determined by the load flow and stability analysis of the system under the influence of the $E_{1}$ environment at the time of the MHDEMP event, are part of the initial conditions for the MHD-EMP assessment. The MHDEMP assessment methodology has been adapted from power system analysis techniques developed to analyze the effects of geomagnetic storms on electric power systems. 


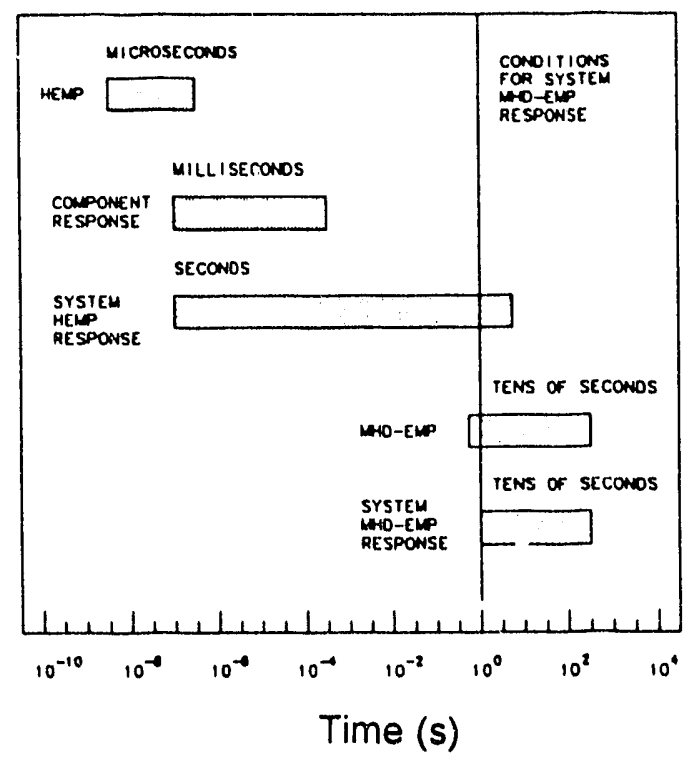

Fig. 4. Time sequence of events for the power system response to a single high-altitude burst.

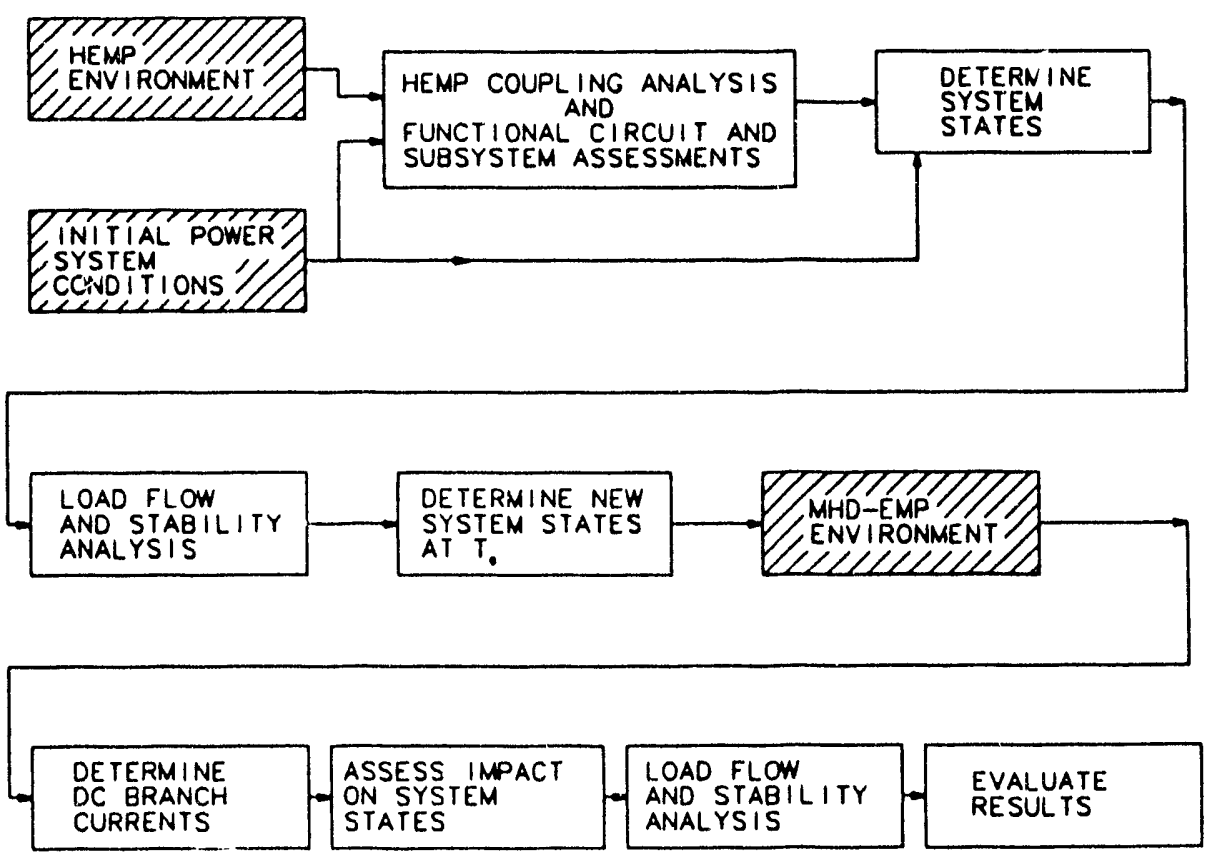

RZZZD INPUTS TO THE ASSESSMENT METHODOLOCY

Fig. 5. Simplified flow diagram of the assessment methodology for $E_{1}$ and $E_{3}$ assessments of electric power systems. 


\subsection{STATISTICAL CONSIDERATIONS IN THE ASSESSMENT}

Due to the complexity of the power system, a completely deterministic approach for implementing the assessment methodology is impractical. Many of the geometrical parameters describing the HEMP coupling to power system components can lie within a range of values. Examples are power line orientation on the ground, line height, tower separation, and load configurations. As a consequence, the assessment methodology utilized probabilistic descriptions of both the HEMP-excited power system responses (stress) and the possible responses of components (strength).

As an example of this, Fig. 6 shows a flowchart of the process of the stress-strength comparison for a selected device excited by a HEMP. Although the incident HEMP fields may be considered deterministic due to the specification of a burst scenario, the location of the system under consideration can vary. Furthermore, the shielding effects of nearby equipment and the coupling mechanisms of the HEMP energy into a device can vary. These facts lead to a range of possible stress excitation values experienced by a component. The resulting uncertainty in the component stress is frequently expressed by a probability density function. This is can be obtained by developing a computer model for the complicated system interaction with the HEMP fields and exercising this model for the specified ranges of input parameters.

In using such stress probability functions, it is necessary to define a suitable measure, or basis, for the comparison of the stress-strength relationship at the device. This can be a peak voltage of the impressed transient waveform, the peak time derivative, the total charge passing into the device, or a number of other quantities that are referred to as norms ${ }^{3}$.

The strength of the device also can be estimated as a distribution function over a range of possible excitations experienced by the device. This involves measurements on a class of identical components to determine the rate of failure or upset based on the same definition of the norm quantity. A comparison of the stress-strength relationships for the device provides an indication of the probability of damage or upset of the device due to the HEMP stress ${ }^{4}$. This is illustrated in Fig. 7 as the area under the intersection of the appropriately normalized stress-strength curves.

This stress-strength comparison is made difficult, however, by the fact that the strength distribution function usually is not known well enough to accurately determine the damage or upset probability distribution. One way of circumventing this difficulty is to describe the stress on the component with a cumulative probability function and to use a single-threshold value for approximately describing the onset of damage or upset ${ }^{5}$. This method of estimating component damage or upset has been used frequently in the assessment of the commercial power system. 


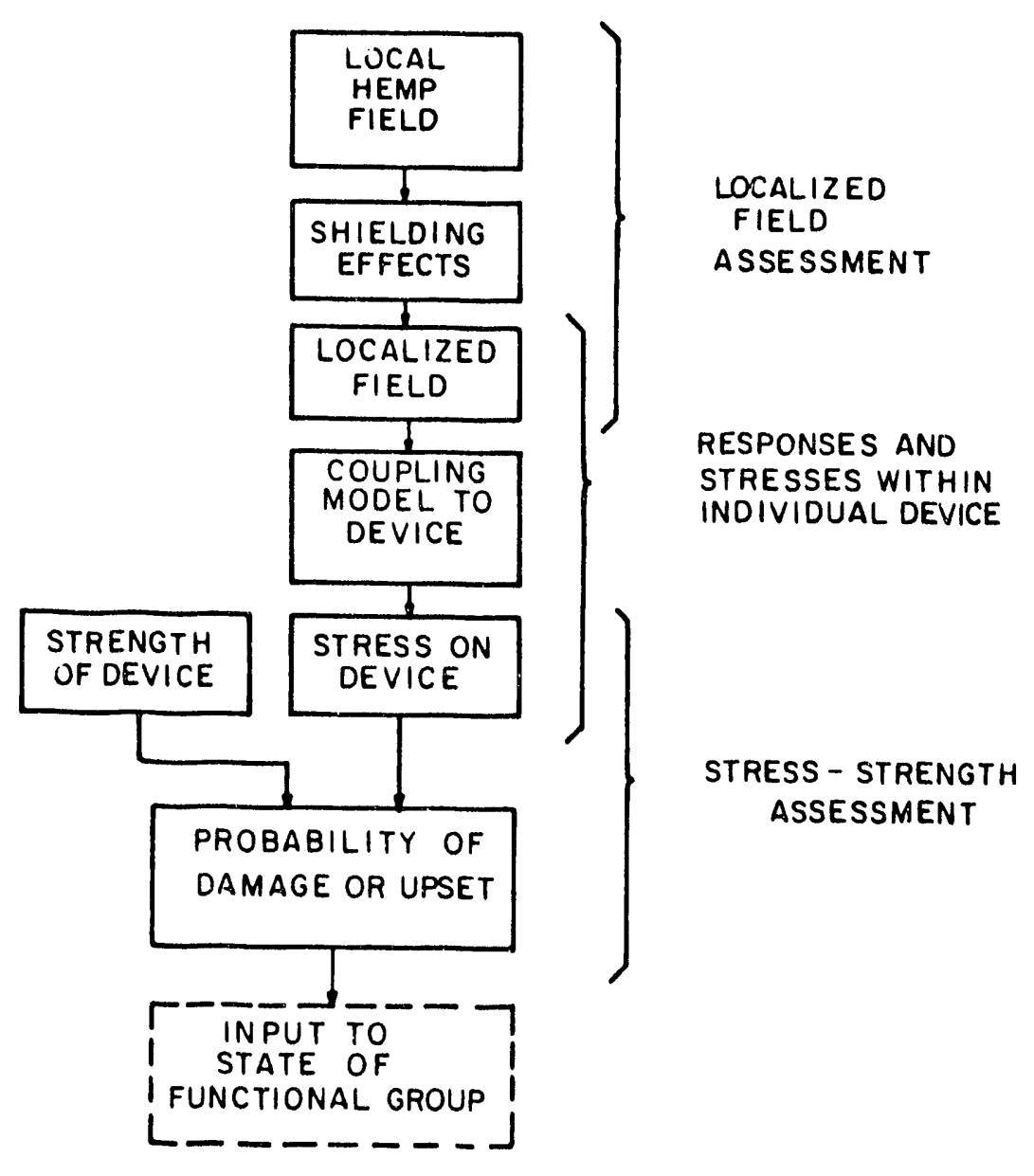

Fig. 6. Flowchart of the process of stress-strength comparison. 


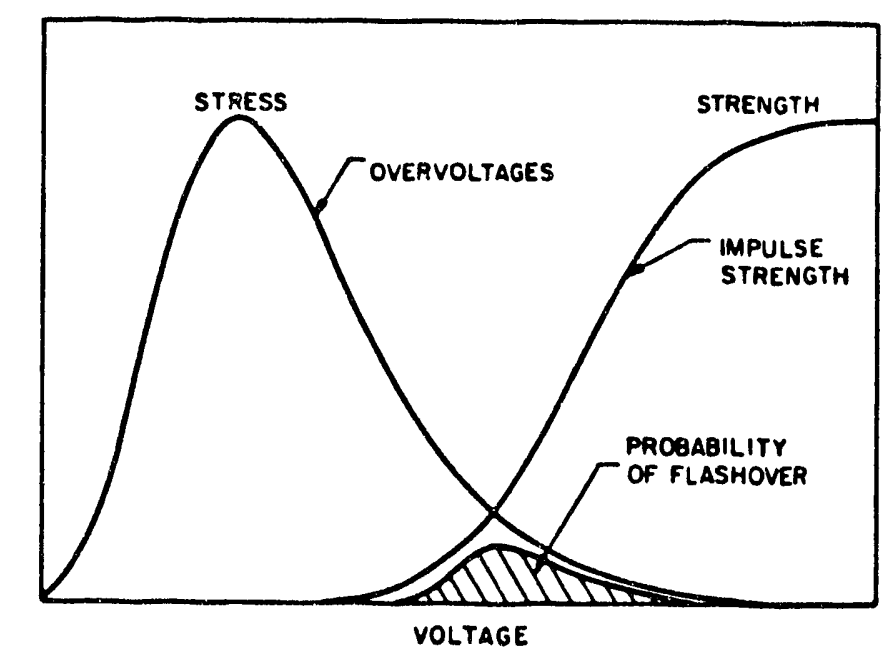

\section{Fig. 7. Graphic representation of stress- strength comparisons.}

\subsection{PRACTICAL LIMITATIONS IN THE IMPLEMENTATION OF THE ASSESSMENT}

In practice, HEMP assessment methodology must be abbreviated. This is because a number of practical limitations impede a more comprehensive HEMP assessment of electric power systems. The technology used in electric power systems can range from equipment installed in the early 1900s to that of modern systems. Because the type and number of components that can be tested are limited by time and budget constraints, statistical data for system and component responses will be limited. Consequently, the electrical strength of many components must be estimated from other data. The HEMP-induced stress at the component or device level in complex facilities cannot be calculated with a high degree of confidence. There is no assurance that measured response data for a complex facility can be extrapolated to other similar facilities. Furthermore, a full system-level test with simulated HEMP is not technically feasible. Finally, extensive load flow and stability studies are expensive to conduct.

The assessment methodology for this program was abbreviated by including only those functional circuits that are relatively simple and that can be modeled for HEMP coupling analysis. The responses of most functional circuits within complex facilities are, and will likely continue to be, unknown. It is possible to determine the overall system vulnerability from the vulnerability of individual elements within the power system exposed to HEMP. However, the converse is not true. The invulnerability of exposed elements does not imply system invulnerability, because the responses of circuits within complex facilities are unknown. As it is not practical to retrofit all complex facilities in power 
systems with HEMP protection, post-HEMP facility testing and repairs should be cons dered as part of emergency restoration plans.

In a recent paper, Rabinowitz concluded that the HEMP from a single burst would not result in a total nationwide blackout ${ }^{6}$. This conclusion was partially based on his premise that HEMP peak fields would be nearly an order of magnitude smaller than those generally agreed upon within the HEMP community and associated with the nominal HEMP environment used in our assessments. Furthermore, the impacts of MHD-EMP were not considered in his study. Nevertheless, as will be indicated later in this summary report, our assessments concur that a total nationwide blackout caused by single highaltitude nuclear burst is unlikely. This conclusion is based on the variations of the EM disturbances over the country and the tendency of the power grid to breakup into isolated power islands, some of which may continue to operate if the HEMP-induced damage is minor.

\subsection{SECTION REFERENCES}

1. J. R. Legro, et al., "A Methodology to Assess the Effects of Magnetohydrodynamic Electromagnetic Pulse (MHD-EMP) on Power Systems," IEEE Transactions on Power Delivery PWRD-1 (3), (July 1986).

2. J. R. Legro, et al., A Methodology to Assess the Effects of Electromagnetic Pulse on Electric Power Systems - Phase I Executive Summary, ORNL/Sub/83-43374/V1, Martin Marietta Energy Systems, Inc., Oak Ridge National Laboratory, September 1985.

3. C. E. Baum, "Norms and Eigenvector Norms", Mathematics Note 63, Air Force Weapons Laboratory, Kirtland AFB, New Mexico, November 1979.

4. A. R., Hileman, "Transmission Line Insulation Coordination," Transactions of the South African Institute of Electrical Engineers 71 (Part 6), (June 1980).

5. V. Kruse, P. R. Barnes, and F. M. Tesche, "Flashover Vulnerability of Transmission and Distribution Lines to High Altitude Electromagnetic Pulse," IEEE Transactions on Power Delivery 5 (2), (April 1990).

6. M. Rabinowitz, "Effect of the Fast Nuclear Electromagnetic Pulse on the Electric Power Grid Nationwide: A Different View," IEEE Transactions on Power Delivery PWRD-2 (4), (October 1987). 


\section{ANALYTICAL MODELING}

In support of the assessment program, a number of analytical efforts were initiated by ORNL. The main purpose of these investigations was to provide numerical modeling tools for predicting the HEMP responses of power system components, which would ultimately lead to the determination of the stress distribution functions. As in most programs, there was a desire to build upon the existing technology base rather than to redevelop existing work. Thus, early in the program, the HEMP modeling techniques described in refs. 1-3 were examined for applicability. Furthermore, the HEMP publication series ${ }^{4}$ that contains many pertinent reports documenting the interaction of incident HEMP fields with power system components was reviewed. The results of this review and suggestions pertaining to the initial direction of this assessment project were reported in ref. 5 .

The results of the analytical investigations undertaken in this effort have been reported in a number of different publications. The final reports from the Westinghouse Phase 1 study provide descriptions of many of the developed models and indications of how they are used in the power system assessments ${ }^{6-9}$. These coupling models include single- and multiple-overhead transmission and distribution lines, buried lines, shielded cables, and isolated equipment. A brief discussion of coupling to antennas commonly found in communications facilities is also presented in these reports.

In addition to these documents, individual technical reports and papers have documented the analytical models developed in this program. These are summarized in the following subsections.

\subsection{OVERVIEW OF HIGH-ALTITUDE ELECTROMAGNETIC PULSE ANALYSIS}

A general description of the models and techniques for determining the HEMP coupling to above-ground and buried cables has been described in ref. 10. This paper discusses both the $E_{1}$ and the $E_{3}$ environments, and it served as the introductory paper for a special session on HEMP Effects on Power Systems at the 1987 Zurich Symposium and Technical Exposition on Electromagnetic Compatibility. In the same session, a paper by ORNL investigators discussed the overall objectives of the assessment program and summarized the achievements as of the that date ${ }^{11}$. Early work reported in ref. 12 also discusses the HEMP response of power systems. Reference 13 provides additional insight into the HEMP environment and its possible effects by comparing and contrasting this man-made environment with natural lightning environments.

In addition to these formal references, a number of technical presentations were made at project review and interchange meetings over the duration of the assessment 
program. Reference 14 presents abstracts of 13 presentations on HEMP analysis models, effects, and experiments. A number of pertinent references are also listed in this document.

\subsection{HIGH-ALTITUDE ELECTROMAGNETIC PULSE ENVIRONMENT DEFINITION}

Several papers dealing with the definition of the HEMP environments have been published. The $E_{1}$ field description described in ref. 15 has been an important factor in the development of an unclassified version of the early-time E-field for the assessment program. The use of this HEMP environment for exciting a simple single-wire, aboveground transmission line was described in ref. 16. This paper extends the single-line coupling analysis of ref. 3 to permit an arbitrary incident field behavior and a general treatment of the lossy earth effects. Moreover, this paper illustrates the approach for generating cumulative probability distributions for the line responses to the $E_{1}$ HEMP fields.

A limited amount of information about the unclassified $E_{3}$ environment has been published. Besides the information given in ref. 7 , ref. 10 provides some data on this latetime environment.

\subsection{HIGH-ALTITUDE ELECTROMAGNETIC PULSE INTERACTION WITH THE EARTH}

The reflection of the incident $E_{1}$ fields in the earth is important in determining the total fields exciting the power system. Reference 17 discusses the determination of the reflected field from the earth for an assumed double exponential incident field. This technique used a frequency-domain analysis of reflection coefficients, coupled with a Fourier transform, to determine the transient reflected field. An alternate direct timedomain approach for approximately computing the reflected field was described in ref. 18 . This method is useful in the cases when a direct time-domain calculation of line coupling is performed using the Electromagnetic Transients Program (EMTP) ${ }^{8}$. A related paper was presented describing EM field interaction with other types of lossy material, such as conducting wires and sheets ${ }^{19}$.

\subsection{BASIC ELECTROMAGNETIC COUPLING ANALYSIS}

A significant amount of new work in the area of HEMP coupling to power lines was conducted under this effort. Reference 20 discusses the coupling problem from an EM scattering viewpoint and develops equations similar to the low-frequency Telegrapher's equations that are valid at higher frequencies. The work reported in ref. 21 expanded upon this approach and applied it to the case of specific transmission and distribution line configurations involving towers. In addition, ref. 22 describes the response of an infinite line over a lossy earth, using both scattering theory and an approximate model. This early work on line coupling was expanded upon in refs. 23 and 24 for the case of single conductor lines and in ref. 25 for multi-wire lines that included overhead shield wires. 
Early work in the area of HEMP-induced corona effects on high-voltage power lines was reported in refs. 20 and 26. Later, several different analytical models for predicting the onset of corona and its subsequent effect on conducted HEMP surges on overhead lines were developed and reported in refs. 27 and 28. These analytical models were then compared with experimental results.

\subsection{ANALYSIS VALIDATION}

Throughout the model development, emphasis was placed on ensuring that the models were accurate and properly validated. This validation was accomplished by using either experimental results or by results calculated from other models that were based on other formulations. This process of examination and comparison of the calculated results led to increasingly more complex models as more features of the EM coupling process were added.

One of the main assumptions used in the development of the HEMP coupling models was that quasi-transverse EM transmission line theory could provide a reasonably accurate knowledge of the coupled line surges. To verify this assumption, rigorous calculations using scattering were used to compare the transmission line models with scattering theory. The basic theory behind the scattering models was described in refs. 29-31, and a more recent paper illustrates the favorable comparisons between these two approaches ${ }^{32}$.

In addition, experimental validation of the HEMP coupling models has been achieved using measured lightning-induced currents on an above-ground power line ${ }^{33}$. A similar comparison of results is reported in ref. 34 .

\subsection{SYSTEM-LEVEL ANALYSIS}

Most of the analytical coupling models used in this program are geometrically simple, for example, that of a single conductor over a ground. However, several such models may be combined to form a more complex, composite interaction model. Several papers treat this process. Reference 35 documents an early attempt to consider the network effects on a power distribution circuit under HEMP excitation. The response of a power distribution circuit recloser unit was analyzed using a complex multiconductor model of the distribution line and the control cables of the unit ${ }^{36}$. This unit was later tested in an HEMP simulator, and this provided a further verification of the accuracy of the analytical modeling. This test will be discussed in more detail in Section 5.

An alternate approach for analyzing the HEMP behavior of a large, complex power system is to use suitably measured responses in the system and to combine them with a knowledge of the incident HEMP. Reference 37 describes results of current injection tests on a power generation facility in Sweden. This report illustrates the use of coupling 
models to predict the HEMP-induced response on the incoming power lines connected to the facility and to compute the internal responses.

\subsection{EXPERIMENT DESIGN}

In addition to the development and use of analytical models for predicting HEMP responses, some effort was spent in applying analysis to the design of new HEMP pulser technology for performing current injection testing of power systems. For testing a system for both its $E_{1}$ and $E_{3}$ responses, several different efforts were reported. References 38 and 39 describe coupling responses of overhead lines to the $E_{1}$ environment and develop pulser specifications for testing facilities to this environment. Unfortunately, this work and documentation were performed before the completion of the new HEMP environment definition of ref. 15. Consequently, the suggested pulser responses are too large. A similar analysis design effort was conducted for the $E_{3}$ pulse, as documented in ref. 40.

\subsection{SECTION REFERENCES}

1. EMP Engineering and Design Principles, Bell Laboratory Publication, Whippany, N.J., 1975.

2. E. F .Vance, Electromagnetic Pulse Handbook for Electric Power Systems, DNA AD/A-009 288, February 1975. FL, 1987.

3. E. F .Vance, Coupling to Shielded Cables, Krieger Publishing Co., Melbourne,

4. Carl E. Baum, ed., AFWL Interaction and Sensor and Simulation Note Series, Air Force Weapons Laboratory, Kirtland AFB, N.M.

5. P. R. Barnes, E. F. Vance, and H. W. Askins, Nuclear Electromagnetic Pulse (EMP) and Electric Power Systems, ORNL-6033, Martin Marietta Energy Systems, Inc., Oak Ridge National Laboratory, April 1984.

6. J. R. Legro, et al., Study to Assess the Effects of Electromagnetic Pulse on Electric Power Systems - Phase I Executive Summary, ORNL/Sub/83-43374/V1, Martin Marietta Energy Systems, Inc., Oak Ridge National Laboratory, September 1985.

7. J. R. Legro, N. C. Abi-Samra and F. M. Tesche, Study to Assess the Effects of Magnetohydrodynanic Electromagnetic Pulse on Electric Power Systems, ORNL/Sub83/43374/1/V3, Martin Marietta Energy Systems, Inc., Oak Ridge National Laboratory, May 1985.

8. J. R. Legro, et al., Study to Assess the Effects of High-Altitude Electromagnetic Pulse on Electric Power Systems - Phase I Final Report, ORNL/Sub/83-43374/1/V1, Martin Marietta Energy Systems, Inc., Oak Ridge National Laboratory, February 1986. 
9. J. R. Legro, et al., Study to Assess the Effects of Nuclear Surface Burst Electromagnetic Pulse on Electric Power Systems - Phase I Final Report, ORNL/Sub/8343374/V4, Martin Marietta Energy Systems, Inc., Oak Ridge National Laboratory, September 1985.

10. F. M. Tesche, "An Overview of High Altitude EMP Effects on Power Systems," Proceedings of the 7th International Zurich Technical Exhibition on EMC, Zurich, Switzerland, March 1987.

11. B. W. McConnell and P. R. Barnes, "A Research Program to Assess the Impact of the Electromagnetic Pulse on Electric Power Systems", Proceedings of the 7th International Zurich Technical Exhibition on EMC, Zurich, Switzerland, March 1987.

12. H. W. Zaininger, Electromagnetic Pulse (EMP) Interaction with Electrical Power Systems, ORNL/Sub/82-47905/1, Martin Marietta Energy Systems, Inc., Oak Ridge National Laboratory, August 1984.

13. E. F. Vance, and M. A. Uman, "Differences Between Lightning and Nuclear Electromagnetic Pulse Interactions," IEEE Transactions on Electromagnetic Compatibility 30(1), (1988).

14. I. Gyuk, ed., Proceedings of the DOE EMP Program Review Meeting, U.S. Department of Energy, Office of Energy Storage and Distribution, Washington D.C., November 2-3, 1989.

15. C. L. Longmire, R. M. Hamilton and J. M. Hahn, A Nominal Set of High-Altitude EMP Environments, ORNL/Sub/86-18417/1, Martin Marietta Energy Systems, Inc., Oak Ridge National Laboratory, February 1987.

16. F. M. Tesche, and P. R. Barnes, "Development of a New High Altitude Electromagnetic Pulse (HEMP) Environment and Resulting Overhead Line Responses," Electromagnetics 8(2-4), (1988).

17. H. P. Neff, Jr. and D. A. Reed, "Plane Wave (EMP) Incidence on a Finitely Conducting Plane Earth with Magnetic Field Intensity Parallel to the Earth's Surface," Theoretical Note 351, Air Force Weapons Laboratory, Kirtland AFB, N.M., Feb. 8, 1984.

18. P. R. Barnes, and F. M. Tesche, "On the Direct Calculation of a Transient Plane Wave Reflected from a Finitely Conducting Half-Space", IEEE Transactions on Electromagnetic Compatibility 33, (May 1991).

19. F. M. Tesche, "On the Inclusion of Loss in Time-Domain Solutions of Electromagnetic Interaction Problems," IEEE Transactions on Electromagnetic Compatibility, (February 1990). 
20. K. S. H. Lee, F. C. Yang, and N. Engheta, "Interaction of High Altitude Electromagnetic Pulse (HEMP) with Transmission and Distribution Lines: An Early Time Consideration" Interaction Note 435, Air Force Weapons Laboratory, Kirtland AFB, N.M., December 1983.

21. N. Engheta, et al., HEMP Induced Transients on Transmission and Distribution (T\&D) Lines, ORNL/SUB-84/73986/1, Martin Marietta Energy Systems, Inc., Cak Ridge National Laboratory, September 1985.

22. P. R. Barnes, and R. A. Stevens, "Early-Time Response of an Infinitely Long Wire Above a Finitely Conducting Plane Earth to a Transient Plane Wave," Electromagnetics 8(2-4), (1988).

23. F. M. Tesche, "Calculational Models for Lightning and EMP Interaction with Long Lines", digest of the USNC/URSI meeting, Boulder, Colo., January 14, 1987.

24. F. M. Tesche, and P. R. Barnes, "The HEMP Response of an Overhead Power Distribution Line," IEEE Transactions on Power Delivery 4(3), (July 1989).

25. F. M. Tesche, and P. R. Barnes, "A Multiconductor Model for Determining the Response of Power Transmission and Distribution Lines to a High Altitude Electromagnetic Pulse (HEMP)," IEEE Transactions on Power Delivery 4(3), (July 1989).

26. B. W. McConnell, and P. R. Barnes, "Corona Effects on EMP Induced Surges in Long Wires," Paper presented at the 1984 Nuclear EMP Meeting, Baltimore, Md., July $2-6,1984$.

27. F. M. Tesche, and J. P. Blanchard, "Experimental Determination of EMP-Induced Corona Effects on Conducting Lines," Proceedings of the 7th International Zurich Technical Exhibition on EMC, Zurich, Switzerland, March 1987.

28. J. P. Blanchard, and F. M. Tesche, "Corona Effects on Power Systems Due to Lightning and EMP Induced Surges," Paper presented at the 1986 Nuclear EMP Meeting, Albuquerque, N.M., May 1986.

29. H. P. Neff, Jr. and D. A. Reed, "Finitely Conducting, Infinitely Long, Cylindrical Wire in the Presence of a Plane Wave (EMP)," Interaction Note 436, Air Force Weapons Laboratory, Kirtland AFB, N.M., Feb. 21, 1984.

30. H. P. Neff, Jr. and D. A. Reed, "The Current Induced in an Infinitely Long and Finitely Conducting Wire over a Plane and Homogeneous Earth Due to a Uniform Plane Wave Having Various Waveshapes (EMP)," Interaction Note 451, Air Force Weapons Laboratory, Kirtland AFB, N.M., August 1985. 
31. H. P. Neff, Jr. and D. A. Reed, "The Effects of Secondary Scattering on the Induced Current in an Infinite Wire Over an Imperfect Ground from an Incident Electromagnetic Pulse, " IEEE Transactions on Antennas and Propagation 37, (April 1989).

32. F. M. Tesche, "Comparison of the Transmission Line and Scattering Models for Computing the HEMP Response of Overhead Cables,", IEEE Transactions on Electromagnetic Compatibility, 34(2), (May 1992).

33. Z. Yacoub, et al., "Voltages Induced on a Power Distribution Line by Overhead Cloud Lightning", Proceedings of the 1991 International Conference on Lightning and Static Electricity, Cocoa Beach, Fl., April 16--19, 1991.

34. N. Georgiadis, et al., "Lightning-Induced Voltages at Both Ends of a 450-meter Distribution Line," to be published in the IEEE Transactions on Electromagnetic Compatibility.

35. H. W. Zaininger, and G. M. Jaszewski, HEMP Interaction with an Electric Power Distribution Circuit, ORNL/Sub/84-73986/2, Martin Marietta Energy Systems, Inc., Oak Ridge National Laboratory, August, 1985.

36 F. M. Tesche, and P. R. Barnes, "Transient Response of a Distribution Circuit Recloser and Control Unit to a High-Altitude Electromagnetic Pulse (HEMP) and Lightning," IEEE Transactions on Electromagnetic Compatibility 32(2), (May 1990).

37. F. M. Tesche, and P. R. Barnes, "Extrapolation of Measured Power System Response Data to High-Altitude EMP Excitation," IEEE Transactions on Electromagnetic Compatibility, (August 1988).

38. I. D. Smith, et al., Study for a Facility to Simulate High Altitude EMP Coupled Through Overhead Transmission Lines, ORNL/Sub/84-89643/1, Martin Marietta Energy Systems, Inc., Oak Ridge National Laboratory, November 1985.

39. A. Ramrus, Design Concepts for a Pulse Power Test Facility to Simulate EMP Surges in Overhead Power Lines: Part 1, Fast Pulse, ORNL/Sub/84-89642/1, Martin Marietta Energy Systems, Inc., Oak Ridge National Laboratory, Feb. 1986.

40. R. Dethlefsen, Design Concepts for a Pulse Power Test Facility to Simulate EMP Surges in Overhead Power Lines: Part 2, Slow Pulses, ORNL/Sub/84-89642/2, Martin Marietta Energy Systems, Inc.s Oak Ridge National Laboratory, October 1985. 


\section{EXPERIMENTS}

As discussed in Section 3, important input data for the assessment methodology is the susceptibility levels of power system components to HEMP-induced surges. It was recognized early in the program that experiments were necessary to build a data base for performing these assessments ${ }^{1}$. The effectiveness of surge arresters, the vulnerability level of protective relays, the responses of transmission and distribution components to steepfront short-duration (SFSD) HEMP-induced surges, and the impact of corona are issues that could be resolved only by appropriate experiments. Because electric power networks are geographically large, the entire system cannot be tested by HEMP simulation. Even tests on subsystems, such as power plants, are difficult and costly. The assessment methodology described in Section 3 has taken these constraints into account and it requires experimental data at the component or functional circuit levels.

In view of this requirement for data, various tests were conducted under the DOE EMP Program and some of the key results are presented in this section. These experiments provided valuable data necessary for HEMP assessments of electric power systems, and added new information on the response of power system components and functional circuits to SFSD impulses.

A major constraint in the DOE experimental program was cost. A single detailed test could have easily cost more than the entire program budget. Fortunately, it was possible to conduct many of the tests by using hig voltage pulsers or HEMP simulators provided at no cost to the program by the Defense Nuclear Agency (DNA). Such arrangements, however, often added severe scheduling restrictions to the experiments because they were usually conducted in conjunction with other tests.

\subsection{TEST OBJECTIVES AND OVERVIEW}

The objective of the experimental program was to build a data base for assessments. Such data as the response of power system components to SFSD transients, component malfunction and vulnerability thresholds, and the effectiveness of arresters and filters in protecting against fast surges were required. For electric power systems, the simulation of HEMP coupling to long lines over a ground is important. An earlier study found that HEMP-induced surges in overhead power lines can be experimentally simulated with the Thévenin-equivalent circuit of the HEMP-excited line 2,3 . A high-voltage pulser is required to simulate the open-circuit voltage induced on the line by HEMP, and the characteristic surge impedance $\left(Z_{0}\right)$ (the Thévenin-equivalent circuit impedance) conr $\cdots$ ts the pulser to the test object. For testing secondary voltage class power line equipment, it is also necessary to account for the effects of the distribution transformer on the primary power line surge and to include the surges induced in the secondary line. 
Test waveforms were selected to encompass the shortest rise time and a long fall time of HEMP-induced power line surges. The earlier studies indicated that the 30 to $90 \%$ rise time should be 20 to $40 \mathrm{~ns}$, and the fall time to half value should be about 500 to 2000 ns (ref. 2). In some tests, a range of rise times was used to better link the SFSD surge test to the more conventional lightning test waveforms.

For the test program, high-voltage current injection tests were conducted at three facilities: Maxwell Laboratories, McGraw-Edison High Voltage Laboratory, and the Mississippi State University High Voltage Laboratory. At Maxwell Laboratories, tests were conducted by personnel from Westinghouse Electric Corporation, McGraw-Edison Company, and ORNL. Free field tests were conducted in the Advanced Research EMP Simulator (ARES) and the Vertically Polarized Dipole (VPD) II simulation facilities located at Kirtland Air Force Base, in New Mexico. This testing was conducted by LuTech, Inc., with instrumentation supplied by the test facilities in most cases. To supplement the facility instrumentation, the DOE EMP Program supplied LeCroy digital oscilloscopes (9400 and 6880 models) and Pearson model 3882 fast response current transformers.

\subsection{TEST DESCRIPTION}

In this section, a brief description of the tests and an overview of the important experimental results are provided. More detailed information on these tests can be found in the detailed references and in the task reports.

\subsubsection{Distribution Transformers}

Tests were performed on distribution transformers by Westinghouse and McGrawEdison 4,5 . Earlier low-voltage tests had indicated that SFSD transients might stress the windings differently from standard lightning test impulses ${ }^{6}$. These tests showed that unprotected $15-\mathrm{kV}$ class distribution transformers are vulnerable to $400 \mathrm{kV}$ SFSD surges. However, gapless arresters mounted on the transformer responded adequately to provide protection against surges of up to 1.1 MV. Earlier studies by ORNL had indicated that arresters would not respond fast enough to provide adequate protection?. However, when the transformer is in the circuit, the transformer reactance "slows down" the voltage rise and permits the arrester to respond in time to protect the unit.

\subsubsection{Insulators and Insulation Systems}

Tests by McGraw-Edison on insulators and insulation systems suggest that the critical flashover (CFO) voltage for SFSD surges is about 2 times that of the 1.2 by $50 \mu \mathrm{s}$ standard pulse for pin and suspension type insulators 6,8 . Insulators and insulation systems were also found to be vulnerable to destructive damage under certain conditions; viz., a SFSD impulse of about $900 \mathrm{kV}$ was applied to an insulator under energized conditions in a test conducted at the McGraw-Edison High Voltage Laboratory. Physical damage to the insulator string occurred when $2000 \mathrm{~A}$ or more of $60-\mathrm{Hz}$ power-follow current was available. 


\subsubsection{Power Line Filters}

In other high-voltage tests, it was found that power line filters can be employed along with arresters and transient suppressers to provide HEMP protcction ${ }^{9}$. Three power line filters were tested at Maxwell Laboratories by applying SFSD impulses with amplitudes up to $1 \mathrm{MV}$ (pulser open-circuit voltage) to the primary of a distribution transformer. The filters were connected to the $120 / 240-\mathrm{V}$ secondary of a transformer. Thus, the impact of the transformer on power line surges was simulated in the test. This test showed that the combination of the surge suppressor and the power line filter reduced the HEMP transients of $6 \mathrm{kV}$ at a $11 \Omega$ load in a $120-\mathrm{V}$ circuit to about $75 \mathrm{~V}$.

\subsubsection{Underground Distribution Cables}

Steep-front, high-voltage surge tests on underground distribution cables were conducted at Mississippi State University, and the results of this work were reported in a conference paper ${ }^{8}$. The investigators found that polyethylene cable has a characteristic degradation in which failure voltage decreases with the number of SFSD pulses. Tests were also conducted on field-aged cable, with results indicating that an aged cable has a significantly lower withstand voltage capability to SFSD pulses than does a new cable. The degradation of aged cable could be due to the effects of lightning and switching surges and/or the effects of water on the insulation.

\subsubsection{Corona Testing}

A simulated HEMP free-field test to determine the impact of corona on the induced surge was conducted at Kirtland Air Force Base ${ }^{10,11}$. The researchers found that HEMPinduced corona is present a few tens of nanoseconds after the SFSD surge is induced on the line. However, it was estimated that corona did not provide a large modification to the predicted HEMP response levels on the lines; consequently, its effects were neglected in the assessments.

\subsubsection{Protective Relay Equipment}

SFSD high-voltage surge tests were conducted on protective relay equipment connected by instrumentation cables to the primary of potential transformers (PTs) and current transformers $(\mathrm{CTs})^{12,13}$. High-voltage SFSD surges up to $1.1 \mathrm{MV}$ were applied to the PT and CT primary terminals. Thus, the presence of instrument transformers was simulated in the tests. The results of these tests revealed that the coupled surges did not cause the relays to misoperate, but some degradation in voltage withstand strength may have occurred. Additional surge tests on protective relays have been conducted by the BDM Corporation in Albuquerque, New Mexicolt. The BDM tests applied a SFSD surge directly to the relay terminals; these tests also indicated that no misoperations occurred. 


\subsubsection{Recloser Control Units}

A simulated HEMP free-field test on distribution circuit recloser control units was conducted in the ARES facility at Kirtland Air Force Base ${ }^{15}$. A peak field of about 40 $\mathrm{kV} / \mathrm{m}$ with a rise time that varied from around 3 to $10 \mathrm{~ns}$ was used. Vulnerability of the three units tested to this HEMP environment was not demonstrated. One unit did malfunction, but a post-test analysis identified a possible preexisting defect in the unit as the cause: a diode had been replaced with minor damage being done to the circuit-board. The number of controllers with such defects is unknown.

\subsubsection{Power Plant Instrumentation}

Finally, a test on a pressure transmitter, part of power plant instrumentation, was conducted by the BDMi Corporation ${ }^{16}$. This instrumentation, which normally operates at a few milliamps, was subjected to damped sinusoids up to the maximum pulser output of $8 \mathrm{~A}$ over a frequency range of $100 \mathrm{kHz}$ to $5 \mathrm{MHz}$. The unit continued to work properly and did not fail.

\subsection{SUMMARY OF TEST RESULTS}

Selected results of HEMP tests on a limited number of components are summarized in Tables 1 and 2. Generally, electric power system components are required to operate in a harsh environment of lightning and switching transients. Indeed, many of the transmission and distribution (T\&D) components operate at high-voltage levels (many kilovolts), related controls operate at $120-250 \mathrm{~V}$, and lower voltage control circuits are designed with extensive EM interference (EMI) protection. As a consequence, power system components have been found to be relatively invulnerable to simulated HEMP fields and induced surges.

An important element in the HEMP assessment of electric power systems is the vulnerability analysis of insulators and insulation systems. Experiments on $T \& D$ components with SFSD impulses representative of HEMP-induced surges have contributed to a data base for assessments. In general, it has been found that insulators will likely flashover at SFSD impulse levels at about 2 times the lightning impulse CFO. Puncture can occur at this level with many pulses (10-20) or at higher levels (about 4 times the CFO) for a few pulses. Similar cumulative effects of SFSD transients have also been observed for cable insulation.

Unprotected distribution transformers can be damaged with applied SFSD impulses at levels of about 1.75 times the lightning impulse basic insulation level (BIL). A peak Thévenin voltage of about 2.8 times the BIL is normally required to achieve 1.75 times the BIL at the transformer. Tank-mounted arresters have been found to provide good HEMP protection, but arresters installed remotely from the transformer, such as on a crossarm, provide a lower degree of protection. With this lower level of protection, transformers can be damaged by 10 to 20 multiple pulses. The peak HEMP response of arresters alone, i.e., arrestors not mounted on transformers, can be about five times that for lightning impulses. 
Thus, arresters may not provide good protection for power system components with a low input capacitance, such as cable terminators, due to the slowing of the wavefront by the capacitance.

Table 1. Selected results of component tests

\begin{tabular}{|c|c|c|c|c|}
\hline $\begin{array}{c}\text { Test } \\
\text { number. }\end{array}$ & Component & $\begin{array}{c}\text { Test } \\
\text { waveform }\end{array}$ & Amplitude $b$ & Comments \\
\hline 1 & $\begin{array}{l}15-k V \text { class } \\
\text { transformer }\end{array}$ & $\begin{array}{c}100 \times 2000 \\
\text { ns }\end{array}$ & $400 \mathrm{kV}$ & Failure likely without arrester. \\
\hline 2 & $\begin{array}{l}15-\mathrm{kV} \text { class } \\
\text { transformer }\end{array}$ & $\begin{array}{l}100 \times 2000 \\
\text { ns }\end{array}$ & $\begin{array}{l}\text { up to } \\
1.0 \mathrm{MV}\end{array}$ & $\begin{array}{l}\text { Failure unlikely with case mounted } \\
\text { arrester. }\end{array}$ \\
\hline 3 & $\begin{array}{l}15-\mathrm{kV} \text { class } \\
\text { transformer }\end{array}$ & $\begin{array}{l}100 \times 2000 \\
\text { ns }\end{array}$ & $\begin{array}{l}\text { up to } \\
1.0 \mathrm{MV}\end{array}$ & $\begin{array}{l}\text { Failure after about } 10 \text { shots with } \\
\text { arrester mounted on crossarm. }\end{array}$ \\
\hline 4 & $\begin{array}{l}25-k V \text { class } \\
\text { transformer }\end{array}$ & $25 \times 350 \mathrm{~ns}$ & $1.1 \mathrm{MV}$ & $\begin{array}{l}\text { Failed on 20th shot, with arrester on } \\
\text { crossarm. }\end{array}$ \\
\hline 5 & $\begin{array}{c}\text { 43.8-kV } \\
\text { power } \\
\text { transformer }\end{array}$ & $25 \times 300 \mathrm{~ns}$ & $\begin{array}{l}\text { up to } \\
1.48 \mathrm{MV}\end{array}$ & $\begin{array}{l}\text { Tested with and without arresters. } \\
\text { Failure unlikely when protected with } \\
\text { arresters. Failed on the secondary side } \\
\text { wher. unprotected with arresters. }\end{array}$ \\
\hline 6 & $\begin{array}{l}\text { substation } \\
\text { relays }\end{array}$ & $25 \times 300 \mathrm{~ns}$ & $1.2 \mathrm{MV}$ & $\begin{array}{l}\text { Relays continued to function with high } \\
\text { altitude electromagnetic pulse-induced } \\
\text { transients up to } 7 \mathrm{kV} \text {. }\end{array}$ \\
\hline 7 & $\begin{array}{c}34.5-\mathrm{kV} \\
\text { potential } \\
\text { transformers }\end{array}$ & $\begin{array}{l}180 \times 600 \\
\mathrm{~ns}^{d}\end{array}$ & $\begin{array}{l}\text { up to } \\
1.1 \mathrm{MV}^{d}\end{array}$ & $\begin{array}{l}\text { Failure occurred on one out of two units } \\
\text { at } 1.1 \mathrm{MV}(600 \mathrm{kV} \text { applied). About } 2 \% \\
\text { of primary voltage coupled to } \\
\text { secondary. }\end{array}$ \\
\hline 8 & $\begin{array}{c}\text { 43.8-kV } \\
\text { current } \\
\text { transformers }\end{array}$ & $25 \times 300 \mathrm{~ns}$ & $\begin{array}{l}\text { up to } \\
1.4 \mathrm{MV}\end{array}$ & $\begin{array}{l}\text { No failures occurred. About } 200 \mathrm{kV} \\
\text { applied to bushing. About } 4 \% \text { of } \\
\text { applied voltage coupled to current } \\
\text { transformer secondary. }\end{array}$ \\
\hline
\end{tabular}

Time to crest $\times$ time to decay to half value (time to crest $=67 \times 30-90 \%$ rise time).

Open-circuit pulser voltage.

Connected by a cable to power transformer current transformers.

Pulser voltage with potential transformers in the circuit (pulse may have been slowed down). 
Table 2. Selected results from steep-front short-duration impulse tests on insulators, cables, and arresters

\begin{tabular}{|c|c|c|c|c|c|c|}
\hline $\begin{array}{c}\text { Test } \\
\text { number }\end{array}$ & Type & Insulator & $\begin{array}{c}\text { Critical } \\
\text { flashover } \\
(\mathrm{kV})\end{array}$ & $\begin{array}{c}\text { Test } \\
\text { waveform }\end{array}$ & $\begin{array}{c}\text { Test } \\
\text { Amplitude }\end{array}$ & Comments \\
\hline 1 & $55-6$ & Pin & 150 & $42 \times 600 \mathrm{~ns}$ & $238 \mathrm{kV}$ & Flashed over. \\
\hline 2 & $55-6$ & Pin & 150 & $40 \times 600 \mathrm{~ns}$ & $1.1 \mathrm{MV}$ & Puncture at $600-800 \mathrm{kV}$. \\
\hline 3 & $55-6$ & Pin & 150 & $100 \times 500 \mathrm{~ns}$ & $375 \mathrm{kV}$ & Flashed over at $300 \mathrm{kV}$. \\
\hline 4 & $55-4$ & Pin & 105 & $65 \times 5000 \mathrm{~ns}$ & $220 \mathrm{kV}$ & Flashed over. \\
\hline 5 & $52-3$ & $\begin{array}{l}\text { Single suspension } \\
\text { disk }\end{array}$ & $125^{d}$ & $100 \times 500 \mathrm{~ns}$ & $375 \mathrm{kV}$ & Flashed over at $131 \mathrm{kV}$. \\
\hline 6 & 52.3 & $\begin{array}{l}\text { Single suspension } \\
\text { disk }\end{array}$ & $125^{d}$ & $25 \times 250 \mathrm{~ns}$ & $300 \mathrm{kV}$ & Flashed over on tail. \\
\hline 7 & $52-3$ & $\begin{array}{l}\text { Single suspension } \\
\text { disk }\end{array}$ & $125^{d}$ & $30 \times 600 \mathrm{~ns}$ & $1.1 \mathrm{MV}$ & $\begin{array}{l}\text { Punctured on tail at } 747 \\
\mathrm{kV}^{\mathrm{b}} \text {. }\end{array}$ \\
\hline 8 & $52-3$ & $\begin{array}{l}\text { Double suspension } \\
\text { disk }\end{array}$ & $125^{d}$ & $30 \times 600 \mathrm{~ns}$ & $1.1 \mathrm{MV}$ & $\begin{array}{l}\text { Flashed over at } 650 \mathrm{kV} \text { with } \\
\text { system .energized }\end{array}$ \\
\hline 9 & $52-3$ & $\begin{array}{l}\text { Double suspension } \\
\text { disk }\end{array}$ & $125^{d}$ & $80 \times 500 \mathrm{~ns}$ & $1.1 \mathrm{MV}$ & $\begin{array}{l}\text { Flashed over at } 334-698 \\
\mathrm{kV} \text {, failed when } 2300 \mathrm{~A} \text { fault } \\
\text { current available. }\end{array}$ \\
\hline 10 & $52-3$ & $\begin{array}{l}\text { Four suspension disk } \\
\text { string }\end{array}$ & $125^{d}$ & $40 \times 600 \mathrm{~ns}$ & $1.1 \mathrm{MV}$ & Flashed over on tail. \\
\hline 11 & $52-3$ & $\begin{array}{l}\text { Double suspension } \\
\text { disk }\end{array}$ & 125 & $80 \times 500 \mathrm{~ns}$ & $1.1 \mathrm{MV}$ & $\begin{array}{l}\text { Flashed over at } 500 \mathrm{kV} \text { with } \\
8 \text { in wood. }\end{array}$ \\
\hline 12 & - & 115-kV bushing & $550^{c}$ & $100 \times 500 \mathrm{~ns}$ & $1.2 \mathrm{MV}$ & $\begin{array}{l}\text { Failed at } 900 \mathrm{kV} \text { applied } \\
\text { voltage. }\end{array}$ \\
\hline 13 & $\begin{array}{l}\text { poly- } \\
\text { ethlyene }\end{array}$ & 15-kV class cables & - & $100 \times 300 \mathrm{~ns}$ & $400 \mathrm{kV}$ & $\begin{array}{l}\text { Aged cable. New cable } \\
\text { breaks down at } 50 \% \text { higher } \\
\text { levels. }\end{array}$ \\
\hline 14 & 一 & $\begin{array}{l}15-\mathrm{kV} \text { cable } \\
\text { terminators }\end{array}$ & $95^{c}$ & $100 \times 300 \mathrm{~ns}$ & $\begin{array}{l}\text { up to } \\
400 \mathrm{kV}\end{array}$ & $\begin{array}{l}\text { Punctured at } 220 \mathrm{kV} \text { and } \\
\text { higher. }\end{array}$ \\
\hline 15 & $10 \mathrm{kV}$ & $\begin{array}{l}\text { 10-kV metal oxide } \\
\text { varistor arrester }\end{array}$ & - & $100 \times 300 \mathrm{~ns}$ & $95 \mathrm{kV}$ & $\begin{array}{l}\text { At } 6 \mathrm{kA} \text {, discharge voltage }= \\
95 \mathrm{kV} \text {, three times higher } \\
\text { than for } 8 \times 20 \text { s wave. }\end{array}$ \\
\hline
\end{tabular}

a Time to crest - time to decay to half value.

b One sample was punctured on the impulse front at $420 \mathrm{kV}$.

$c$ Basic inpulse insulation level (BIL)

d Single suspension disk rating 
Limited tests on PTs indicate that the HEMP-induced surge withstand voltage is about three times the lightning BIL. No failures were observed for CTs rated at $250-\mathrm{kV}$ BIL for a 1-MV HEMP-type open-circuit voltage surge. This excitation resulted in 200$\mathrm{kV}$ transients at the $\mathrm{CT}$ primary and $2-7 \mathrm{kV}$ at the secondary terminals.

Relays connected to CTs during HEMP-surgu testing were subjected to transients up to $7 \mathrm{kV}$ with no observed failures. Recloser control units tested in the ARES simulator with a free-field environment of up to $40 \mathrm{kV} / \mathrm{m}$, resulted in recloser trips for one out of three units. This response was later traced to a manufacture defect. Overall, the control units are considered to be relatively hard to HEMP. It was also concluded that some power plant instruments are relatively hard to HEMP-type transients from limited tests on a current signal transmitter, a unit that converts voltage signals to current signals. Power line filters intended for EMI protection can be used in conjunction with surge suppressors at the filter input to provide good surge protection against HEMP-induced power ine surges.

Many more tests are required to build a statistically significant data base on the response of power system coinpr nents to HEMP-type transients. This is unlikely to occur due to time and budget constraints. However, for flashover and puncture vulnerabilities of insulators and insulation systems in transformers, etc., it appears reasonable to relate HEMP flashover and damage vulrerabilities of insulation to data on the standard lightning tests until SFSD surge test standards are adopted.

\subsection{SECTION REFERENCES}

1. Program Plan for Kesearch and Development of Technologies and Systems for Electrical Power Systems Under the Influence of Nuclear Electromagnetic Pulses, DOE/NBB-003, May 1983.

2. I. D. Smith, et al., Study for a Facility to Simulate High Altitude EMP Coupled Through Overhead Transmission Lines, ORNL/Sub/84-89643/1, Martin Marietta Energy Systems, Inc., Oak Ridge National Laboratory, November $: 985$.

3. A. Ramrus, Design Concepts for a Pulse Power Test Facility to Simulate EMP Surges in Overhead Power Lines: Part 1, Fast Pulse, ORNL/Sub/84-89642/1, Martin Marietta Energy Systems, Inc., Oak Ridge National Laboratory, February 1986.

4. H. Eichler, J. R. Legro, and P. R. Barnes, "Experimental Determination of the Effects of Steep-Front Short-Duration Surges on 25 kVA Pole Mounted Distribution Transformers," IEEE Transactions on Power Delivery 4(2), 1103-10, (April 1989).

5. L M. Burrage, J. H. Shaw, and B. W. McConnell, "Distribution Transformer Performance When Subjected to Steep Front Impulses," 1989 IEEE Power Engineering Society Transmission and Distribution Conference, Paper No. 89TD 400-3 PWRD. 
6. L. M. Burrage, et. al, Impact of Steep-Front Short-Duration Impulses on Power System Insulation, ORNL/Sub/85-28611/2, Martin Marietta Energy Systems, Inc., Oak Ridge National Laboratory, April 1991.

7. H. Marable, P. R. Barnes, and D. B. Nelson, Power System EMP Protection, ORNL-4958, Martin Marietta Energy Systems, Inc., Oak Ridge National Laboratory, March 1975.

8. B. Miller, A. E. Lux, S. Grzybowski, and P. R. Barnes, "The Effects of SteepFront Short-Duration Impulses on Power Distribution Components," IEEE Transactions on Power Delivery 5(2), 708-13, (April 1990).

9. P. R. Barnes and T. L. Hudson, "Steep-Front Short-Duration Voltage Surge Tests of Power Line Filters and Transient Voltage Suppressors," IEEE Transactions on Power Delivery 4(2), 1029-36, (April 1989).

10. J. P. Blanchard, F. M. Tesche, and B. W. McConnell, The Effects of Corona on Current Surges Induced on Conducting Lines by EMP: A Comparison of Experimental Data with Results of Analytic Corona Models, ORNL/Sub/85-27461/1, Martin Marietta Energy Systems, Inc., Oak Ridge National Laboratory, September 1987.

11. F. M. Tesche, and J. P. Blanchard, "Experimental Determination of EMP-Induced Corona Effects on Conducting Lines," Proceedings of the 7th International Zurich Technical Exhibition on EMC, Zurich, Switzerlani, March 1987.

12. E. R. Taylor, HEMP-Type Impulse Transfer Tests on High-Voltage Bushing Current Transformers at the Maxwell Laboratory February 1987, Westinghouse AST Report No. AST 88-2081, submitted to ORNL, September 1988.

13. E. R. Taylor, HEMP-Type Impulse Tests on High-Voltage Potential Transformers at Maxwell Laboratory Jamuary 1987, Westinghouse AST Report No. AST 88-7072, submitted to ORNL, July 1988.

14. T. M. Salas, et al., "Steep-Front Impulse Flashover Tests on a Solid-State Relay", paper 90 WM 126-3 PWRD, presented at the 1990 Winter IEEE Power Engineering Society Meeting, Atlanta, Ga., February 4-8, 1990

15. T. K. Liu, et al., HEMP Test and Analysis of Selected Recloser-Control Units, ORNL/Sub/88-02238/1, Martin Marietta Energy Systems, Inc., Oak Ridge National Laboratory, August, 1988.

16. M. L. LaGrassa, Test Report for the EMP Surge Testing of E1IGM Series Pressure Transmitter, BDM Corporation, Albuquerque, N.M, BDM/ABQ-87-0258-TR, December 29, 1986. 


\section{ASSESSMENT RESULTS}

As stated previously, the three components of the overall HEMP environment occur in different time periods after a high-altitude burst and can have substantially different impacts on the electric power system. The early-time HEMP effects appear as flashovers and voltage-stress damage to power delivery equipment and to communications electronics. The late-time MHD-EMP manifests itself on power lines of great length as a quasi-direct current $(\mathrm{dc})$, which flows through grounded transformers and shunt reactors. MHD-EMP, at extremely high levels, can also affect radio communications used throughout the power system. Although present in the HEMP environment, the intermediate-time $E_{2}$ component was not found to be important in assessing the behavior of the power system.

During a HEMP event, there is a possibility of load and generation loss. Either of these events, or their combination, can cause instability for the power grid. If, after experiencing the initial $\mathrm{E}_{1}$ transient excitation, the power system remains intact or breaks up into large interconnected "islands," it can experience MHD-EMP. The effects of this environment are a function of power line length, orientation, and the $E_{3}$ field strength. During a nominal MHD-EMP event, quasi-dc currents flowing through the power transmission system can result in insupportable reactive power demand. This can cause a further breakup of the system due to unacceptably low alternating current (ac) voltages on the system.

Because these two EM effects manifest themselves on the power system in such dissimilar ways, they must be evaluated separately. However, it must be realized that MHD-EMP may affect a system already modified by HEMP.

\subsection{EARLY-TIME $\mathrm{E}_{1}$ EFFECTS}

All impacts of the $E_{1}$ component of the HEMP were evaluated assuming a nuclear burst with nominal characteristics. However, for sensitivity purposes, power system impacts at peak HEMP field levels other than nominal were also investigated. The probabilities of HEMP-induced flashover were calculated over the entire area illuminated by the HEMP, assuming a $400-\mathrm{km}$-high burst unless specified otherwise. This resulted in an illuminated area of approximately $2200 \mathrm{~km}$ in radius.

To assess the $E_{1}$ effects on transmission and distribution lines, the multiconductor frequency-domain coupling algorithms described in ref. 1 were used to calculate flashover probabilities $^{2}$. As an example of the calculated results, Fig. 8 shows a typical contour plot of the peak $E_{1}$-induced voltage between the line and a support tower of a long $15-\mathrm{kV}$ class power distribution line located within the illuminated region. Figure 9 presents the cumulative probability distribution function for the line-to-tower voltage for four different classes of transmission and distribution lines. This figure indicates the probability of the 
voltage on any line in the illuminated region exceeding the value indicated on the abscissa of the plot. Probability distributions such as these were then used for comparisons with the estimated component or subsystem vulnerabilities to predict the power system behavior.

HEMP vulnerability data was assembled for equipment from numerous sources including testing at Maxwell Laboratories that included transformers, voltage transformers, and current transformers; testing at Westinghouse Relay-Instrument Division that included protective relays; and unclassified information on equipment such as motors, terminal boards, and low-voltage switch gear. ORNL supplied transmission and distribution line insulation strengths, based on tests conducted at Maxwell Laboratories. These latter tests were conducted for isolated insulators and did not take into account the presence of wooden supports for the lines.

For power delivery equipment, an important $E_{1}$ impact is flashover or insulation damage, with the ultimate result being the loss of the load or generation. The resulting imbalance could be such that the stability of the system cannot be maintained. Figure 10 shows a typical plot of the areas within the illuminated region that experience at least one flashover for the nominal HEMP event.

In the following sections, the various results of the assessment of the $E_{1}$ effects on the power system are summarized.

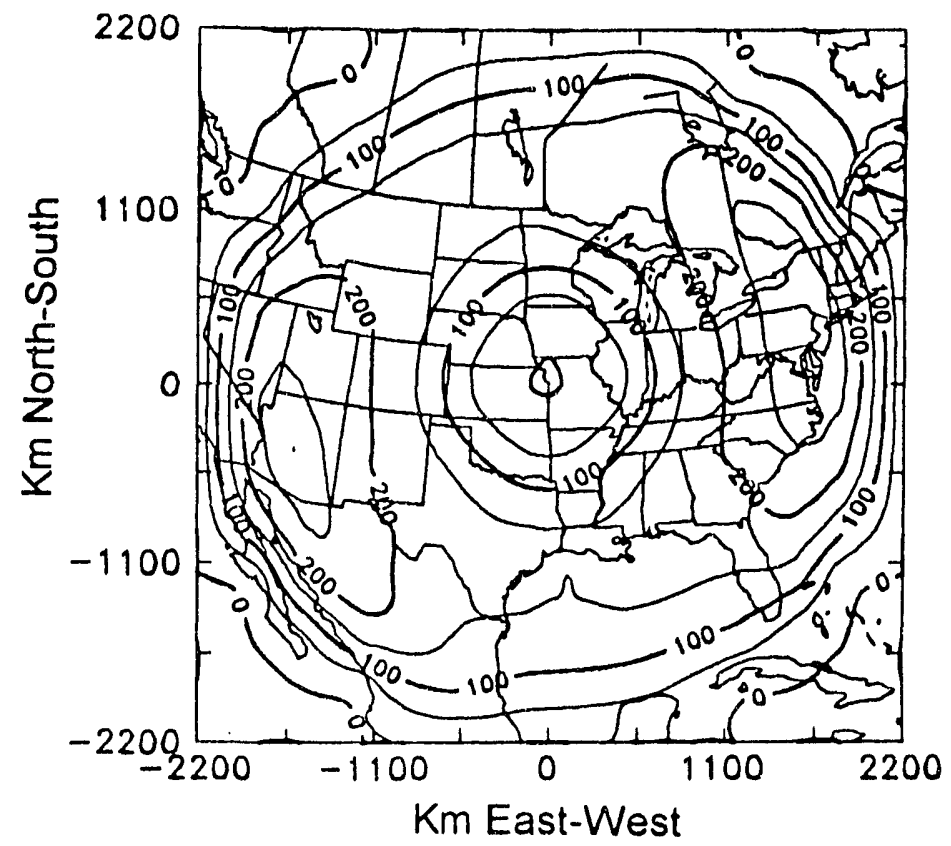

Fig. 8. Peak $V_{o c}$ for a $15-k V$ class power distribution line (contours in kilovolts per meter). 


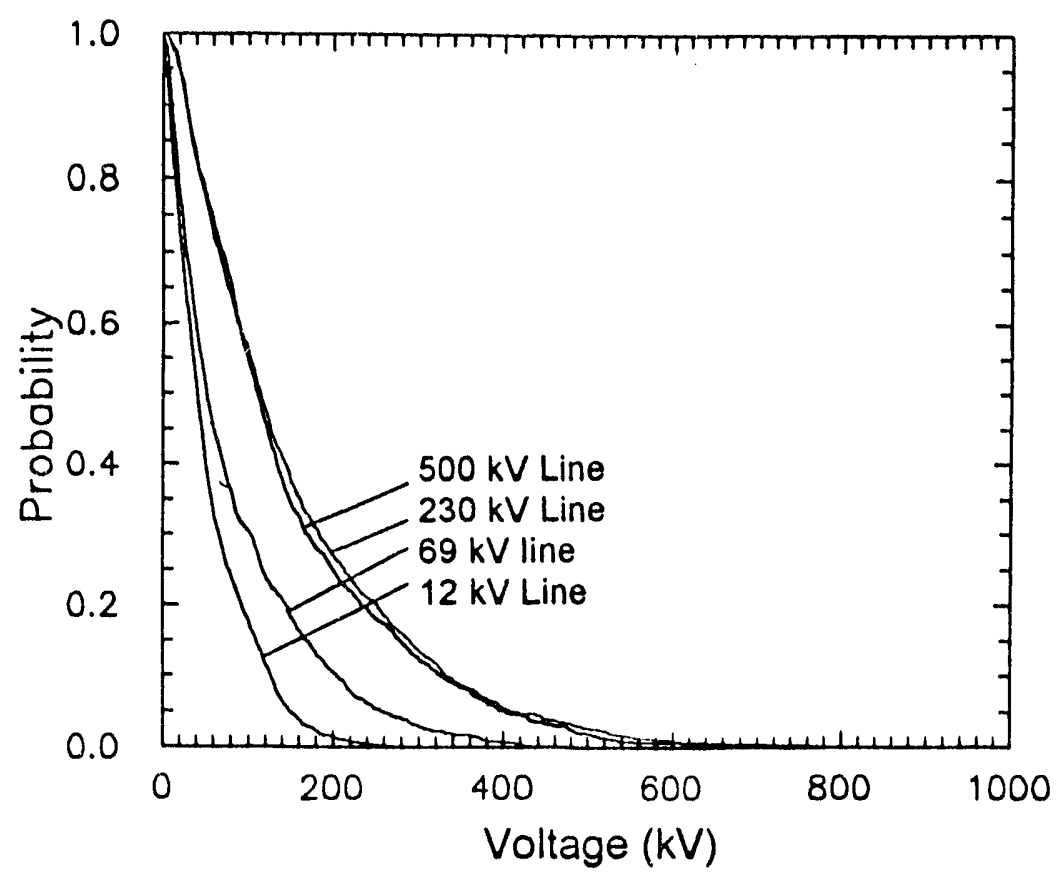

Fig. 9. Cumulative probability distribution for $V_{o c}$ for different classes of transmission and distribution lines.

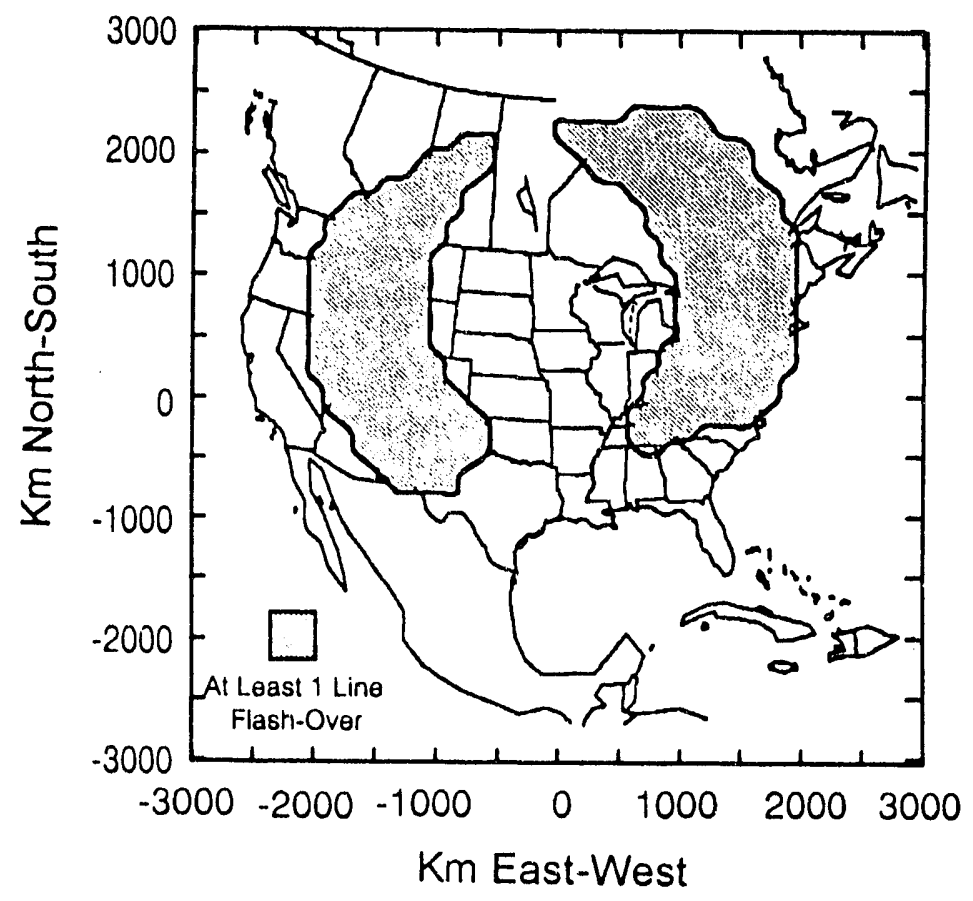

Fig. 10. Regions of flashover for the $12.47-\mathrm{kV}$ power distribution line with grounded insulators. 


\subsubsection{Line Flashover}

The research conducted during this program with the nominal HEMP environment has not demonstrated a HEMP flashover vulnerability in power systems having operating voltages above $69 \mathrm{kV}$. The normal insulation level for such systems appears to be sufficient to offer protection against the $\mathrm{E}_{1}$ stress. Furthermore, this study has indicated that $69-\mathrm{kV}$ systems are, at most, only marginally vulnerable. However, the iower voltage 5- and $15-\mathrm{kV}$ class distribution systems do exhibit flashovers. Table 3, taken from ref. 2, shows estimated percentages of lines with flashovers for three different peak HEMP field values. This analysis was conducted using specific representative line configurations for four operating voltages, with HEMP insulation strength conservatively assumed to be 1.5 times the lightning $\mathrm{CFO}^{3}$. This quantity is the voltage magnitude of a defined surge for which flashover occurs $50 \%$ of the time. As previously mentioned, these calculations did not consider the possible extra insulation due to the wood supports on the distribution lines, nor did it consider the possible degradation of the insulation due to contamination and previous overstress.

Table 3. Percentage of line flashovers for several operating voltages and peak $\mathrm{E}_{1}$ fields.

\begin{tabular}{|c|c|c|c|c|c|c|}
\hline $\begin{array}{c}\text { System } \\
\text { operating } \\
\text { voltage } \\
\text { (kV) }\end{array}$ & \multicolumn{2}{|c|}{$\begin{array}{c}\text { 25-kV } \\
\text { Peak field } \\
\text { Min \% }\end{array}$} & \multicolumn{2}{c|}{$\begin{array}{c}\text { Ma-kV } \\
\text { Peak field }\end{array}$} & \multicolumn{2}{c|}{$\begin{array}{c}\text { 50-kV } \\
\text { Peak field }\end{array}$} \\
\hline 500 & 0 & 0 & 0 & 0 & 0 & 0 \\
230 & 0 & 0 & 0 & 0 & 0 & 0 \\
69 & 0 & 0 & 0 & 0 & 0 & 1.7 \\
12 & 0.2 & 1.0 & 3.1 & 6.0 & 9.0 & 15. \\
\hline
\end{tabular}

Source: Kruse, V., P. R. Barnes, and F. M. Tesche 1990. "Flashover Vulnerability of Transmission and Distribution Lines to High Altitude Electromagnetic Pulse," IEEE Transactions on Power Delivery $\mathbf{5}(2)$.

The table shows that power distribution systems are most prone to flashovers. In the United States, distribution systems are classified into four voltage classes: $5 \mathrm{kV}, 15 \mathrm{kV}$, $25 \mathrm{kV}$, and $35 \mathrm{kV}$. The percentages of the overall power load served by distribution circuits are $10.6 \%, 77.5 \%, 9.4 \%$, and $2.5 \%$, respectively 4 .

For voltage classes other than $15 \mathrm{kV}$, flashover probabilities were determined by assuming a line configuration similar to that of the $12-\mathrm{kV}$ line, with the HEMP insulation strength adjusted for each distribution voltage class. Only the maximum representative probability of flashover was calculated for operating voltages other than $15 \mathrm{kV}$. Table 4 shows the estimated percentage of distribution-class lines experiencing a HEMP-induced flashover for the three strengths of the HEMP field. Because, as before, the insulating value of wood supports has not been taken into account, the values shown here are assumed to be conservative. 


\section{Table 4. Percentage of distribution class lines experiencing a flashover for various peak $E_{1}$ field strengths ${ }^{a}$}

\begin{tabular}{|c|c|c|c|c|c|c|}
\hline \multirow{2}{*}{$\begin{array}{c}\text { Voltage } \\
\text { class } \\
(k V)\end{array}$} & \multicolumn{2}{|c|}{$\begin{array}{c}25-k V \\
\text { Peak field }\end{array}$} & \multicolumn{2}{|c|}{$\begin{array}{c}\text { 39-kV } \\
\text { Peak field }\end{array}$} & \multicolumn{2}{|c|}{$\begin{array}{c}50-k V \\
\text { Peak field }\end{array}$} \\
\hline & $\operatorname{Min} \%$ & $\operatorname{Max} \%$ & Min \% & Max \% & $\operatorname{Min} \%$ & $\operatorname{Max} \%$ \\
\hline 5 & - & 2.8 & $\overline{-}$ & 14.0 & - & 22.0 \\
\hline 15 & 0.2 & 1.0 & 3.1 & 6.0 & 9.0 & 15.0 \\
\hline 25 & - & 0 & - & 0.8 & - & 2.0 \\
\hline 35 & - & 0 & - & 0 & - & 0.8 \\
\hline
\end{tabular}

${ }^{a}$ For grounded insulators

Source: Kruse, V., P. R. Barnes, and F. M. Tesche 1990. "Flashover Vulnerability of Transmission and Distribution Lines to High Altitude Electromagnetic Pulse," IEEE Transactions on Power Delivery 5(2).

\subsubsection{Loss of Load Due to Flashovers}

Flashovers themselves do not directly affect the power system security. It is the resultant loss of load that ultimately affects the power system. Simply determining the level of flashovers on transmission and distribution lines is not sufficient to indicate expected loss of load. A number of factors affect the expected load loss given a flashover on any line section.

Because no expected flashovers have been demonstrated for transmission and subtransmission systems for the nominal HEMP environment, only the load loss caused by distribution system flashovers was considered. Expected load loss was determined by considering three major components of distribution systems: substation supply lines, substation primary feeders downstream of the reclosers, and the sublateral lines and interconnected network serving the customer. A flashover within any of these components affects a different amount of the load, depending on the component level. Figure 11 illustrates the relevant components of a power distribution system.

The amount of load loss within this system depends both on the hierarchy of the component levels and on the protection philosophy. The highest component level shown in Fig. 11 is the $69-\mathrm{kV}$ supply. A flashover on the $69-\mathrm{kV}$ supply line will drop more load than would a flashover on a sublateral line serving a limited number of customers. The component level determines the amount of affected load, because for every component level there exists a statistical distribution of load for any one device of that component. This statistical distribution has an expected value that is the mean or average value of load supported by that component. 


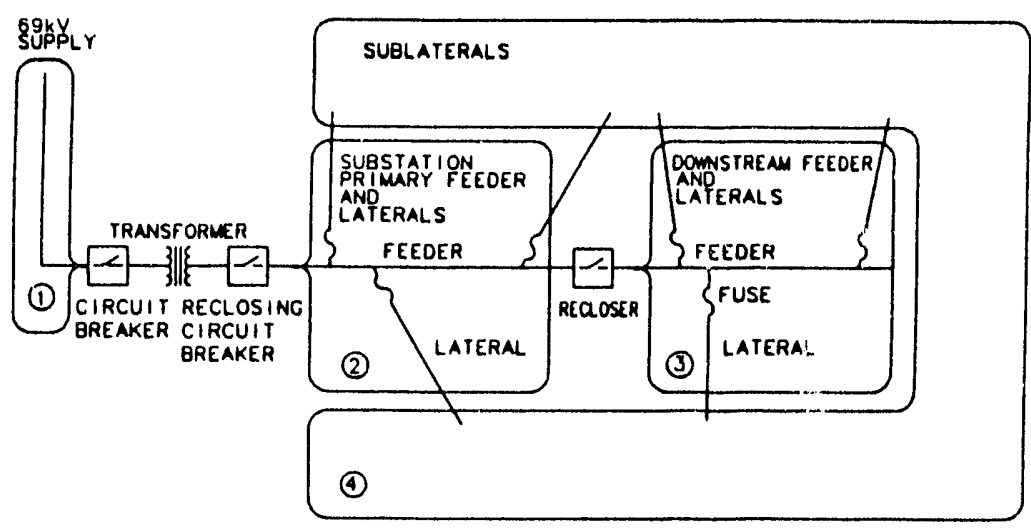

Fig. 11. Component levels in a typical distribution system.

If the probability of load loss for every component level is calculated, the total system effect can be estimated. Each component level depends on its upstream component. If an upstream component is out of service, downstream component-level flashovers will affect neither fuses nor total load loss. This indicates a hypergeometric effect.

The philosophy of protection for each component level must also be considered. A flashover on a sublateral may blow a fuse, disconnecting the sublateral from the rest of the circuit. The sublateral will remain out of service until the fuse is replaced. Similarly, for a flashover on a $69-\mathrm{kV}$ supply line, a circuit breaker is expected to remove the line until intervention occurs.

However, the situation for feeders is somewhat different. Feeders leave substations through a reclosing circuit breaker, and the breaker can open under fault and then close after a short delay. This prevents permanent outages for what is often a temporary fault. In Fig. 11, several laterals typically branch off primary feeders by way of fuses. Due to this protection philosophy, a flashover on a lateral will trip the recloser or breaker on the feeder before blowing the fuse. This protection scheme is designed to minimize unnecessary fuseblowing due to temporary faults.

What this implies in terms of the probability of load loss is that there are more opportunities for flashover on such a network than just on one line section. In fact, there is an opportunity for flashover for every line orientation associated with each feeder and lateral assembly. A flashover on any lateral line, or on the feeder itself, will cause the recloser to operate and the load will be lost. The reclosers themselves are expected to be unaffected by HEMP5

Using this method, which is described in more detail in the Appendix of ref. 6 , it is concluded that the power system load loss for a nominal HEMIP event may be significant. 


\subsubsection{Loss of Load Due to Secondary Voltage Transients}

Voltage transients in the secondary distribution circuits will result from the primary circuit transients that couple across distribution transformers, and from the direct HEMP interaction with secondary conductors. Experiments indicate that $10-25 \mathrm{kV}$ surges can be expected due to transformer coupling (see Sec. 5.4 of ref. 4 and ref. 8). Transients due to direct coupling are estimated to range from a few hundred volts to several tens of $\mathrm{kV}$, depending on the detailed configuration of this rather complicated HEMP coupling problem.

A recent study concluded that electronic devices associated with the end-use loads have a high potential for damage, unless these devices are protected against fast transients ${ }^{7}$. These loads include switching power supplies, microprocessor-based controllers, and computer components. EPRI estimates that $35-45 \%$ of electric power flows through electronic devices and this level is expected to increase to $60 \%$ by the year $2000^{8}$.

Failures in electronic components results in open-circuits or short-circuits caused by solid-state device fusing. Short-circuits will cause fuses to blow, and circuit breakers to trip. Completely self protecting (CSP) distribution transformers may also trip, causing a loss of load served by these transformers. In $480-\mathrm{V}$ commercial and industrial power circuits, motor failures and power-follow arcs could occur in addition to electronic failures. Furthermore, failures of $120 / 240-\mathrm{V}$ motors cannot be ruled out.

\subsubsection{High-Altitude Electromagnetic Pulse-Induced Damage On Power System Components}

Distribution transformers with directly mounted surge arresters are expected to be undamaged. Although most distribution transformers are protected in this manner, in some regions of the country lightning is so infrequent that these surge arresters are not cost effective. For these unprotected distribution transformers, there is some probability of damage, especially for the 5- or 15-kV class transformers. However, for a burst of nominal characteristics, less than $2 \%$ of the unprotected transformers are expected to be damaged. For a burst yielding a $50-\mathrm{kV} / \mathrm{m}$ peak HEMP field, less than $4 \%$ damage is expected 9 .

In addition to the danger of flashover on distribution-class lines, there is the possibility of immediate insulator puncture. Furthermore, there is the possibility of latent damage, due to the rapid voltage rise of the larger HEMP waveforms. Distribution pintype insulators designed to survive $10-\mathrm{kV} / \mathrm{ns}$ risetimes have been shown to be the vulnerable. However, tests have indicated a strength distribution variation of 2 to $20 \mathrm{kV} / \mathrm{ns}$ (ref. 3) At the distribution level, punctures may occur due to antiquated (predating 10 $\mathrm{kV} / \mathrm{ns}$ designs) pin insulators, previously damaged insulators, or those on the tail of the puncture-withstand distribution.

For HEMP events of nominal characteristics, research has not demonstrated a vulnerability of generation equipment to damage caused by the induced surges coupled into the electric power transmission grid. However, it was found that remote $480-\mathrm{V}$ motors 
served by long, unshielded runs of wire exhibit substantial risk to permanent damage caused by the $\mathrm{E}_{1} \mathrm{HEMP}{ }^{10}$. This damage is attributed to insulation punclure by the HEMP surge, coupled with a $60-\mathrm{Hz}$ power follow current. The degree of vulnerability depends on orientation and location within the area of HEMP illumination. Any 480-V motor, operating at the time of a HEMP event and supplied over distances of $60 \mathrm{~m}$ or greater with unshielded wires, has some probability of risk. As these motors are frequently found in cooling towers for steam generation power plants, it is expected that their failure will have an adverse impact on the reliability of power generation during a HEMP event. Other damage occurring at generating plants is expected to be random and scattered, with the exception of the remote $480-\mathrm{V}$ motors previously described. The extent of damaged equipment will be neither severe nor extensive, but it will cause some difficulty and will be a factor in continued operation of the system. No damage is expected in 4-kV power plane auxiliary equipment.

High-voltage substation equipment has not been demonstrated to be vulnerable to $\mathrm{E}_{1}$. Furthermore, it is expected that a typical solid-state-relay is unlikely to be damaged or to misoperate by the nominal HEMP threat with a peak field strength of $50 \mathrm{kV} / \mathrm{m}$ (ref. 11). However, it is possible for both dc control wires to flash over to ground simultaneously, causing fuses to blow and placing the relay in an inoperative state.

\subsubsection{Power Generation Loss due to $\mathbf{E}_{1}$}

The loss of power generation capability due to HEMP arises from either damage or upsets in power plant electrical, control, and instrumentation systems. These systems include switchyard power, control and instrumentation systems, combustion turbine generator packages, and control rooms. The operation of the power plant is dependent upon proper functioning of all these subsystems, as well as of their major components. During analysis described in ref. 6, these subsystems were represented to the major component level, such as motors, relays, and transducers.

In assessing the probability of HEMP affecting the operation of generation equipment, all power, control, and instrumentation cables buried below the ground grid were assumed to be effectively shielded to HEMP. Therefore, the cable duct-bank network in main-plant areas was considered to be effectively shielded. It was assumed that the major threat in the main plant areas where an extensive ground grid is located would be from transmitted surges. All mutual inductive and capacitive effects were neglected for conductors in duct banks, in trenches, and overhead. All cables were represented on a single-wire basis.

The following equipment was assumed to be effectively shielded by their metallic enclosures:

- electrical conduits,

- indoor and outdoor metal-enclosed switch gear,

- metal-enclosed control and relay cabinets,

- indoor and outdoor motor control centers,

- battery rooms that are metal enclosed, and

- control rooms that are metal enclosed. 
Duct banks outside the main power plant area were considered to be unshielded, because the ground grid in these areas is limited, and the duct banks are shallow. These duct banks run to remote equipment such as gas turbines, fuel transfer pumps, well pumps, switchyards, and cooling towers.

For a generation facility relying on the remote $480-\mathrm{V}$ motors that have a vulnerability to the HEMP surge, there is some probability of a disruption of power generation. Possible subsystems at risk within the generation facility are water treatment facilities, demineralizing plants, fuel unloading pumps, fuel transfer pumps, and cooling water treatment plants.

Plant-trip or forced shutdown of steam-generation power plants is possible due to loss of the critical 480-V equipment. This appears to be particularly true of cooling-tower fan motors. These fans are critical to power plant operation. Their motors are remote from the motor control center, with distances up to several hundred feet, and are vulnerable to the large HEMP-induced voltage surges if cabling is unshielded and shallowly buried. Control wiring flashovers can also be expected at cooling towers and in control rooms. Some instrument damage is possible.

Auxiliary power to power circuit breakers in switchyards may be lost due to panelboard failures or circuit breaker trips due to surges transferred to low-voltage panelboards. If one of the auxiliary motors is operating at the instant of the surge, failure is possible. However, a limited number of power circuit breaker operations are still possible using energy stored in the operating mechanism of the breakers. It is possible that fuses in the dc control lines could be blown by the HEMP-induced flashovers.

Voltage transformers used for power system monitoring may experience fuses blowing on the low side, causing false circuit breaker tripping. In the control room, relay coils or relay rack terminal strips may flashover on both ac and dc circuits.

With these events occurring within generation facilities, it is important to evaluate the percentage of generation lost due to HEMP. The assessment showed particular vulnerability for the $480-\mathrm{V}$ motors supplied by shallowly buried, unshielded 200 - $\mathrm{ft}$ or longer cables ${ }^{10}$. If these $480-\mathrm{V}$ motors are the key factors, the probability of generation loss is similar to the probability of damage. Table 5 shows the probability of $480-\mathrm{V}$ motor damage when supplied by long, unshielded, shallowly buried cables.

On this basis, it has been assumed that HEMP would affect only large, steamgeneration facilities relying on cooling towers. A conservative assumption would be that this occurs only for nuclear and coal generation plants that constitute $17.4 \%$ and $55.9 \%$ of the total capacity ${ }^{12}$. There is also the possibility of nuclear generation being vulnerable to tripping off-line, due to HEMP-induced problems in the extremely complex reactor control circuitry 9 . 
Table 5. Percentage of remote $480-\mathrm{V}$ motors failing when supplied by an unshielded, buried cable (for a $2200-\mathrm{km}$ radius area of illumination)

\begin{tabular}{|c|c|c|c|}
\hline $\begin{array}{c}\text { Peak } \\
\text { field strength } \\
(\mathrm{kV} / \mathrm{m})\end{array}$ & \multicolumn{3}{|c|}{ Average burial depth } \\
\hline 25 & $0.5 \mathrm{~m}$ & $0.7 \mathrm{~m}$ & $1.0 \mathrm{~m}$ \\
39 & $0 \%$ & $0 \%$ & $0 \%$ \\
50 & $2.5 \%$ & $0 \%$ & $0 \%$ \\
\hline
\end{tabular}

Source: Bonk, J. J., and C. H., Eichler 1989. Sensitivity Analysis Task Report for Generation Plant Auxiliary and Control and Substation Protection and Control, Report to ORNL, AST 89-2115, ABB Power Systems, Inc., Advanced Systems Technology, Pittsburgh, Pa., August.

Neglecting the losses in generation capacity due to reactor control room circuitry, the initial estimate of probability of generation loss can be determined from the probabilities of Table 5. Because cooling-pump fan motors are the vulnerable components, the total power generation loss is a function of the amount of steam-generation. The combined percentages of nuclear and coal generation were " sumed to be the vulnerable quantity of generation and are reflected in Table 6.

Table 6. Percentage of generation loss based on 480-V motor damage when supplied by unshielded buried cable

(2200-km radius area of illumination)

\begin{tabular}{|c|c|c|c|}
\hline $\begin{array}{c}\text { Peak } \\
\text { field strength } \\
(\mathrm{kV} / \mathrm{m})\end{array}$ & \multicolumn{3}{|c|}{ Average burial depth } \\
\hline 25 & $0.5 \mathrm{~m}$ & $0.7 \mathrm{~m}$ & $1.0 \mathrm{~m}$ \\
39 & $0 \%$ & $0 \%$ & $0 \%$ \\
50 & $1.8 \%$ & $0 \%$ & $0 \%$ \\
\hline
\end{tabular}




\subsection{INTERMEDIATE-TIME E EFFETS $_{2}$ EFE}

Early in the assessment process, a preliminary investigation into the effects of the intermediate-time $\mathrm{E}_{2}$ component of the HEMP environment was begun ${ }^{14}$. It was concluded that this environment is not very important in determining the overall vulnerability of the electric power system. Calculated $E_{2}$ voltage responses on a $1000-\mathrm{km}$ transmission-class line were similar to a $90-\mathrm{kV}, 0.5 \times 4.0 \mathrm{~ms}$ transient. For shorter lines, this response was smaller in amplitude. For these transmission systems, the $E_{2}$-induced pulse was well below the normal operating levels, and this transient energy thus will be dissipated in the system loads with little or no adverse consequences. For subtransmissionclass lines about $100 \mathrm{~km}$ long, the observed voltage response was a $80-\mathrm{kV}, 0.25 \times 0.5 \mathrm{~ms}$ transient. This is less severe than switching surges $(0.25 \times 2.5 \mathrm{~ms})$, and no adverse effects are expected for this class of line. Long power distribution lines about $60 \mathrm{~km}$ in length will have a $60-\mathrm{kV}, 0.2 \times 0.5 \mathrm{~ms}$ transient open-circuit voltage response.

Surge arresters can survive an excess of $50 \%$ of their maximum continuous operating root mean square voltage rating for over 1 s (ref. 15). Arresters on subtransmission and transmission systems have sufficiently large voltage ratings to easily survive the effects of $E_{2}$. Distribution-class arresters have considerably lower voltage ratings, which will be exceeded by the $E_{2}$ surges. However, distribution arresters can easily handle the available $\mathrm{E}_{2}$ energy collected by the overhead lines. According to ref. 14, the maximum HEMP energy collected by $50-\mathrm{km}$ lines is less than $0.4 \mathrm{~kJ}$. Arresters in 4and $12-\mathrm{kV}$ distribution systems can safely handle 11 and $42 \mathrm{~kJ}$, respectively. Thus, distribution arresters are expected to safely discharge the $\mathrm{E}_{2}$-induced transients.

Consequently, little or no adverse impacts on electric power systems are expected from the $E_{2}$ environment. $E_{2}$-induced transients are similar to, but less severe than, the system-generated transients to which the power system is routinely exposed.

\subsection{MAGNETOHYDRODYNAMIC ELECTROMAGNETIC PULSE EFFECTS}

During a HEMP event, quasi-dc currents are induced in the electric power system by the late-time MHD-EMP environment. These currents can reach levels exceeding the exciting currents of transmission and subtransmission transformers. These quasi-dc currents cause severe half cycle saturation, resulting in harmonics and an increased reactive power demand. In addition, the quasi-dc currents disturb internal transformer flux paths causing conductor, core, and tank heating. Both of these effects can adversely affect the overall power system.

The effects of a recent geomagnetic storm on October 28 and 29, 1991, on electrical power systems across the United States have been documented in ref. 16. Although there was no dramatic power blackout similar to that occurring in the HydroQuebec system in 1989 (ref. 17), there were reports of shunt capacitors tripping, strange transformer noises, and abnormal operating voltage fluctuations. Some power lines and associated equipment were temporarily removed from service due to this storm. 
For an assumed earth conductivity of $\sigma=10^{-4} \mathrm{~S} / \mathrm{m}$, the peak E-field produced by this geomagnetic storm was estimated from magnetometer data from the Canadian Observatory in Ottawa to be about $14 \mathrm{~V} / \mathrm{km}$. This is roughly a factor of 2 less than the peak unclassified MHD-EMP environment of $24 \mathrm{~V} / \mathrm{km}$ developed in ref. 18. As the E-field varies inversely with the square root of the earth conductivity, lower values of the field will be expected as the earth conductivity increases. For example, with an earth conductivity of $\sigma=10^{-2} \mathrm{~S} / \mathrm{m}$, the peak field would be a factor of ten lower at $1.4 \mathrm{~V} / \mathrm{km}$.

Given the direct evidence of the effect of geomagnetic field variations on power system operation, the MHD-EMP threat is likely to pose a problem to the power system. Probable effects of this environment are described in the following sections.

\subsubsection{Direct Damage}

Due to the inherently short interval of MHD-EMP (400 s maximum), it is unlikely that the transformer will suffer immediate, noticeable damage due to the nominal $E_{3}$ environment. Transformer damage arising from severs geomagnetic storms has been suspected in the past, but these storms typically last for much longer periods of time than does the MHD-EMP. Consequently, direct immediate damage due to $\mathrm{E}_{3}$ may not be very probable.

\subsubsection{Faulty Operation of Power System Components}

It is likely, however, that the increased reactive power demand due to $\mathrm{E}_{3}$ will adversely affect a power system. The increased reactive power demand can exceed the system capability and can result in severe voltage depression throughout the system. Static reactive power compensators appear vulnerable to MHD-EMP, due to a demonstrated vulnerability to geomagnetic storm effects ${ }^{17}$. Furthermore, grounded shunt capacitor banks have experienced neutral overcurrent trips during previous geomagnetic storms. These are expected to be adversely affected by MHD-EMP as well ${ }^{19}$.

Several types of relaying problems can occur. Delta-wye power transformers can be affected by the differential effects of current through one side of the transformer and not the other. Because of this, differential relaying schemes are vulnerable to misoperation. During past geomagnetic storm events, several occurrences of transformer-differential tripping have occurred. This tripping has occurred, however, only on relays without harmonic restraint. Overcurrent ground relays are also subject to false tripping due to increased zero sequence current. MHD-EMP could also cause problems during switching, and system reconfiguration may be inhibited during an MHD-EMP event ${ }^{20}$.

High-voltage de transmission is also at risk during an MHD-EMP event due to the possibility of overcurrent trips in harmonic filters. MHD-EMP-induced current flow will generate high magnitudes of low-order harmonics, but it has been shown that higher harmonics can also be of a magnitude sufficient to cause overcurrent trips in higher-order filters ${ }^{20}$. 
There is also a possibility of commutation failure of inverter terminals due to severe voltage distortion caused by harmonics. Commutation failure is a definite possibility with voltage distortion of $30 \%$ or higher ${ }^{20}$. Converter transformers are subject to voltage distortion due to the quasi-dc current.

Turbine generators are vulnerable to induced harmonics in the stator windings. In particular, a second harmonic or a negative harmonic sequence, which could arise from an unequal excitation of a transformer bank, are of concern. No occurrence of tripping of these generators during geomagnetic storms has been documented to date, but instances of alarms have occurred. Tripping might occur if the level of MHD-EMP were high enough.

Finally, geomagnetic storms sometimes cause some difficulty in radio communications. While MHD-EMP effects are of shorter duration than these storms, the EM distortion can be expected to be much more intense, and the possibility of communication disruption exists.

\subsubsection{System-Wide Magnetohydrodynamic Electromagnetic Pulse Effects}

Previous theoretical work shows electric power systems to be at some risk from MHD-EMP21. In a simulation of a nominal MHD-EMP event on the Arizona Public Service (APS) system, the surrounding Western States Coordinating Council (WSCC) system was included in the analysis. For this analysis, however, the surrounding network was assumed to be unaffected by the MHD-EMP environment. Load flow analysis indicated severe voltage problems on the APS system during the nominal MHD-EMP event.

The percentage of APS system buses below various per-unit voltage levels is shown in Table 7. On the basis of these data, it is estimated that system breakup is possible during a nominal MHD-EMP event 6 . 
Table 7. Percentage of busses with a per-unit voltage level helow the specified values as a result of the Arizona

Public Service magnetohydrodynamic electromagnetic pulse analysis

\begin{tabular}{|c|c|}
\hline $\begin{array}{c}\text { Voltage level } \\
\text { (per-unit) }\end{array}$ & $\begin{array}{c}\text { Buses with voltages } \\
\text { below the specified } \\
\text { level (in \%) }\end{array}$ \\
\hline 0.9 & 54 \\
0.8 & 41 \\
0.7 & 18 \\
0.6 & 2 \\
0.5 & $\approx 2$ \\
\hline
\end{tabular}

Source: Kruse, V. J., G. B. Rackliffe, and P. R. Barnes 1989. "Load Flow Studies in the Presence of Magnetohydrodynamic Electromagnetic Pulse," IEEE Transactions on Power Delivery, 5(2), 1158-1163 April.

\subsection{POWER SYSTEM RESPONSE TO THE COMBINED HIGH-ALTITUDE ELECTROMAGNETIC PULSE ENVIRONMENTS}

The complete power system response to a HEMP will be due to both the $E_{1}$ and $E_{3}$ components of this environment. Due to the direct physical damage caused by $E_{1}$ in unprotected distribution transformers and $480-\mathrm{V}$ motors, reductions in power generation capability and in the load connected to the system are expected. Extensive plans and protective systems are in effect throughout the power system grid for load shedding in steps, triggered by underfrequency relaying. Overfrequency (overspeed) and underfrequency protection schemes are also applied to trip turbine-generator units. These off-normal frequency schemes are designed to protect turbine generators from operating continuously at speeds that are a resonant frequency for the various rows of blades. These schemes are coordinated with the load-shedding schemes. Most overfrequency or overspeed relaying schemes are applied to prevent excessive acceleration due to opening the generator breaker. Line trips and capacitor bank trips caused by $E_{3}$ would increase the severity of the disturbances.

The actual effect of excessive load loss or generation loss is dependent on the system configuration and load. Several factors affect the response of a system to an event that causes a frequency deviation:

- power factor of the system load,

- level of capacity of the on-line generation,

- distribution of the load loss, and

- distribution of the generation, in particular, spinning reserve. 
Loss of generation capacity can be estimated with and without assuming the total loss of nuclear generation due to control-room circuitry disturbances. For a nominal HEMP event, generation loss may be as high as $17 \%$, assuming all nuclear generation is affected, and as low as $0 \%$, if nuclear generation is not specifically affected. Thus, ref. 6 concludes that for a burst with a nominally characteristic, $39-\mathrm{kV} / \mathrm{m}$ peak $\mathrm{E}_{1}$ field followed by $E_{3}$ fields on the order of several tens of $V / \mathrm{km}$, stability of the power system is questionable. This study, however, did not take into account the possible additional increase in insulation level provided by the wooden support structures of the power lines, and thus, may be overly pessimistic.

\subsection{EFFECTS OF MULTIPLE BURSTS ON POWER SYSTEMS}

A complete evaluation of high-altitude burst effects on power systems requires consideration of multiple bursts. For multiple bursts, the assessment has assumed that their occurrence is sequential, occurring at least $1 \mathrm{~s}$ apart. Because of this staggered occurrence, the $E_{1}$ and $E_{3}$ environments affect power systems differently, due to their different characteristic time periods.

The effects of the $E_{1}$ environment on power systems for multiple HEMP events appear as sequential events: each $E_{1}$ event ends before the next event occurs. The impact on load and generation is cumulative and hypergeometric. There is geographic overlap of HEMP illumination, but no overlap in time.

The effects of the $E_{3}$ environment on the power system are assumed to superimpose. The multiple HEMP events appear to occur simultaneously when viewed on a time scale commensurate with that of the MHD-EMP environment. Consequently, the effects of MHD-EMP are additive. The severity of the overall impact of the multipleHEMP environment increases with spatial overlap of the illuminated regions, because MHD-EMP events overlap in both time and geography.

\subsubsection{Multiple $E_{1}$ Effects on the Power System Load}

The cumulative effect of $E_{1}$ is not additive but hypergeometric. For example, once a fuse is blown, it cannot be blown again. For every subsequent illumination, the extent of load loss is a function of even smaller amounts of surviving load. The effect is similar for the case of power generation loss.

Multiple bursts have the same $E_{1}$ consideration as a single burst, with the addition of overlapping the illuminated regions for each burst, which gives the number of times an area is illuminated. For multiple $\mathrm{E}_{1}$ events, the considerations are the following:

- component-level hierarchy,

- protection philosophy of each component level, and

- HEMP-overlap level. 
Protection philosophy and overlap level add considerable complexity to multiple burst evaluation. A probabilistic assessment is tediously complex.

It is important to realize that for a number of bursts $N$, there are $N$ possible levels of overlap; those regions that experience the effect of only one $E_{1}$ illumination have an overlap level of one. A probabilistic evaluation of load loss is necessary for each level of overlap and must be proportioned according to the area involved. The weighted values of load loss can be summed to indicate total expected load loss from a multiple-burst scenario.

Protection schemes complicate $\mathrm{E}_{1}$ overlap, even more so than for single bursts. It is typical in power distribution systems for reclosers to delay tripping after the first reclose cycle. Reclosers remain closed after the first cycle because the fault is probably temporary under ordinary conditions. If the first recloser cycle did not clear the fault, the recloser will trip a second time and then reclose. Many reclosers are set to "lock out" on the third trip. The idea is to allow the "permanent" fault to blow the closest fuse, minimizing load loss under normal conditions.

Probability evaluation is possible for distribution systems where reclosers have tripped, and reclosing devices are assumed to reclose after $1 \mathrm{~s}$ and to hold through subsequent HEMP events. Lateral feeders now become an additional component level because reclosing devices on feeders no longer trip due to faults on laterals. Faults on laterals will blow fuses, permanently removing load from the system. The factors for the feeder component levels are no longer raised to a power. Each distribution voltage class must be addressed separately for each level of HEMP-illumination overlap and weighted before summation.

\subsubsection{Multiple $\mathrm{E}_{1}$ Effects on Arresters}

Standards for surge arresters used in distribution systems do not address multiple operations. However, both gapped silicon-carbide and metal-oxide arresters undergo multiple tests during duty-cycle testing. Duty-cycle tests consist of at least 20 arrester operations staggered 50 or $60 \mathrm{~s}$ apart. Each operation passes an $8 \times 20 \mu$ s discharge current with a magnitude of $5000 \mathrm{~A}$ for normal-duty and 10,000 A for heavy-duty. On this basis, multiple bursts are not expected to affect arrester performance for nominal $E_{1}$ events.

\subsubsection{Multiple $E_{1}$ Effects on Generation}

A similar effect occurs with generation, but without such complications as those caused by reclosing devices on distribution. The surviving generation for each level of overlap is merely the survival percentage for a single burst raised to a power equal to the level of overlap. For example, if the level of overlap were two, the surviving-generation percentage would be squared. The values of surviving load for each level of overlap must be weighted based on the proportion of area of overlap, and the results summed to get total surviving generation and its complement, total generation lost. 


\subsubsection{Multiple Magnetohydrodynamic Electromagnetic Pulse Events}

The MHD-EMP effects on the system superimpose. MHD-EMP effects easily span tens of seconds and can last up to several hundred seconds. It is assumed that a multiple burst will involve a spatially overlapping superposition of effects and will raise the effective quasi-dc earth-induced-potential over the area of MHD-EMP illumination. The resultant E-field will be the superposition of the field's effect of each burst. Thus, the effect of multiple bursts can be viewed as being an MHD-EMP event of higher field intensity.

\subsubsection{Other Assessments}

Portions of the assessment methodology, its data bases, and the calculational models developed under this DOE/ORNL Power Systems Technology Program have been used in another study performed by Lawrence Livermore National Laboratory (LLNL) ${ }^{22}$. This study was designed to consider other HEMP environments and involved the participation of DOE, ORNL, DNA, EPRI, and electric utility personnel.

\subsection{SECTION REFERENCES}

1. F. M. Tesche, and P. R. Barnes, "A Multiconductor Model for Determining the Response of Power Transmission and Distribution Lines to a High Altitude Electromagnetic Pulse (HEMP)," IEEE Transactions on Power Delivery 4(3), (July 1989).

2. V. Kruse, P. R. Barnes, and F. M. Tesche, "Flashover Vulnerability of Transmission and Distribution Lines to High Altitude Electromagnetic Pulse," IEEE Transactions on Power Delivery 5(2), (April 1990).

3. M. Burrage, et al., Impact of Steep-Front Short-Duration Impulses on Power System Insulation, ORNL/Sub/85-28611/2, Martin Marietta Energy Systems, Inc., Oak Ridge National Laboratory, April 1991.

4. C. H. Eichler, Taylor, E. R., and P. R. Barnes, "A Methodology to Assess the Effects of High Altitude Electromagnetic Pulse (HEMP) on Electric Power Systems," Westinghouse Advanced Systems Technology Memo, 1987.

5. T. K. Liu, et al., HEMP Test and Analysis of Selected Recloser-Control Units, ORNL/Sub/88-02238/1, Martin Marietta Energy Systems, Inc., Oak Ridge National Laboratory, August, 1988.

6. V. J. Kruse, et al., "Impacts of a Nominal Nuclear Electromagnetic Pulse on Electric Power Systems: A Probabilistic Approach," IEEE Transactions on Power Delivery 6(3), (July 1991).

7. T. W. Reddoch, et al., HEMP Emergency Planning and Operating Procedures for Electric Power Systems, ORNL/Sub/91-SG105/1, Martin Marietta Energy Systems, Inc., Oak Ridge National Laboratory, to be published January 1993. 
8. "Problems with Power Quality," EPRI Journal 16(5), (July/August 1991).

9. F. M Tesche, and P. R. Barnes, "The HEMP Response of an Overhead Power Distribution Line," IEEE Transactions on Power Delivery 4(3), (July 1989).

10. J. J. Bonk, and C. H., Eichler, Sensitivity Analysis Task Report for Generation Plant Auxiliary and Control and Substation Protection and Control, Report to ORNL, AST 89-2115, ABB Power Systems, Inc., Advanced Systems Technology, Pittsburgh, Pa., August 1989.

11. C. M. Wiggins, D. E. Thomas, T. M. Salas, HEMP-Induced Transients in Electric Power Substations, ORNL/Sub/88-SC863, Martin Marietta Energy Systems, Inc., Oak Ridge National Laboratory, February 1992.

12. "1989 Annual Statistical Report", Electrical World, (April 1989).

13. P. R. Barnes, Manwiler, R. W., and R. R. Davis, The Effects of Nuclear Electromagnetic Pulse (EMP) on Nuclear Power Plants, ORNL-5029, Martin Marietta Energy Systems, Inc., Oak Ridge National Laboratory, September, 1977.

14. J. R. Legro, et al., Study to Assess the Effects of High-Altitude Electromagnetic Pulse on Electric Power Systems - Phase I Final Report, ORNL/Sub/83-43374/1/V1, Martin Marietta Energy Systems, Inc., Oak Ridge National Laboratory, February 1986.

15. "Type SMX Station Class Gapless Metal Oxide Surge Arresters,", Westinghouse Electric Corporation Performance Data Sheet 38-312, Bloomington, Ind., June 1986.

16. "Preliminary Report of Geomagnetically Induced Currents for the Week of October 27, 1991," memo dated November 1, 1991, Electric Research and Management, Inc., P.O. Box 165, State College, Pa.

17. D. Larose, "The Hydro-Quebec System Blackout of 13 March, 1989," System Protection Analysis Division, Hydro-Quebec, Montreal, Canada, July 1989.

18. J. R. Legro, N. C. Abi-Samra and F. M. Tesche, Study to Assess the Effects of Magnetohydrodynamic Electromagnetic Pulse on Electric Power Systems, ORNL/Sub83/43374/1/V3, Martin Marietta Energy Systems, Inc., Oak Ridge National Laboratory, May 1985.

19. V. D. Albertson, J. M. Thorson, Jr., and S. A. Miske, Jr., "The Effects of Geomagnetic Storms on Electrical Power Systems, IEEE Transactions on Power Apparatus and Systems T-PAS 74, 1031-44, (July/August 1974).

20. N. Mohan, J. G. Kappenman, and V. D. Albertson, "Harmonics and Switching Transients in the Presence of Geomagnetically Induced Currents," IEEE Transactions on Power Apparatus and System.s, T-PAS 100, 585-93, (February 1981). 
21. V. J. Kruse, G. B. Rackliffe, and P. R. Barnes, "Load Flow Studies in the Presence of Magnetohydrodynamic Electromagnetic Pulse," IEEE Transactions on Power Delivery, 5(2), 1158-1163 (April 1990)

22. Chrzanowski, P. and J. Futterman, "An Assessment of the Electromagnetic Pulse (EMP) Effects on the U.S. Civilian Infrastructure - Unclassified Summary and Recommendations", CD-90-0014, Lawrence Livermore National Laboratory, June 1992. 


\section{SOCIOECONOMIC IMPACTS OF HIGH-ALTITUDE ELECTROMAGNETIC PULSE}

This section examines the potential socioeconomic costs resulting from HEMP disruptions on electric utility systems. Because this work has not been previously published, a more detailed analysis is provided. To do this analysis it is necessary to first identify the major components of socioeconomic costs of electric outages. The literature was reviewed to obtain estimates one of the most important socioeconomic costs of outage: the cost of unserved demand. This information is then used in developing estimates of economic costs for several scenarios of HEMP disruptions.

\subsection{COMPONENTS OF SOCIOECONOMIC COSTS OF ELECTRIC OUTAGE}

Economic costs of electric outages include short-term outage costs and long-term adaptive costs. Long-term adaptive costs are incurred in response to outages that are in some way anticipated. These costs may include coping measures such as backup power, voltage regulators, or a permanent switch to a more secure fuel supply. For this study we assume that HEMP outages are unanticipated events; therefore, we do not consider longterm adaptive costs in our analysis of socioeconomic impacts. This analysis is similar to that discussed in a recent paper on solar geomagnetic storms ${ }^{1}$.

The short-term costs of outages are measured by loss of benefits associated with electricity. These lost benefits may or may not normally be considered in monetary terms. For instance, physical damage to equipment, spoilage of goods, and increased maintenance requirements are normally thought of in terms of monetary costs. This is also true of lost opportunities of production due to idle equipment and labor. These losses can be quantified by calculating the value of lost production. However, many activities that depend on electricity and have social value do not have explicit market prices. For instance, residential consumers may suffer from inconvenience and loss of leisure opportunities that depend on electricity. Although foregone leisure and inconvenience are not ordinarily thought of in terms of monetary loss, consumer expenditures on things such as lighting, air conditioning, television, etc., are indicative of the value placed on leisure and convenience.

Some components of short-term outage costs are indirect results of electric outage such as the crime wave that occurred in the New York city blackout of 1977 where looting and burning were $45 \%$ of the total calculated cost of the blackout ${ }^{2}$. Other costs, such as increased social strain, are intangible but could be important. Some of the direct and indirect impacts of the 1977 New York city blackout are listed in Table 8. 
Table 8. Some social and economic impacts of the New York city blackout

\begin{tabular}{|c|c|}
\hline Direct impacts & Indirect impacts \\
\hline Production time loss & Production time loss from looting \\
\hline Damages to plant equipment & Equipment loss due to looting \\
\hline Inventory loss (food spoilage, etc.) & Inventory loss from looting \\
\hline Transit revenue loss & Tax and transit revenue loss \\
\hline City tax revenue loss & Emergency aid \\
\hline State tax revenue loss & $\begin{array}{l}\text { Overtime payments to city employees, } \\
\text { including police, sanitation, water }\end{array}$ \\
\hline Electric revenue loss & $\begin{array}{l}\text { Increased costs from looting and arson } \\
\text { investigations }\end{array}$ \\
\hline Overtime costs for recovery & Increased court and correction costs \\
\hline Spoilage of medical specimen & $\begin{array}{l}\text { Increased hospital patient load from looting } \\
\text { and arson }\end{array}$ \\
\hline Hospital costs for backup power & Increased legal fees \\
\hline
\end{tabular}

Source : Convin, J. L., and W. T. Miles, 1978. Impact Assessment of the 1977 New York City Blackout, final report for U.S. Department of Energy, HCP/T5103-01, Systems Control, Inc., Arlington, Va., July.

\subsection{ESTIMATING COSTS OF ELECTRIC OUTAGE}

Attempts to estimate the short-term costs of electrical outages have generally focused on loss by service category: residential, commercial, and industrial. There are two approaches for estimating costs to residential customers or households. One approach values outages as a loss of leisure, which is calculated at the household wage rate. The rationale for using the wage rate as the proxy for the household wage rate assumes that leisure is being "purchased" with the wages that could otherwise be earned during the time spent in leisure activities. Therefore, if electricity is out from 7 to 9 p.m. when the household is engaged in watching television, and the household wage rate is $\$ 10 / \mathrm{h}$, the household outage cost is $\$ 20$. This type of calculation is aggregated across all households affected by an outage to determine the total cost to households. The estimated cost using this technique for a 4-h outage during winter in the northeastern United States was $\$ 4.54 / \mathrm{kWh}$, adjusted to 1988 dollars $^{3}$.

The second approach estimates a household demand function for electricity. This approach attempts to calculate the willingness of a household to pay for avoiding an outage. The household will be willing to pay at various rates depending on the activity that is interrupted. If the activity can be easily deferred or has a ready substitute, then the loss of convenience will be relatively low. For instance, if the electricity is off from 2 to 4 a.m. when the household is normally sleeping, the willingness to pay to avoid such an outage 
may only be the price paid for electricity. However, if a 2-h outage occurs during the Superbowl, with outdoor temperatures below zero, in a household dependent on electric space heating, then the willingness to pay may be very high. This calculation is more difficult than valuing leisure at the household wage rate because of information requirements. However, experience suggests that it may be a more accurate method of accounting for various aspects of the effect on residential costs.

Using this technique, one study of an outage in the Northeastern United States provided an estimated cost of $\$ 2.70 / \mathrm{kWh}$, adjusted to 1988 dollars. Other studies indicate significantly lower values, including a Wisconsin study that estimated from $\$ 0.17 / \mathrm{kWh}$ for a 1 -h outage starting at noon on a typical weekday in summer to $\$ 1.29 / \mathrm{kW}$ for a $12-\mathrm{h}$ outage. In general this approach yields much lower estimates than the wage rate technique ${ }^{3}$.

The direct costs of power outage to businesses can by attributed to idled resources, damaged equipment, "despoiled" products, and added maintenance costs. For instance, food may spoil as the result of loss of refrigeration, equipment may be damaged by sudden loss of power, and additional costs for maintenance may be incurred when equipment must be restarted. Indirect costs may include looting and arson.

The costs from idled resources (land, labor, and capital) will depend on the level at which they would have been employed during the outage. If they would have been fully employed (i.e., no excess capacity), the cost of outage is at a maximum and is equivalent to the lost value of the production process. However, if these productive factors are not fully employed, then there is a possibility of offsetting some of the production loss that occurred during the outage by increasing power production after restoration. If the outage reduces production so that it affects output markets, then consumers may suffer indirect loss from shortages and/or higher prices.

Total costs of an outage increase with the duration of the outage, but they do not necessarily increase in direct proportion to the loss of electricity. For instance, there may be little damage to refrigerated food if the outage is less than 1 hour. An outage of several days, however, may result in significant spoilage costs to firms that process and store food and to households. Another example of the significance of outage duration is the effect on computer equipment. Loss of power will have an immediate impact as computer operations shut down. This computer shutdown may cause relatively small costs if the duration of the outage is limited. Over longer periods the change in environmental conditions, especially increased temperatures from lack of air conditioning, may damage storage media and result in equipment damage and loss of data. Thus, outage cost as a function of duration is strongly related to the type of damage caused by the outage.

Notwithstanding the aforementioned examples, studies generally indicate that costs per kilowatt-hour decrease significantly as the length of the outage increases. This decrease reflects the initial effects attributed to fixed costs of the outage associated with one-time losses such as damaged goods and equipment and increased maintenance and restart costs. These fixed costs are predominant in the unit-cost calculation at the 
beginning of an outage. However, as they are spread over increasing loss of kilowatthours, the average unit cost tends to decrease, approaching the variable component associated with lost production opportunities.

Costs to industry are generally estimated by the survey method. For example, an Institute of Electrical and Electronics Engineers, Inc. (IEEE) survey of 30 companies used a questionnaire to ask what was the cost per failure; what was the cost of lost production per hour of plant downtime; and what the maximum electric power demand was in kilowatts when the plant operated at its rated design capacity. Answers to these questions allowed the calculation of costs in terms of dollars per kilowatt interrupted and dollars per kilowatt-hour of undelivered energy 4 . Of course the former costs are fixed and the latter costs vary with the time of the power outage.

The costs of outage in the commercial sector are perhaps the most difficult to estimate because of the various ways utilities define this customer class and the widely divergent activities commercial businesses perform. Commercial sales represent essentially a residual customer class that can have businesses similar in activity to either the industrial class or the residential class. For instance, both laundries and commercial apartment buildings may be included in the commercial sector. The laundry may be modeled as an industrial firm with a production process, but the apartment building has energy use patterns similar to residential users. Electricity use of retail sales firms would require a different understanding with respect to the cost of electric outages.

The selection of a rate of cost per kilowatt-hour to evaluate outage cost is difficult because studies that estimate outage costs vary widely. The variance can be partially explained in terms of differences in regional dependence on electricity. For instance, a region or country that has relatively high levels of industrial output per kilowatt-hour will tend to show higher outage costs. Thus, regions or countries that use electricity relatively efficiently will tend to suffer a higher loss per kilowatt-hour, although they may lose fewer kilowatt-hours per outage. Regions that have relatively high electricity use in the residential sector will tend to have lower outage cost per kilowatt-hour, because losses in the residential sector tend to be valued at a lower rate per kilowatt-hour. The variance may also reflect the wide differences in methodology, including the inherent problems with survey instruments, especially as they pertain to the residential sector. Out of 10 studies reported by Sanghvi, the cost range (in 1988 dollars) was from $\$ 1.55 \mathrm{kWh}$ to $\$ 5.51 \mathrm{kWh}$, with an average cost of $\$ 3.27 \mathrm{kWh}$ (ref. 3). Of the three studies done for the United States, one that was for the state of New York was $\$ 3.33 \mathrm{kWh}$ (ref. 5), one was $\$ 2.18$ $\mathrm{kWh}$ (ref. 6), and one was $\$ 1.87 \mathrm{kWh}$ (ref. 7). The relatively low cost per kilowatt-hour for the U. S. studies may reflect that electricity is used more intensively due to its relatively low price. The rate for the New York state study may be more representative of a regional rate in the United States, reflecting relatively less intensive use of electricity per unit of output. To reflect the uncertainty with respect to these estimates, we calculate the costs of HEMP outage scenarios using a low rate of $\$ 1.87 / \mathrm{kWh}$ and a high rate of $\$ 3.27 / \mathrm{kWh}$. 


\subsection{OUTAGE SCENARIOS}

If HEMP caused a widespread power outage, the economic consequences could be significant. To obtain an indication of the costs involved in this event, we calculated the economic costs of a HEMP-induced outage based on four burst scenarios. Scenario I was a single burst at an altitude of $400 \mathrm{~km}$ over Topeka, Kansas. Scenario II considered two bursts at a height of $100 \mathrm{~km}$; one burst was over Salt Lake City, Utah, and the other was over Lexington, Kentucky. Scenario III was a combination of Scenarios I and II, and Scenario IV included Scenario III plus seven additional $100-\mathrm{km}$ bursts. Of the seven additional bursts, one was centered over Syracuse, New York; one was over Montreal, Canada; one was centered over Reno, Nevada; and four were over the central United States.

On the basis of these four scenarios, the researchers developed assumptions to estimate the potential effects on the electric utility systems in the United States, and ultimately, estimated the economic effects from blackouts and equipment damage. For this estimation, four power regions of NERC were used: Electric Reliability Council of Texas, the Mid-America Interconnected Network, the South Eastern Electrical Reliability Council, and WSCC. As discussed in the previous section, it was assumed that HEMP from the nuclear bursts would (1) damage some percentage of the motors in cooling towers that are without surge protection, resulting in the temporary loss of some fossil and nuclear power plants; (2) induce MHD-EMP voltage drops, resulting in relay malfunction and outages until relays and switches could be reset; (3) damage distribution line insulators; and (4) damage distribution transformers where lightning protection is not utilized or properly installed. The outage assumptions were made in terms of the percentages of the average hourly energy consumption for affected loads and the duration of the outage in each of the NERC reliability regions.

Tables 9 through 12 present the range of economic costs for the base case scenarios examined. Table 13 presents a summary of the estimated costs for Scenarios I through IV for the base case and an alternative case. In the base case we assumed that the maximum outages lasted no more than 5 days. In the alternative case the longest outages are increased to 2 weeks. Costs for Scenario I remain constant because all outages were assumed to be less than 5 days. Increasing the maximum outage results in a somewhat higher range of costs.

\subsection{HIGH-ALTITUDE ELECTROMAGNETIC PULSE OUTAGE COSTS IN PERSPECTIVE}

All scenarios examined resulted in significant direct economic costs, with the least costly scenario resulting in about $\$ 3$ billion. Damage to utility equipment is not significant relative to total costs. However, losses from equipment damage to individual utilities are quite high if they are compared with equipment losses of other firms. The most significant damage to utility equipment would be to distribution transformers in the WSCC region. As indicated in Scenarios I, II, III, and IV, there is minor damage to cooling fan motors although the resulting shutdown of plants can prolong outages for specific service areas. 
Table 9. Scenario I: High-altitude electromagnetic pulse costs due to effects on electric system (costs in millions of 1988 dollars)

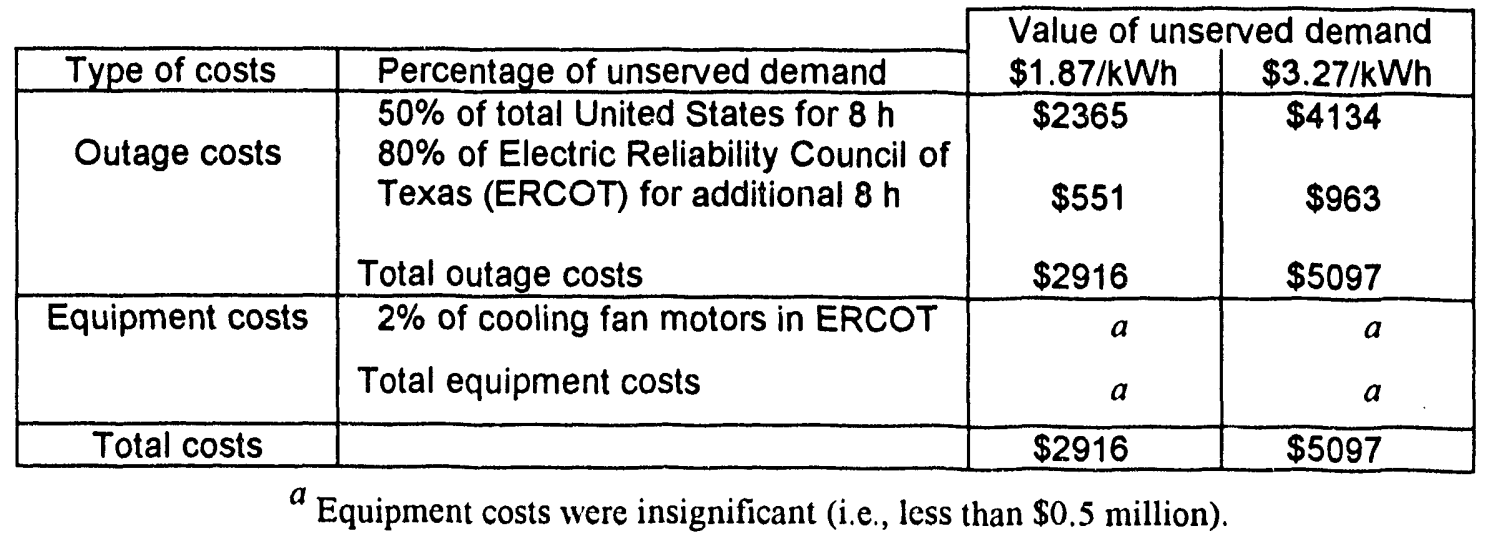

Table 10. Scenario II: High-altitude electromagnetic pulse costs due to effects on electric system (costs in millions of 1988 dollars)

\begin{tabular}{|c|c|c|c|}
\hline \multirow{2}{*}{ Type of cost } & \multirow[b]{2}{*}{ Percentage of unserved demand } & \multicolumn{2}{|c|}{$\begin{array}{c}\text { Value of unserved } \\
\text { demand }\end{array}$} \\
\hline & & $\$ 1.87 / \mathrm{kWh}$ & $\$ 3.27 / \mathrm{kWh}$ \\
\hline Outage costs & $\begin{array}{l}\text { Burst in east: } \\
50 \% \text { of Mid-America Interconnected } \\
\text { Network for } 3 \mathrm{~h} \\
80 \% \text { of South Eastern Electrical } \\
\text { Reliability Council (SERC) for } 12 \mathrm{~h} \\
10 \% \text { of SERC for } 5 \text { days less } 12 \mathrm{~h} \\
\text { Burst in west: } \\
80 \% \text { of Western States Coordinating } \\
\text { Council (WSCC) for } 3 \mathrm{~h} \\
30 \% \text { of WSCC for additional } 21 \mathrm{~h} \\
15 \% \text { of WSCC for additional for } 4 \text { days } \\
\text { Total outage costs }\end{array}$ & $\begin{array}{r}\$ 268 \\
\$ 703 \\
\$ 1606 \\
\\
\$ 5227\end{array}$ & $\begin{array}{r}\$ 468 \\
\$ 1229 \\
\$ 2808 \\
\\
\$ 9137\end{array}$ \\
\hline Equipment costs & $\begin{array}{l}2 \% \text { of cooling fan motors in SERC } \\
2 \% \text { of cooling fan motors in WSCC } \\
10 \% \text { of distribution transformers } \\
\text { Total equipment costs }\end{array}$ & $\begin{array}{r}a \\
a \\
\$ 200 \\
\$ 200\end{array}$ & $\begin{array}{r}a \\
a \\
\$ 200 \\
\$ 200\end{array}$ \\
\hline Total costs & & $\$ 5427$ & $\$ 9337$ \\
\hline
\end{tabular}


Table 11. Scenario III: High-altitude electromagnetic pulse costs due to effects on electric system (costs in millions of 1988 dollars) ${ }^{a}$

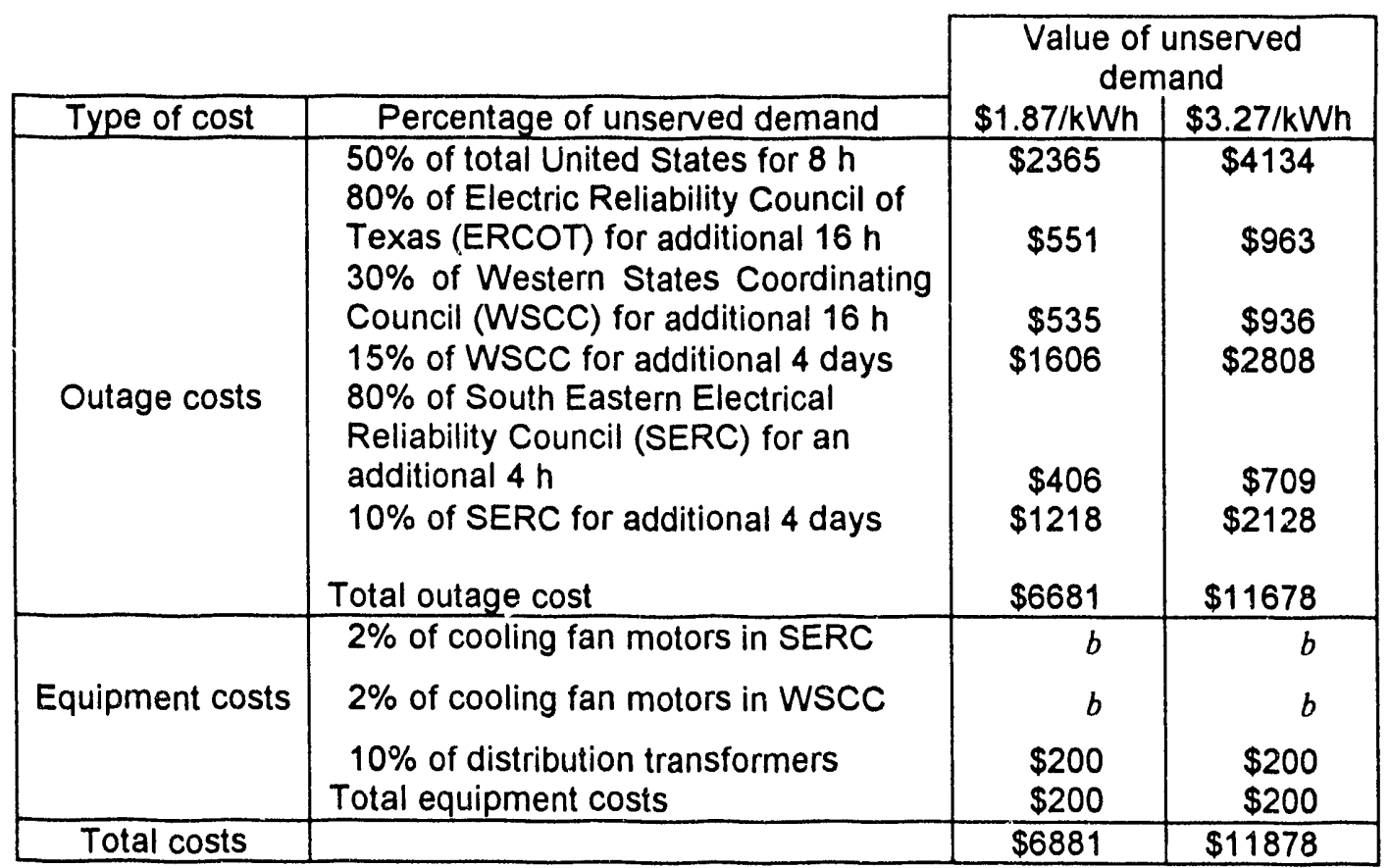

${ }^{a}$ Scenario III is a combination of Scenarios I and II (i.e., one burst at $400 \mathrm{~km}$ over Topeka; one at $100 \mathrm{~km}$ orer Salt Lake City; and one at $100 \mathrm{~km}$ over Lexington, Kentucky).

${ }^{b}$ Equipment costs were insignificant (i.e., less than $\$ 0.5$ million).

Table 12. Scenario IV: High-altitude electromagnetic pulse costs due to effects on electric system (costs in millions of 1988 dollars)

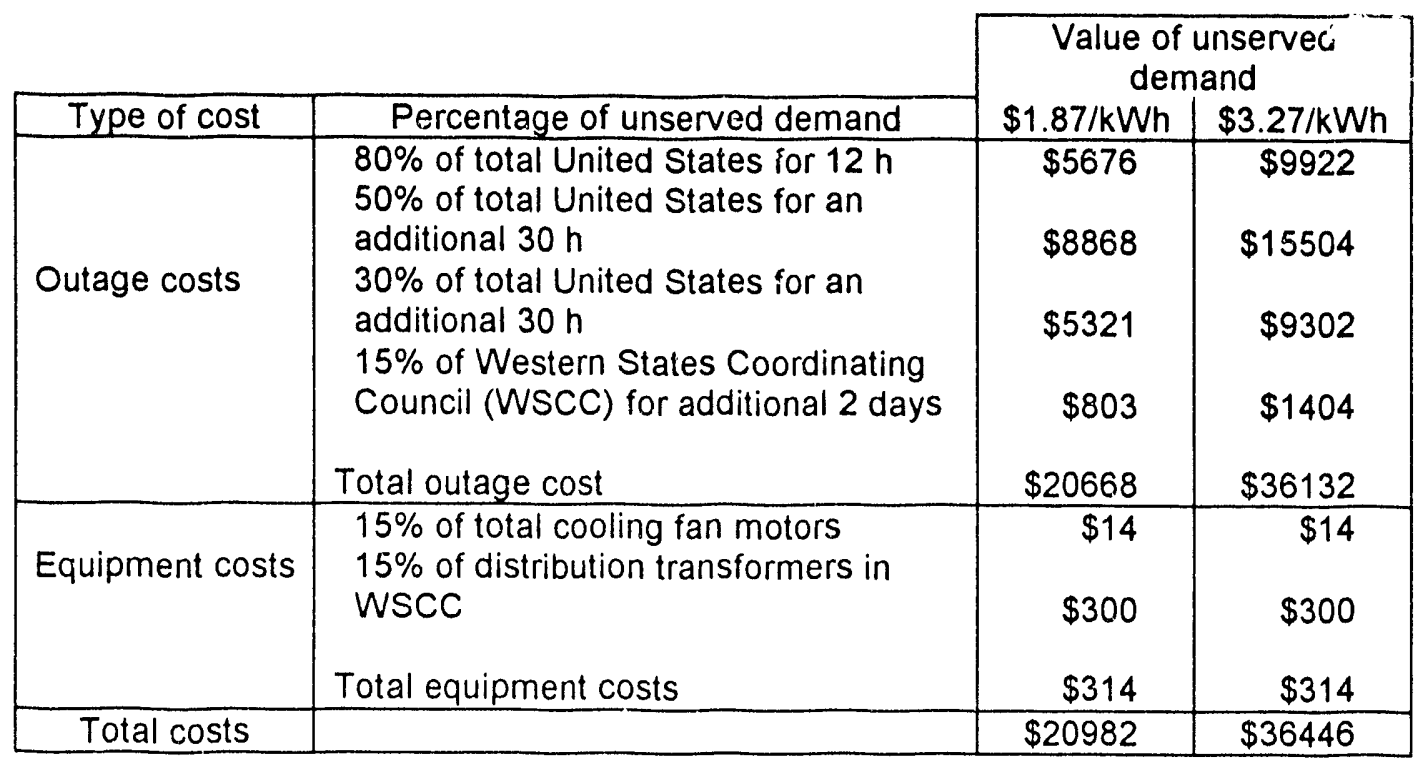


Table 13. Summary table: range of high-altitude electromagnetic pulse costs (billions of 1988 dollars)

\begin{tabular}{|c|c|c|}
\hline Scenario & Base case $^{a}$ & Longer outage $^{b}$ \\
\hline I & $\$ 2.9-5.1$ & $\$ 2.9-5.1$ \\
II & $\$ 5.4-9.3$ & $\$ 11.8-20.4$ \\
III & $\$ 6.9-11.9$ & $\$ 13.2-23.0$ \\
IV & $\$ 21.0-36.4$ & $\$ 24.9-43.1$ \\
\hline
\end{tabular}

${ }^{a}$ The base case assumes that the maximum outage is $5 \mathrm{~d}$.

${ }^{b}$ The alternative case assumes that 2 weeks is the maximum outage.

To provide a comparison for the costs of possible widespread outages that might result from HEMP, Table 14 presents estimated damage costs from several natural disasters in the past. To assist in putting all of these monetary figures into the proper perspective, they may be compared with $1 \%$ of the 1988 United States personal income of $\$ 42,173$ million or $1 \%$ of 1988 Texas personal income of $\$ 2,534$ million.

It is clear from this comparison that even the lowest-cost HEMP scenario would have direct economic costs at least equivalent to those at most of the major natural disasters for res ont years in the United States. However, strictly comparing the total magnitude of economic costs may be misleading. Economic costs of outages tend to be spread across large regions with many individuals experiencing a small economic loss. Relatively few individuals, communities, or businesses would suffer a catastrophic loss. Natural disasters tend to affect smaller populations but may impose very large costs to individuals. Floods and other natural calamities can destroy homes and businesses, resulting in catastrophic losses to individual businesses and even communities.

Table 14. Estimated costs of disasters

\begin{tabular}{|c|c|c|c|}
\hline Disaster description & Area covered & Year & $\begin{array}{l}\text { Estimated cost } \\
\text { (millions of } \\
\text { dollars) }\end{array}$ \\
\hline $\begin{array}{l}\text { Hurricane Agnes floods } \\
\text { General flooding } \\
\text { Hurricane Eloise floods }\end{array}$ & $\begin{array}{c}\text { Eastern United States } \\
\text { Mississippi System } \\
\text { Puerto Rico \& } \\
\text { northeastern United } \\
\text { States } \\
\end{array}$ & $\begin{array}{l}1972 \\
1973 \\
1975\end{array}$ & $\begin{array}{r}\$ 11820 \\
\$ 3034 \\
\$ 941\end{array}$ \\
\hline $\begin{array}{l}\text { Average Annual Damage: } \\
\text { Floods } \\
\text { Hurricanes } \\
\text { Tornadoes } \\
\text { Power Blackout }\end{array}$ & $\begin{array}{l}\text { United States } \\
\text { United States } \\
\text { United States } \\
\text { New York City }\end{array}$ & $\begin{array}{c}1970-77 \\
1965-77 \\
1965-77 \\
1977\end{array}$ & $\begin{array}{r}\$ 2721 \\
\$ 1838 \\
\$ 925 \\
\$ 624\end{array}$ \\
\hline
\end{tabular}

$a$ costs in millions of 1988 dollars

Source: Sorkin, A. L. 1982. Economic Aspects of Natural Hazards, D. C. Heath and Company. 


\subsection{SECTION REFERENCES}

1. P. R. Barnes, and J. W. Van Dyke, "Potential Economic Costs from Geomagnetic Storms", Geomagnetic Storm Cycle 22: Power System Problems on the Horizon, IEEE Special Panel Session Report 90TH0357-4-PWR, pp. 80-83, July 17, 1990.

2. J. L. Corwin and W. T. Miles, Impact Assessment of the 1977 New York City Blackout, final report for U.S. Department of Energy, HCP/T5103-01, Systems Control, Inc., Arlington, Va., July 1978.

3. A. P. Sanghvi, "Economic Costs of Electricity Supply Interruptions," Energy Economics 4(3), 180-98, (1982).

4. "Report on Reliability Survey of Industrial Plants, Part II: Costs of Power Outages, Plant Restart Time, Critical Service, Loss Duration Time, and Type of Loads Lost Versus Time of Power Outages," IEEE Transactions on Industry Applications 1A10(2), (March-April 1973).

5. M. L. Telson, "The Economics of Alternative Levels of Reliability for Electric Power Generation Systems," The Bell Journal of Economics 6(2), 679,.(Autumn 1975).

6. W. B. Shew, "Costs of Inadequate Capacity in the Electric Utility Industry," Energy Systems and Policy 2(1), 85-110, (1977).

7. R. B. Shipley, et al., "Power Reliability Cost Versus Worth," IEEE Transactions on Power Apparatus and Systems PAS-91, 2204-12, (September-October 1972). 1982.

8. A. L. Sorkin, Economic Aspects of Natural Hazards, D. C. Heath and Company, 


\section{RECOMMENDATIONS FOR UTILITIES AND EMERGENCY PLANNERS}

It is possible that major power failures could result from the widespread disturbance caused by one or more high-altitude EMP events. During the 1990s, this vulnerability will increase as generation and transmission lines are operated closer to their limits. Also, the vulnerability of electric power systems to EMI could increase as more microprocessor computer-type controls and protection are added to the system.

As a consequence, it is in the national interest to enhance the reliability of electric power systems under the influence of HEMP. However, electric utilities in the United States cannot economically justify retrofit hardening of systems and components against a threat that may never occur. Cost-effective means of mitigating HEMP impacts may be designed into new components and subsystems if they also enhance immunity to interference by related phenomena. These phenomena include lightning, SFSD surges generated by switching operations, and geomagnetic storms. Although it should be possible to enhance the EMP immunity of new components and facilities in electric power systems, the vulnerability of the overall system will remain. Thus, electric utilities must depend on emergency system operations and restoration plans to enhance the reliability of electric power systems and to minimize periods of power disruptions. In this section, various recommendations for reliability enhancement are discussed.

\subsection{RETROFIT HARDENING}

Retrofit hardening of the power system would not be cost effective in most cases . However, because they are critical for restoration, mobile communications may be an exception. Reliability of such communications can be greatly enhanced by the installation of low-cost surge protection devices at the antenna input jacks 1 . Furthermore, this protection can be easily installed and such retrofit hardening should be considered. Similar hardening against power line and antenna transients for fixed stations should also be considered.

It may also be cost effective to add low-cost metal oxide varistor (MOV) surge arresters and transient voltage surge suppressers (TVSS) to important 480-V power circuits and de control circuits. However, utilities may be reluctant to install MOVs unless they are presently experiencing problems with transients.

\subsection{GOOD ENGINEERING DESIGN PRACTICES}

While retrofit hardening may not be cost effective, new equipment and subsystems can be designed and installed with EM and transient control techniques that improve EMI and HEMP immunity at little or no additional cost. Unfortunately, no cost effective technical fixes to mitigate MHD-EMP at the system level are presently available. 
Reference 2 has reviewed much of the ORNL-sponsored work on HEMP effects on the electrical power system, and has discussed various engineering design practices that are useful for designing a system that is unaffected by EMI and HEMP. Some of these practices are listed as follows:

1. Install surge arresters or TVSSs as close as possible to the components they are intended to protect. Minimize arrester lead lengths and provide a low impedance ground for the frequencies of interest. For transformers, use case-mounted arresters when possible 3,4 .

2. For distribution reclosers, a grounding practice that reduces the potential rise at the recloser controls is recommended. This grounding practice is described as the "best method" in Fig. 3 of ref. 5.

3. Install transient suppression devices on dc control circuits, particularly those circuits that extend outside buildings, to prevent blown fuses ${ }^{6}$.

4. Install transient suppressers on essential 480-V motors associated with cooling towers, fuel pumps, etc., which are more likely to be exposed to lightning and other transients?

5. Protect sensitive communications and microprocessor-based control and relay protection equipment by employing antenna surge suppressers, protected power line filters, power line conditioners and/or uninterruptable power supplies (UPSs) to reject power line transients, and by providing proper grounding (see following paragraphs). For very sensitive equipment, shielding may be required $1,8,9$.

6. Design the ground system so that it is not a surge path to sensitive electronics. Separate the external and internal grounds by shielding (equipment cases, building structures, etc.). Use separate conductors for the safety ground and signal and power returns. Establish the signal ground at the lowest signal level stage and carefully evaluate the effects of interconnecting earth grounds for separate buildings.

7. For critical facilities susceptible to geomagnetically induced current, install a harmonic filter on the secondary of a three-phase distribution transformer with a grounded-wye primary, or use a delta-primary distribution transformer.

8. Employ shielded signal cables with the shield grounded to the equipment shield (metal case) by a peripheral connection. If it is necessary to use a "pigtail" connection, the pigtail lead should be kept as short as possible. Where low-frequency interference is not a problem, cable shields should be grounded at both ends. If low-frequency interference is a problem, a double shielded cable with both ends of the outer shield grounded and one end of the inner shield grounded can be used.

9. Install distribution lines insulated at a higher voltage level, such as $35 \mathrm{kV}$, if a future voltage upgrade is a possibility. Consider distribution line protection with surge 
arresters or, if available, integral arrester-insulator units at every third pole or every second pole for lines with long spans of over $100 \mathrm{~m}$ (ref. 10). The cost in implementing this practice may be large, however.

10. Use fiber optics for communications and control signal links when feasible.

11. Require steep-front surge tests such as the C37.90.1 surge withstand capability test ${ }^{2}$ as part of equipment acceptance tests for sensitive electronic systems.

12. Employ other low-cost design features that may not have been identified here.

These and other design practices that provide EMI immunity should be studied and documented in a manual for electric utilities. This study should include, when possible, a revenue requirement analysis for each recommended design feature. Reference 2 provides a start in this direction. In addition, existing specifications and standards pertaining to power system design may need to be modified to incorporate the possibility of HEMP protection. This is also discussed in ref. 2 .

\subsection{COMMUNICATION FACILITY DESIGN PRACTICES}

Because communication facilities are an important aspect of the electrical power system, it is important to ensure that they are also protected against HEMP environments. This subsection suggests ways of improving the HEMP immunity of utility-operated communication systems. Some of these techniques are similar to those described in the previous section for power system protection. Others, however, are specific to communications facilities.

Most new communication systems now being installed are microwave line-of-sight links, but some power-line carrier communication is also in use. The power-line carrier equipment is designed to tolerate the rather harsh substation environment; therefore, most of it will be substantially protected against HEMP transients. The microwave equipment is commercial communication gear that has no specified transient tolerance. Thus, any inherent immunity to lightning and HEMP transients must be inferred from the $\ldots$ hient environment that such equipment normally survives.

Protection of equipment such as this is complicated by the many long conductors attached to it. The system is probably designed to tolerate the transients that routinely occur on the grou $d$ and antenna feed lines in the office environment. If the system is operated from clean uninterruptable power, it will not $\backslash a$ damaged by transients on the commercial power system. Therefore, the telephone lines and the monitor lines are the primary concerns.

The communication stations and relay-repeaters used in microwave systems are compactly packaged in a small rack or cabinet. Their interfaces with the outside world consist of power and telephone lines, antenna feed (coaxial cable or waveguide), grounding, and monitor systems (in manned stations). The HEMP protection of the system 
is affected by the way the system is housed and by the way these interfaces are made. It is also important to recognize that the HEMP protection features described here are relatively inexpensive when incorporated into new installations, and will also improve the system's immunity to lightning and other transients.

\subsubsection{Use of Metal Shelters}

The use of dielectric shelters provides no efficient way to exclude the transient currents arriving on power and telephone lines and on coaxial feeds. If all-metal shelters are used, the shelter can be used as a shield and the currents on the cables can be stripped off at the entry point. The power and telephone lines should be treated at their entry points with MOVs and gas gaps. The coaxial cable or waveguide antenna feeds should also be bonded to the shield with a feedthrough connector or waveguide flange that has contact to the shield around the entire periphery. Used in this way, a metal shelter (even a riveted aluminum structure) can reduce the transient currents reaching the interior by a factor of more than 100 .

\subsubsection{Entry Panel Design}

For equipment already installed in fiberglass or other nonconducting shelters, some improvement can be realized by installing a large sheet-metal entry panel and ground plane. The coaxial cable/waveguide, surge protectors, grounds, UPS, and communication equipment can be bonded to this partial shield in the same manner that would be used if the shield were closed. This is shown in Fig. 12. Though less effective than the closed (sixsided) shield, the two-sided shield can prevent most of the external cable currents from propagating to the interior of the building to the electronic equipment. A factor of 10 reduction in current can be achieved in external cable currents, which tend to be the primary sources of interference. The two-sided shield, however, does not provide protection against the direct interaction of the HEMP wave with the interior wiring and equipment.

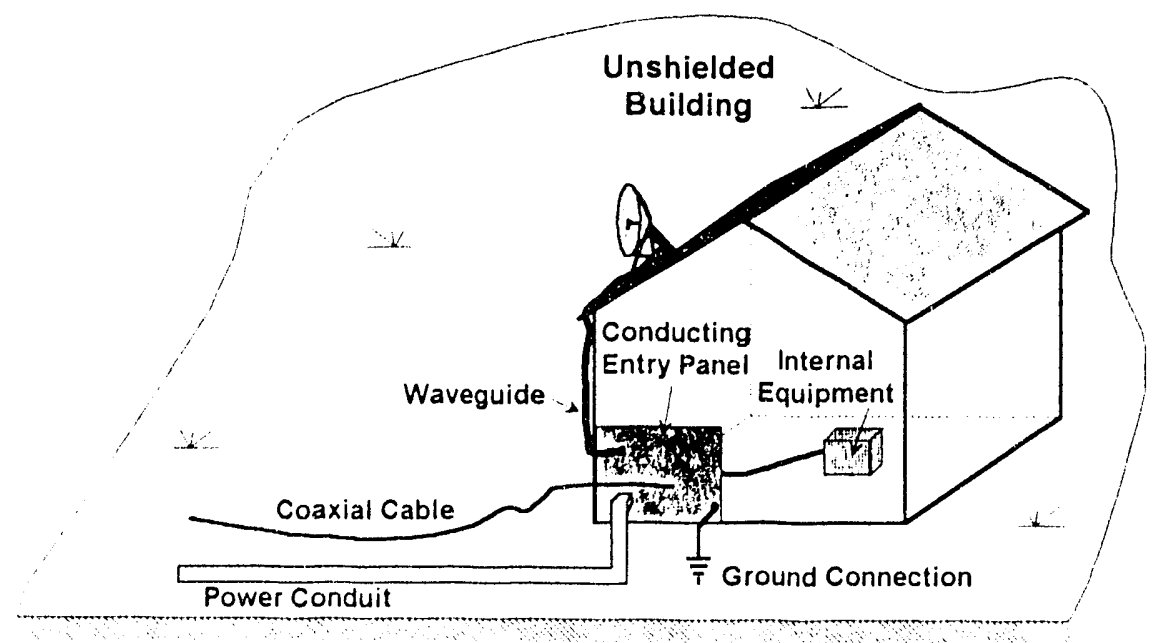

Fig. 12. Illustration of entry panel into a partially shielded facility. 
The partial shield is also recommended for communication equipment at dispatch offices, supervisory centers, and other manned facilities. In these facilities, monitors and printers that display system status and warning messages may be found. It is important that this equipment be treated in the same way as the communication equipment. That is, it should be operated from the UPS, and all signal lines (including telephone lines) to it should be treated at the shield, as described in the next section.

\subsubsection{Treatment of Power Service}

The power entrance conduit and meter base, as well as the emergency power receptacle, should be bonded to the entry plate. MOV surge arresters should be installed in or adjacent to the main power disconnect with the shortest leads possible. For reliability, a UPS system for the communication equipment is usually installed also. The combination of the MOVs and the UPS can be very effective in isolating the internal system from any transients on the power leads.

If external circuits are supplied from the UPS or from a distribution panel on the line side of the UPS, these circuits should be enclosed in metal conduit. Additionally, the conduit should be bonded to the entry panel where it passes through the panel. For example, the conduit for the antenna tower lighting circuit should enter through the entry plate, where the conduit should be circumferentially bonded to the plate. Other external circuits requiring this treatment are security lights and intrusion alarm circuits for the system.

\subsubsection{Coaxial Cable and Waveguide Treatment}

Coaxial cable and waveguide penetrations may have large transients induced on the outside of the shield or guide. Because these can be grounded, they should be peripherally bonded to the entry plate. A convenient way to do this for coaxial cables is to install feedthrough connectors on the entry plate, plug in the cables from the antenna on the outside, and connect the cables from the transmitter on the inside. A similar technique that can be used for waveguides is to weld or solder to the entry panel the end flanges of a short section of waveguide.

\subsubsection{Protection of Telephone Lines}

A local telephone line should be installed with a gas tube protector on the entry plate. The entry plate should be used as the local ground for the protector block. Another option is to use fiber optic telephone and data lines. While this option is currently more expensive than surge suppression, it also provides more positive protection.

\subsubsection{Grounding System Design}

A metal shelter or partial shield also facilitates a more effective grounding system. Both a partial shield and a closed metal shelter will be very effective potential equalizers for the equipment inside the shelter. If a metal shelter is used, the ground system inside the 
facility should be grounded to the interior of the shelter. A separate connection of the exterior of the shelter to the earth should be made. Then any transients induced on the exterior ground conductors flow onto the exterior of the shield. They can enter the interior only by diffusing through the metal shield; however, only the low frequencies can diffuse through the shield wall without significant attenuation.

No insulated grounding conductor (or any other conductor) should be allowed to penetrate the shield, because all frequencies can then propagate unattenuated through the shield. Transients induced on external conductors are carried directly into and distributed throughout the interior. The technique of separating the exterior ground from the interior ground has provided noise reduction by a factor of more than 100 in controlled tests. Inside the metal shelter, any grounding system is acceptable, as long as it is safe, meets applicable codes, and allows the equipment to finction properly.

\subsection{SPARES}

Damages can occur to the electric power system from HEMP-caused transients and/or the over-voltages resulting from an inadvertent shutdown caused by the HEMP event. For example, during a March 13, 1989, geomagnetic storm experienced by the Hydro-Quebec System, major equipment was damaged by over-voltage transients resulting from an inadvertent shutdown of the system ${ }^{11}$. Two generation station transformers, a substation transformer, and several capacitor bank units were damaged.

The type of equipment that could be damaged by an inadvertent shutdown is likely to be associated with the transmission system. Utilities should assess the effects of transient overvoltages caused by abnormal shutdown processes and take appropriate countermeasures to minimize damage. It may be prudent to increase the inventory of spares available to repair the transmission system.

HEMP-induced transients could also damage distribution system components such as transformers and line insulators. Utilities normally have spares for these items to replace equipment damaged by lightning. The maximum number of spares that can be justified for replacement due to lightning and aging should be kept in stock.

At power plants, it is possible that low-voltage (480-V) motors connected to cables could be damaged when exposed to HEMP. Motors used in cooling towers and fuel pumps that are located outside the main plant building are in this category. Utilities should assess the need for and the cost benefit of spare motors. Spare motors probably cannot be justified, except, for nuclear plants. It would be more economical to add surge protection than to keep spare motors that cost many thousands of dollars. Power plants with damaged motors may still be able to operate at some fraction of the total rated power. Thus, utilities may decide not to address the motor vulnerability issue.

The vulnerability of power plant controls and instrumentation has not been assessed and is unknown. It is possible that sensitive solid-state circuits will be damaged. Utilities should evaluate the importance of control and instrumentation systems at power plants and 
substations and stock the maximum number of spare parts that can be justified for a severe lightning season. Extra fuses should be stocked for dc control circuits and low-voltage power circuits. Auxiliary and control systems associated with the safe shutdown of nuclear plants are not expected to be damaged $12,13,14,15$. Nuclear plant stocks and spares would likely be adequate if damages did result.

\subsection{EMERGENCY PLANNING}

Establishing an overall approach to emergency planning for a widespread blackout and restoration due to a widespread disturbance such as a HEMP event is an essential action for all electrical utilities. It is prudent to assume that for any given site, such as a generating station, substation, or control center, off-site power could be out for a duration of several days. Therefore, emergency on-site backup power must be provided for generation facilities' essential station services.

A general approach to emergency preparedness is as follows:

- have existing emergency plans for normal contingent power system failures, such as major disruptions due to weather or environmentally induced disasters, as an essential first step;

- formulation of auxiliary plans to cover unique aspects of HEMP events is required, including such items as:

- failures of dc circuits to have access to either their normal or emergency dc power supplies;

- inability to reconnect system loads where motor drive and other electronic controls have failed;

- unavailability of neighboring power systems, a key element that is absent in most emergency plans;

- population panic resulting in limited access to utility personnel;

- inoperable transportation roadways, preventing free movement of repair crews;

- possible failure of repair trucks and equipment due to failed electronic components; and

- provide testing of planned emergency procedures to ensure their effectiveness.

Restoration of the power system will be a primary objective following a HEMP event. Two key aspects of restoration include establishing an infrastructure to carry-out restoration, and restoring the physical well-being of the power system.

In a major, large power outage, a fundamental property of electric emergency preparedness will be absent: ready access to neighboring utilities. Each utility will likely need to care for its own needs. This is a unique attribute of a HEMP power system disruption. Coordination among utilities could likely be confusing. No central organization is in place to coordinate regional or national resources to prioritize the reestablishment of the nation's power system. Understanding how to operate an electrical power system in isolation is critical. 
Civil defense organizations are in place to support emergency restoration crews with food, shelter, and fuel. Questions exist in the effective operation of transportation systems, a key to swift restoration.

Another important consideration associated with national security emergencies is the concern of maintenance and operational personnel for family members and loved ones. In order for utilities to maintain skeleton crews at power plants, control centers, and maintenance facilities during a period of national crisis, essential personnel will need to know that their family members are protected. Therefore, emergency planning should include provisions for family members of essential personnel.

An important procedure for HEMP contingencies is to check out control and instrumentation systems that have sensitive solid-state components. It is possible that some of these types of systems could be damaged, and they should be checked out before reactivating the site. Nuclear plants should develop plans to operate the Residual Heat Removal System by manual control in the unlikely event that instrumentation and control systems are impaired. Instrument transmitters are relatively invulnerable as are resistive temperature devices ${ }^{16}$. Thus, reactor parameters could be monitored at the reactor building interface.

\subsection{OPERATIONAL STRATEGIES}

A number of prudent operational strategies can be developed to minimize, or at least reduce, the vulnerability of electric power systems to widespread disturbances resulting from one or more HEMP events. As the consequences of several of these actions are largely economical, it may be difficult to achieve the consent and cooperation of the electric utility industry. Establishing a priority for alternate operational strategies will require special agreements to be struck between the electric utility industry and the U.S. government. Presently the electric utility industry does not subscribe to the concept that HEMP events are a primary concern.

A HEMP event could invoke power outages across significant areas of the U.S. power system. Any prudent operational strategy will rely on positioning the power system during pre-HEMP events to facilitate and expedite post-event recovery. Such initiatives will ensure minimum electric system disruption.

One plan for minimizing exposure to HEMP events is the one chosen by the Northeast Power Coordinating Council. This plan suggests that power system operations implement the following:

- Discontinue maintenance work and restore out-of-service high-voltage facilities such as transmission lines;

- control voltages to within an acceptable operating range to protect against voltage swings;

- adjust loading on high voltage DC circuits to be within the $40-50 \%$ range of normal rating;

- reduce generator loading to provide reserve power and reactive capacity; 
- prepare for the loss of shunt capacitor banks and reactive power compensators;

- dispatch generation to manage system voltage and line loading, and to distribute operating reserves;

- bring synchronous condenser capacity on-line if available; and

- coordinate with adjacent control areas.

Each of these action items results in moving the NPCC region into a more robust state to ensure a greater level of system reliability. This approach is indicative of prevention actions that could be employed by all regional utilities to improve the security of their respective systems, reduce the vulnerability to failure, and expedite post-event recovery.

Warning time before a HEMP event can play a key role in minimizing consequential outcomes. The warning time can be categorized into three distinct periods:

- no warning - a spontaneous event,

- 30-60 min. notice, and

- advanced notice of 1-3 d.

Each employs alternative awareness and consequential outcomes. Notice of an HEMP event, or suspected event, will significantly reduce the consequences if emergency plans are available for implementation.

Under the first scenario of no warning, a basic response plan must be in place. This response plan must contain special preparations for unique properties of HEMP events which are not characteristic of other emergencies, like weather or environmental factors. Foremost, an electric utility must have the ability to operate in isolation, because neighboring utilities will likely be unavailable to assist.

Acquiring time through an early warning of even $30-60 \mathrm{~min}$. is very valuable. This would permit the early notification of emergency response teams. Depending on power system conditions, some transmission and distribution lines could be removed from service and some generation facilities could be isolated from the wye-connected transmission system.

If the warning period extends into days, an operating scenario can be established that will reduce consequences to a minimum. For example, emergency disaster response teams could be completely prepared by having emergency fuel in temporary supply tanks, equipment and material located, and a review of all emergency procedures conducted. Certain transmission and distribution lines and generating facilities could be secured, as well as prearranging facilities for ready service immediately following the event as needed.

Specific actions include:

- ready combustion turbines, as most are not started on a regular basis,

- fill pumped-storage facilities, 
- ready hydroelectric stations, renewable energy generating stations, or other systems where self-starting is feasible,

- preload bunkers at coal plants,

- position for recovery through maximizing post-event actions, and

- recall key personnel who may be away.

Because system recovery is a key feature to an effective response to a HEMP event, transition into and out of a failed electric system state is critical. Two phenomena, characterized as black stop and black start, describe circumstances of sustaining critical power system elements under a loss of station power and restarting the power system after failure. Under a black stop, turning gear motors in large power plants must remain operational to prevent generator shafts from warping and bending. Oil pumps must be sustained to provide bearing lubrication. These systems are powered by local power supplies that must remain operational. A black start is predicated on a good black stop planning and the establishment of systematic procedures for restarting a power system from an unenergized state. Identifying key power plants, transmission and distribution links, and loads will facilitate reestablishing the power system.

\subsection{TRAINING AND PLANNING DEVELOPMENT}

We recommend that essential utility personnel receive training on HEMP and that utilities expand emergency plans to include very widespread contingencies. A select number of personnel should attend training courses and then help to train other essential personnel and develop internal emergency plans. Widespread contingencies such as solar storms and HEMP events should be made part of the utility's emergency training and planning.

\subsection{SECTION REFERENCES}

1. P. R. Barnes, The Effects of Electromagnetic Pulse (EMP) on State and Local Radio Communications, ORNL-873, Martin Marietta Energy Systems, Inc., Oak Ridge National Laboratory, February 1974

2. C. L. Wagner and W. E. Feero, Recommended Engineering Practice to Enhance the EMI/EMP Immunity of Electric Power Systems, ORNL/Sub/91-SG913/1, Martin Marietta Energy Systems, Inc., Oak Ridge National Laboratory, December 1992.

3. C. H. Eichler, J. R. Legro, and P. R. Barnes, "Experimental Determination of the Effects of Steep-Front Short-Duration Surges on 25 kVA Pole Mounted Distribution Transformers," IEEE Transactions on Power Delivery 4(2), 1103-10, (April 1989).

4. L. M. Burrage, et al., Impact of Steep-Front Short-Duration Impulses on Power System Insulation, ORNL/Sub/85-28611/2, Martin Marietta Energy Systems, Inc., Oak Ridge National Laboratory, April 1991. 
5. T. K. Liu, et al., HEMP Test and Analysis of Selected Recloser-Control Units, ORNL/Sub/88-02238/1, Martin Marietta Energy Systems, Inc., Oak Ridge National Laboratory, August 1989.

6. D. E. Thomas, C. Wiggins and P. R. Barnes, "On the HEMP Environment for Protective Relays," submitted to the IEEE Transactions on Power Delivery.

7. V. J. Kruse, et al., Impacts of a Nominal Nuclear Electromagnetic Pulse on Electric Power Systems, ORNL/Sub/83-43374/2, Martin Marietta Energy Systems, Inc., Oak Ridge National Laboratory, April 1991.

8. P. R. Barnes, and T. L. Hudson, "Steep-Front Short-Duration Voltage Surge Tests of Power Line Filters and Transient Voltage Suppressors," IEEE Transactions on Power Delivery 4(2), 1029-36, (April 1989).

9. E. F. Vance, "EMC/EMP Design," presented at the DOE EMP Program Review Meeting, Washington, D.C., November 3, 1989.

10. T. C. Cheng, "Dynamic Insulation with SOL-GEL Zinc Oxide", University of Southern California, thesis to be published.

11. D. Soulier, "The Hydro-Quebec System Blackout of 13 March 1989," IEEE Power Engineering Review 9(10), 17-18, (October 1989).

12. M. Ericson, et al., Interaction of Electromagnetic Pulse with Commercial Nuclear Power Plant Systems, NUREG/CR-3069 SAND 82/2738, Vol. 1 and 2, Sandia National Laboratory, Albuquerque, February 1983.

13. EMP-Induced Signal Upset Effects on Commercial Nuclear Power Plant Systems, SECY-83-367, Enclosure 3, U.S. Nuclear Regulatory Commission, Washington, D.C., September 6, 1983.

14. G. Dahlen, EMP Vorkam pa Karnkraftverk, Svenska Electriska Kommissionen, Statens Karnkraftinspektion, 1985.

15. H. Mueller and W. Roemhild, Untersuchung Zur Elektromagnettachen Vertraeglichkeit in Einem Kernkraftwerk, Bundesminister Des Innern, Bonn West Germany, April 15, 1986.

16. M. L. LaGrassa, Test Report for the EMP Surge Testing of E1IGM Series Pressure Transmitter, BDM Corp., Albuquerque, N.M., BDM/ABQ-87-0258-TR, December 29, 1986. 


\section{SUMMARY AND CONCLUSIONS}

This report has summarized a multiyear program for assessing the effects of HEMP on the civilian power system. This program involved several key elements:

- a review of existing HEMP coupling and interaction models, and the development of new models pertinent to the power system analysis, as needed;

- performance of laboratory and field experiments to characterize the behavior of power system components and subsystems subjected to fast-rising HEMP-induced surges;

- development of a methodology for combining the analytical results with the measured component responses to permit an assessment of the behavior of power systems subjected to HEMP;

- preliminary application of the assessment methodology to a subset of the U.S. power system to validate the assessment; and

- use of the methodology to provide an indication of the probable behavior of the U.S. power system as a whole in the event of a HEMP excitation.

The studies in this program were conducted by a group of investigators having a broad range of expertise. Technical experts from the areas of power system analysis, HEMP environmental development, EM coupling and interaction, and fast-pulse measurements were involved in this research program. The organizations participating in this project included governmental laboratories, commercial power utilities, private research and development firms, nonprofit institutions, private consultants, and universities.

Throughout this program there has been an effort to verify the accuracy of the models, the measured results, and the use of the assessment methodology. To this end, review groups of independent experts in both HEMP and power systems areas were created to provide advice and guidance to ORNL during these investigations. A list of the review group members that served during the latter program period is shown in Appendix A. Periodic program review meetings were held to discuss the ongoing work for this effort, and a large number of technical reports have been written.

Early studies of possible power system responses to HEMP indicated that the probability of power interruption due to the early-time $E_{1}$ component of this environment is high. However, these early studies did not take into account the additional insulation strength of wooden support structures in distribution lines. Later assessments included this additional insulation strength and found that the probability of power interruption by $E_{1}$ was much lower. 
The early-time $E_{1}$ portion of the HEMP environment is followed by a late-time $E_{3}$ component. HEMP assessments which include both the $E_{1}$ and $E_{3}$ stresses indicate that a major power system iturbance due to the HEMP produced by a single high-altitude burst over the continental United States cannot be ruled out. Such an event could cause the interconnected electric power networks in the country to break up into utility islands, resulting in massive power failures in some areas. However, permanent damage would probably be isolated, and restoration of the electrical power service should be possible within a few hours. If multiple high-altitude bursts were to occur, the size of the blackout areas could increase, along with an increase in component failures and the system restoration time.

The economic consequences of a short-term, widespread blackout would be in the billions of dollars. However, we estimate that a long-term blackout of many months' 'uration is unlikely, because major power system components, such as transformers, are not likely to be damaged by the nominal HEMP environment. Moreover, power system reliability, under both HEMP and normal operating conditions, can be enhanced by simple, often low-cost modifications to current utility practice.

As a result of this assessment program and its requirement for detailed data on HEMP environments, EM coupling to systems, and power system component responses, a number of differences in the existing state of knowledge in these areas have been discovered. This has prompted additional investigations in these areas, and the results of these studies have been incorporated into this HEMP assessment as they were made available. For example, our views of what constitutes a "nominal" HEMP environment have changed markedly since the inception of this effort. Even at the end of this project, research efforts continue in an attempt to refine the $E_{2}$ and $E_{3}$ environments. Thus, it is possible that the results of this assessment could be modified as more up-to-date environmental and component-response data are made available. 


\section{APPENDIX A}

\section{EMP RESEARCH PROGRAM REVIEW GROUPS}

- ORNL Utility Review Group

Ron F. Chu, Philadelphia Electric Co.

D. Wayne Hilson, Tennessee Valley Authority

Joseph Koepfinger, Duquesne Light Co.

Dave L. Mohre, Cajun Electric Power Corp.

Bernie M. Pasternack, American Electric Power Service Corp.

Jim J. Ray, Bonneville Power Administration

Don R. Volzka, Wisconsin Electric Power Co.

Frank Young, Electric Power Research institute

- ORNL EMP Review Group

John Bombardt, R\&D Associates

Hriar Cabayan, Lawrence Livermore National Laboratory

Bron Cikotas, Defense Communication Agency

Maj. Clint Gordon, Defense Nuclear Agency

Conrad Longmire, Mission Research Corporation

Robert Parker, R\&D Associates 


\section{APPENDIX B \\ BIBLIOGRAPHY OF ORNL-RELATED PUBLICATIONS}

During the course of this project, many reports and other publications have been written. These have been issued primarily as formal ORNL reports, ORNL subcontractor report, and technical journal articles. The following is a list of the major publications resulting from, or directly related to, this effort:

1. P. R. Barnes, et al., Electromagnetic Pulse Research on Electric Power Systems: Program Summary and Recommendations, ORNL-6708, Martin Marietta Energy Systems, Inc., Oak Ridge National Laboratory, December, 1992.

2. P. R. Barnes, et al., Mitigation of Magnetohydrodynamic Electromagnetic Pulse (MHD-EMP) Effects from Commercial Electric Power Systems, ORNL-6709, Martin Marietta Energy Systems, Inc., Oak Ridge National Laboratory, March 1992.

3. P. R. Barnes, et al., Electric Utility Industry Experience With Geomagnetic Disturbances, ORNL-6665, Martin Marietta Energy Systems, Inc., Oak Ridge National Laboratory, September 1991.

6. P. R. Barnes, E. F. Vance, and H. W. Askins, Jr., Nuclear Electromagnetic Pulse (EMT) and Electric Power Systems, ORNL-6033, Martin Marietta Energy Systems, Inc., Oak Ridge National Laboratory, April 1984.

7. P. R. Barnes, and F. M. Tesche, "On the Direct Calculation of a Transient Plane Wave Reflected from a Finitely Conducting Half-Space", IEEE Transactions on Electromagnetic Compatibility 33, (May 1991).

8. P. R. Barnes, Manwiler, R. W., and R. R. Davis, The Effects of Nuclear Electromagnetic Pulse (EMP) on Nuclear Power Plants, ORNL-5029, Martin Marietta Energy Systems, Inc., Oak Ridge National Laboratory, September, 1977.

9. P. R. Barnes, and J. W. Van Dyke, "Potential Economic Costs from Geomagnetic Storms", Geomagnetic Storm Cycle 22: Power System Problems on the Horizon, IEEE Special Panel Session Report 90TH0357-4-PWR, pp. 80-83, July 17, 1990.

10. P. R. Barnes, The Effects of Electromagnetic Pulse (EMP) on State and Local Radio Communications, ORNL-873, Martin Marietta Energy Systems, Inc., Oak Ridge National Laboratory, February 1974. 
11. P. R. Barnes and F. M. Tesche, "Transient Response of a Distribution Circuit Recloser and Control Unit to a High-Altitude Electromagnetic Pulse (HEMP) and Lightning," IEEE Transactions on Electromagnetic Compatibility 32(2), 113-24, (May 1990).

12. P. R. Barnes and R. A. Stevens, "Early-Time Response of an Infinitely Long Wire Above a Finitely Conducting Plane Earth to a Transient Plane Wave," Electrom rgnetics 8(2-4), 159-70, (1988).

13. P. R. Barnes and T. L. Hudson, "Steep-Front Short-Duration Voltage Surge Tests of Power Line Filters and Transient Voltage Suppressors," IEEE Transactions on PowerDelivery 4(2), 1029-36, (April 1989).

14. J. P. Blanchard, F. M. Tesche, and B. W. McConnell, The Effects of Corona on Current Surges Induced on Conducting Lines by EMP: A Comparison of Experimental Data with Results of Analytic Corona Models, ORNL/Sub/85-27461/1, Martin Marietta Energy Systems, Inc., Oak Ridge National Laboratory, September 1987.

15. J. Bonk, and C. H., Eichler, Sensitivity Analysis Task Report for Generation Plant Auxiliary and Control and Substation Protection and Control, Report to ORNL, AST 89-2115, ABB Power Systems, Inc., Advanced Systems Technology, Pittsburgh, Pa., August 1989.

16. L. M. Burrage, E. F. Veverka, and B. W. McConnell, "Steep Front Short Duration Low Voltage Impulse Performance of Distribution Transformers," IEEE Transactions on Power Delivery, Vol. PWRD-2(4), October 1987.

17. L. M. Burrage, B. W. McConnell, and P. R. Barnes, "Steep-Front Short-Duration Impulse Test on Energized Insulators," Proceedings of the 6th International Conference of High Voltage Engineering 2(article 25.03), Mississippi State Univ., (September 1, 1989).

18. L. M. Burrage, J. H. Shaw, and B. W. McConnell, "Distribution Transformer Performance When Subjected to Steep Front Impulses," IEEE Transaction on Power Delivery, 5(2), 984-90, (April 1990).

19. L. Burrage, et al., Assess the Impact of Steep-Front Short-Duration Impulses on Power System Insulation - Phase I Final Report, ORNL/Sub/85-28611/1, Martin Marietta Energy Systems, Inc., Oak Ridge National Laboratory, February 1987.

20. L. Burrage, et al., Impact of Steep-Front Short-Duration Impulses on Power System Insulation - Phase II: Laboratory Evaluation of Selected Power System Components, ORNL/Sub/85-28611/2, Martin Marietta Energy Systems, Inc., Oak Ridge National Laboratory, May 1991

21. R. Dethlefsen, Design Concepts for a Pulse Power Test Facility to Simulate EMP Surges in Overhead Power Lines - Part II: Slow Pulses, ORNL/Sub/84-89642/2, Martin Marietta Energy Systems, Inc., Oak Ridge National Laboratory, October 1985. 
22. C. H. Eichler, J. R. Legro, and P. R. Barnes, "Experimental Determination of the Effects of Steep-Front Short-Duration Surges on 25 kVA Pole Mounted Distribution Transformers," IEEE Transactions on Power Delivery 4(2), 1103-10, (April 1989).

23. N. Engheta, et al., HEMP-Induced Transients in Transmission and Distribution (T\&D) Lines, ORNL/Sub/84-73986/1, Martin Marietta Energy Systems, Inc., Oak Ridge National Laboratory, September 1985.

24. I. Gyuk, ed., Proceedings of the DOE EMP Program Review Meeting, U.S. Department of Energy, Office of Energy Storage and Distribution, Washington D.C., November 2-3, 1989.

25. K. W. Klein, P. R. Barnes, and H. W. Zaininger, "Electromagnetic Pulse and the Electric Power Network," IEEE Transactions on Power Apparatus and Systems PAS104(6), (June 1985).

26. V. J. Kruse, P. R. Barnes, and G. B. Rackliffe, "Load Flow Studies in the Presence of Magnetohydrodynamic Electromagnetic Pulse," IEEE Transactions on Power Delivery 5(2), 1158-1163, (April, 1990).

27. V. J. Kruse, P. R. Barnes, and F. M. Tesche, "Flashover Vulnerability of Transmission and Distribution Lines to High-Altitude Electromagnetic Pulse (HEMP)," IEEE Transactions on Power Delivery 5(2), 1164-69, (April 1990).

28. V. J. Kruse, et al., "Impacts of a Nominal Nuclear Electromagnetic Pulse on Electric Power Systems: A Probabilistic Approach," IEEE Transactions on Power Delivery 90SM 347-5-PWRD, (1990).

29. V. J. Kruse, et al, Impacts of a Nominal Nuclear Electromagnetic Pulse on Electric Power Systems, ORNL/Sub/83-43374/2, Martin Marietta Energy Systems, Inc., Oak Ridge National Laboratory, April 1991.

30. M. L. LaGrassa, Test Report for the EMP Surge Testing of E11GM Series Pressure Transmitter, BDM/ABQ-87-0258-TR, BDM Corp., Albuquerque, N.M., December 29, 1986.

31. K. S. H. Lee, et al., "Interaction of High-Altitude Electromagnetic Pulse (HEMP) with Transmission and Distribution Lines: An Early-Time Consideration," AFWL Interaction Notes, Note 435, December 1983.

32. J. R. Legro, et al., A Methodology to Assess the Effects of Electromagnetic Pulse on Electric Power Systems, ORNL/Sub/83-43374/V1, Martin Marietta Energy Systems, Inc., Oak Ridge National Laboratory, September 1985.

33. J. R. Legro, et al., Study to Assess the Effects of High-Altitude Electromagnetic Pulse on Electric Power Systems, Phase I Final Report, ORNL/Sub/83-43374/V2, Martin Marietta Energy Systems, Inc., Oak Ridge National Laboratory, February 1986. 
34. J .R. Legro, et al, Study to Assess the Effects of Surface Burst Electromagnetic Pulse on Electric Power Systems, Phase I Final Report, ORNL/Sub/83-43374/V4, Martin Marietta Energy Systems, Inc., Oak Ridge National Laboratory, February 1986.

35. J. R. Legro, et al., Study to Assess the Effects of Magnetohydrodynamic Electromagnetic Pulse on Electric Systems, Phase I Final Report, ORNL/Sub/8343373/V3, Martin Marietta Energy Systems, Inc., Oak Ridge National Laboratory, May 1985.

36. J. R. Legro, et al., "A Methodology to Assess the Effects of Magnetohydrodynamic Electromagnetic Pulse (MHD-EMP) on Power Systems," IEEE Transactions on Power Delivery PWRD-1(3), 203-10, (July 1986).

37. T. K. Liu, S. H. Sands, and P. R. Barnes, HEMP Test and Analysis of Selected Recloser-Control Units, ORNL/Sub/11X-02238C/1, Martin Marietta Energy Systems, Inc., Oak Ridge National Laboratory, August 1989.

38. C. L. Longmire, R. M. Hamilton, and J. M. Hahn, A Nominal Set of HighAltitude EMP Environments, ORNL/Sub/86-18417/1, Martin Marietta Energy Systems, Inc., Oak Ridge National Laboratory, February 1987.

39. H. Marable, P. R. Barnes, and D. B. Nelson, Power System EMP Protection, ORNL-4958, Martin Marietta Energy Systems, Inc., Oak Ridge National Laboratory, March 1975.

40. B. W. McConnell, et al., Impact of Quasi-Dc Currents on Three-Phase Distribution Transformer Installations, ORNL/Sub/89-SE912/1, Martin Marietta Energy Systems, Inc., Oak Ridge National Laboratory, June 1992.

41. B. W. McConnell and P. R. Barnes, "A Preliminary Assessment of the Impact of Electromagnetic Pulse on Electric Power System Insulation," Proceedings of the 4th International Symposium on Gaseous Dielectrics, Knoxville, Tn., pp 354-363, April 29 May 3, 1984.

42. B. W. McConnell and P. R. Barnes, "A Research Program to Assess the Impact of the Electromagnetic Pulse on Electric Power Systems", Proceedings of the 7th International Zurich Technical Exhibition on EMC, Zurich, Switzerland, March 1987.

44. D. B. Miller, Experimental Investigation of Steep-Front, Short Duration (SFSD) Surge Effects on Power Systems Components, ORNL/Sub/87-91345, Martin Marietta Energy Systems, Inc., Oak Ridge National Laboratory, May 1992.

45. D. B. Miller, A. E. Lux, S. Gryzbowski, and P. R. Barnes, "The Effects of SteepFront Short-Duration Impulses on Power Distribution Components," IEEE Transactions on Power Delivery 5(2), 708-15, (April 1990). 
46. H. P. Neff, "Plane Wave (EMP) Incidence on a Finitely Conducting Plane Earth with the Magnetic Field Intensity Parallel to the Earth's Surface," AFWL Theoretical Notes, Note 351, February 1984.

47. H. P. Neff, "Finitely Conducting Infinitely Long, Cylindrical Wire in the Presence of a Plane Wave (EMP)," AFWL Interaction Notes, Note 436, February 1984.

48. H. P. Neff, and D. A. Reed, "The Effects of Secondary Scattering on the Induced Current in an Infinite Wire Over an Imperfect Ground from an Incident Electromagnetic Pulse, "IEEE Transactions on Antennas and Propagation 37, (April 1989).

49. H. P. Neff and D. A. Reed, "The Induced Current in Parallel Wires Over an Imperfect Ground From an Incident EMP," IEEE Proceedings - 1989 Southeastcon, 2, (April 1989).

50. H. P. Neff and D. A. Reed, "Multiple Parallel Wires Above a Finitely Conducting Plane Earth in the Presence of a Plane Wave (EMP)," AFWL Interaction Notes, Note 441, July 1984.

51. Program Plan for Research and Development of Technologies and Systems for Electric Power Systems under the Influence of Nuclear Electromagnetic Pulses, DOE/NBB/0033, U.S. Department of Energy, May 1983.

52. G. B. Rackliffe, et al., "Simulation of Geomagnetic Currents Induced in a Power System by Magnetohydrodynamic Electromagnetic Pulses," IEEE Transactions on Power Delivery 3(1), 392-97 (January 1988).

53. A. Ramrus, Design Concepts for a Pulse Power Test Facility to Simulate EMP Surges in Overhead Power Lines - Pait I: Fast Pulses, ORNL/Sub/84-89642/1, Martin Marietta Energy Systems, Inc., Oak Ridge National Laboraniy, February 1986.

54. T. W. Reddoch, et al., HEMP Emergency Planming and Operating Procedures for Electric Power Systems, ORNL/Sub/91-SG105/1, Marin Marietta Energy Systems, Inc., Oak Ridge National Laboratory, to be published January 1993.

55. T. M. Salas, C. W. Wiggins, and P. R. Barnes, "Steep-Front Impulse Tests on Solid-State Relay," IEEE Transactions on Puner Deisiery, 90 WM 126-3 PRWD, (December 1989).

56. I. D. Smith, et al., Study to Sinwinte Kigis Altitude EMP Surges Induced in Overhead Power Lines, ORNL/Sub/84-89643/, Martin Marietta Energy Systems, Inc., Oak Ridge National Laboratory, November 1987.

57. E. R. Taylor, Jr., HEMP-Type Impulse Transfer Tests on High-Voltage Bushing Current Transformers at the Maxwell Laboratory February, 1987, Westinghouse AST Report No. AST 88-2081, Westinghouse Electric Corp., Pittsburgh, Pa., September 1988. 
58. E. R. Taylor, Jr., HEMP-Type Impulse Tests on High-Voltage Potential Transformers at Maxwell Laboratory, Jamuary, 1987, Westinghouse AST Report No. AST 88-7072, Westinghouse Electric Corp., Pittsburgh, Pa., July 1988.

59. F. M. Tesche, "A Study of Overhead Line Responses to High Altitude Electromagnetic Pulse Environments," AFWL Interaction Notes, Note 458, December 1986.

60. F. M. Tesche, and J. P. Blanchard, "Experimental Determination of EMP-Induced Corona Effects on Conducting Lines," Proceedings of the 7th International Zurich Technical Exhibition on EMC, Zurich, Switzerland, March 1987.

61. F. M. Tesche, et al., Magnetohydrodynamic Electromagnetic Pulse (MHDEMP) Interaction with Power Transmission and Distribution Systems, ORNL/SUB/90SG828/1, Martin Marietta Energy Systems, Inc., Oak Ridge National Laboratory, February 1992.

62. F. M. Tesche, "An Overview of High Altitude EMP Effects on Power Systems," Proceedings of the 7th International Zurich Technical Exhibition on EMC, Zurich, Switzerland, March 1987.

63. F. M. Tesche, "Comparison of the Transmission Line and Scattering Models for Computing the HEMP Response of Overhead Cables,", IEEE Transactions on Electromagnetic Compatibility, 34(2), (May 1992).

64. F. M. Tesche, and P. R. Barnes, "Transient Response of a Distribution Circuit Recloser and Control Unit to a High-Altitude Electromagnetic Pulse (HEMP) and Lightning," IEEE Transactions on Electromagnetic Compatibility 32(2), (May 1990).

65. F. M. Tesche and P. R. Barnes, "The HEMP Response of a Overhead Power Distribution Line," IEEE Transactions on Power Delivery 4(3), 1937-44, (July 1989).

66. F. M. Tesche and P. R. Barnes, "Development of a New High-Altitude Electromagnetic Pulse (HEMP) Environment and Resulting Overhead Line Responses," Electromagnetics 8(2-4), 213-40, (1988).

67. F M. Tesche and P. R. Barnes, "A Multiconductor Model for Determining the Response of Power Transmission and Distribution Lines to a High-Altitude Electromagnetic Pulse (HEMP)," IEEE Transactions on Power Delivery 4(3), 1955-64, (July 1989).

68. F. M. Tesche and P. R. Barnes, "Extrapolation of Measured Power System Response Data to High-Altitude EMP Excitation," IEEE Transactions on Electromagnetic Compatibility 30(3), 38692, (August 1988).

69. D. E. Thomas, C. Wiggins, and P. R. Barnes, "On the HEMP Emvpronment for Protective Relays," submitted to the IEEE Transactions on Power Delivery. 
70. M. A. Uman, et al., The Effects of Lighting and High Altitude Electromagnetic Pulse on Power Distribution Lines, to be published as ORNL report, Martin Marietta Energy Systems, Inc., Oak Ridge National Laboratory

71. M. A. Uman, Voltages Induced by Lightning on Power Distribution Lines, ORNL/Sub/84-89650/1, Marti Marietta Energy Systems, Inc., Oak Ridge National Laboratory, March 1988.

72. C. L. Wagner and W. E. Feero, Recommended Engineering Practice to Enhance the EMI/EMP Immunity of Electric Power Systems, ORNL/Sub/91-SG913/1, Martin Marietta Energy Systems, Inc., Oak Ridge National Laboratory, December 1992.

73. C. M. Wiggins, D. E. Thomas, T. M. Salas, HEMP-Induced Transients in Electric Power Substations, ORNL/Sub/88-SC863, Martin Marietta Energy Systems, Inc., Oak Ridge National Laboratory, February 1992.

74. Z. Yacoub, et al., "Voltages Induced on a Power Distribution Line by Overhead Cloud Lightning", Proceedings of the 1991 International Conference on Lightning and Static Electricity, Cocoa Beach, Fla., April 16-19, 1991.

75. H. W. Zaininger, Electromagnetic Pulse (EMP) Interaction with Electrical Power Systems, ORNL/Sub/82-47905/1, Martin Marietta Energy Systems, Inc., Oak Ridge National Laboratory, August 1984.

76. H. W. Zaininger, et al., HEMP Interaction with an Electric Power Distribution Circuit, ORNL/Sub/84-73986/2, Martin Marietta Energy Systems, Inc., Oak Ridge National Laboratory, August 1985. 
ORNL-6708

\section{INTERNAL DISTRIBUTION}

1-10. P. R. Barnes

11. G. E. Courville

12. C. W. Curtis

13. P. S. Gillis

14. M. A. Kuliasha

15. B. W. McConnell

16. D. T. Rizy

17. R. B. Shelton
18. J. N. Stone

19. J. P. Stovall

20. ORNL Patent Office

21. Central Research Library

22. Document Reference Section

23-25. Laboratory Records

26. Laboratory Records-RC

\section{EXTERNAL DISTRIBUTION}

27. V. D. Albertson, Dept. of Electrical Engineering, University Of Minnesota, 123 Church Street, S.W., Minneapolis, MN 55455.

28. G. Applegren, Main Coordination Center, 1 n301 Swift Road, P.O. Box 278, Lombard, Illinois 60148.

29. G. H. Baker, HQ DNA/RAEE, 6801 Telegraph Road, Alexandria, VA 22310-3398.

30. G. D. Birney, Western Area Power Administration, P. O. Box 3402, Golden, CO 80401 .

31. P. D. Blair, Energy and Materials Program, Congress of the United States, Office of Technology Assessment, Washington, DC 20510.

32. Ellery Block, SAIC, 6725 Odyssey, Huntsville, AL 35806-3301.

33. L. Bolduc, Hydro Quebec, 1800 Montee Ste Julie, Varennes, QC, Canada, J3X 1S1.

34. E. H. Brehm, Dipl.-Ing., ASEA Brown Boveri AG, Postfach 351, Abt. GK/NP 25, 6800 Mannheim 1, Germany.

35. Larry Bressler, Western Area Power Administration, P. O. Box 3402, Golden, CO 80401.

36. Bob Brewer, Office of Energy Management, U.S. Dept. of Energy, CE-141, 5G023/FORS, 1000 Independence Ave., SW, Washingtı ๆ, DC 20585. 
37. W. J. Budney, Distribution Systems, Public Service Electric \& Gas Co., 80 Park Plaza, Newark, NJ 07101.

38. H. S. Cabayan, Lawrence Livermore National Laboratory, P.O. Box 5504, L-81, Livermore, CA 94550.

39. R. F. Campbell, Transmission \& Electrical Projects, Tennessee Valley Authority, 3N 53A Missionary Ridge Place, Chattanooga, TN 37402-2801.

40. J.P. Castillo, R\&D Associates, P.O. Box 9377, Albuquerque, NM 87119-9377.

41. J. Chadwick, 902 Glamis Circle, Signal Mountain, TN 37377.

42. A. Chodorow, Mission Research Corp., 1720 Randolph Rd. SE, Albuquerque, NM 87106-4245.

43. D. J. Christofersen, Manager, Electrical Engineering Division, United Power Association, P. O. Box 800, Elk River, MN 55330-0800.

44. P. Chrzanowski, Evaluation \& Planning Program, Lawrence Livermore National Lab, P.O. Box 808, L-81, Livermore, CA 94550.

45. R. F. Chu, Research Engineer, Philadelphia Electric Co., Research Division (S10-1), 2301 Market Street, Philadelphia, PA 19101.

46. Lynn Coles, Principal Policy Advisor, SERI, 1617 Cole Boulevard, Golden, CO 80401.

47. O. R. Compton, Richmond Plaza, P. O. Box 26666, Richmond, Virginia 23261.

48. T. B. Cook, 80 Castlewood Dr., Pleasanton, CA 94566.

49. G. H. Coplon, U.S. Department Of Energy, Rm. 8F089, 1000 Independence Avenue, S.W., Washington, DC 20585.

50. Dave Curtice, T/Systems, 480 San Antonio Road, Suite 200, Mountain View, CA 94040.

51. S. J. Dale, Manager Transmission Technology Institute, ABB Power T\&D Company Inc., Centennial Campus, 1021 Main Campus Drive, Raleigh, NC.

52. Raymond Dunlop, Director of Research, New England Power Service Co., 25 Research Drive, Westborough, MA 01582.

53. H. Elbadaly, Underground T\&D Research Manager, Consolidated Edison Company, 4 Irving Place, New York, NY 10003. 
54. Bill Getson, E-Systems, Inc., ECI Division, MS-31, P.O. Box 12248, St. Petersburg, FL 33730.

55. D. Fagnan, Philadelphia Electric Co., 2301 Market Street, Philadelphia, PA 19101.

56. W. E. Ferro, Electric Research and Management, Inc., P.O. Box 165, State College, PA 16804.

57. Larry Fry, Teledyne Brown Engineering, MS-50, 300 Sparkman Dr., Huntsville, AL 35807-7007.

58. Hugh Gardner, 7466 Twin Brook Drive, Chattanooga, TN 37421.

59. R. Gates, EMP Program Manager, FEMA, RM 606, 500 C Street, S.W., Washington, DC 20472.

60. P. R. Gattens, Allegheny Power, 800 Cabin Hill Dr., Greensburg, PA 15601.

61. M. R. Gent, President, North American Electric Reliability Council, 101 College Road East, Princeton, New Jersey 08540-8060.

62. M. Granger, Hydro-Quebec, Planning Systems Division, 855 East Ste-Catherine, 20 ieme etage, Montreal, Quebec, Canada, H2L 4PS.

63. J. D. Gregory, Southern Company Services, Inc., P. O. Box 2625, Birmingham, AL $35202-2625$.

64. I. Gyuk, Program Manager, U.S. Department of Energy, 1000 Independence Ave., S.W., Washington, DC 20585.

65. Wayne Hilson, Manager, Transmission and Electrical Systems Department, Tennessee Valley Authority, Missionary Ridge, 3 North 41, 1101 Market Street, Chattanooga, TN 37402-2801.

66. Helen M. Ingram, Director, Udall Center for Studies in Public Policy, The University of Arizonia, 803/811 East First Street, Tucson, AZ 85719.

67. J. Kappenman, Minnesota Power, 30 W. Superior St., Duluth, Minnesota 55802.

68. S. Kashyap, Defense Research Establishment - Ottawa, Electronics Division, 3701 Carling Ave.. Ottawa, Ontario K1A0Z4, Canada.

69. Ken Klein, Energetics, Inc., 501 School Street, Washington, DC 20024.

70. Kurt Klunder, Office of Energy Management, U.S. Dept. of Energy, CE-14, 5E036/FORS, 1000 Independence Ave., SW, Washington, DC 20585. 
71. J. L. Koepfinger, Director, Systems Studies and Research, Duquesne Light Company, One Oxford Center, 301 Grant Street (19-5), Pittsburgh, PA 15279.

72. B. Korbutiak, Alberta Power, Ltd., 10035 195th St., Edmondton, Alberta T5J 2V6, Canada.

73. J. Kulsetås, Division Manager/Research Director, Norwegia Glectric Power Research Institute, Division of High Voltage Technology, N-7034 Trondheim, Norway.

74. E. Larsen, General Electric, ESDS Bldg. 2, Rm 642, One River Road, Schenectady, NY 12345.

75. Major Robert Launstein, Defense Nuclear Agency, DNA/RAEE, 6801 Telegraph Rd., Alexandria, VA 22310.

76. R. C. Liimatainen, Committee on Science, Space and Technology, 374 Rayburn House Office Bldg., Rm. B., Washington, DC 20515.

77. J. Lloyd, CEHND-ED-SY, U.S. Army, Engineering Division Huntsville, P.O. Box 1600, Huntsville, AL 35807.

78. C. L. Longmire, Mission Research Corporation, P.O. Drawer 719, Santa Barbara, CA 93102.

79. Calvin D. MacCracken, President, Calmac Manufacturing Corp., 101 West Sheffield Avenue, Englewood NJ 07631.

80. David Mayhall, Jawrence Livermore National Laboratory, P.O. Box 808, L-156, Livermore, CA 94550.

81. A. P. Meliopoulos, Georgia Tech, School of Electrical Engineering, Atlanta, GA 30332.

82. S. R. Mendoza, Salt River Project, P.O. Box 52025, Phoenix, AZ 85072-2025.

83. D. Merewether, Electro-Magnetic Applications, Inc., P.O. Box 8482, Albuquerque, NM 87198-8482.

84. N. V. Mesland, Tot Keuring Van Elektrotechnische, Materialen, 6800 ET Arnhem, P.O. Box 9035, The Netherlands.

85. D. L. Nickel, Manager, ABB Power Systems, Inc., 777 Penn Center Blvd., Pittsburgh, PA 15235-5927.

86. S. Nilsson, Program Manager, Electric Power Research Institute, Electrical Systems Division, 3412 Hillview Avenue, P.O. Box 10412, Palo Alto, CA 94303. 
87. B. M. Pasternack, American Electric Power Service Corp., 1 Riverside Plaza, P.O. Box 16631, Columbus, OH 43216-6631.

88. J. Z. Ponder, PJM Interconnection, 955 Jefferson Ave., Norristown, PA 19426.

89. J. W. Porter, Electric Power Research Institute, Suite 100, 1019 Nineteenth St. N.W., Washington, DC 20036.

90. M. Rabinowitz, Electric Power Research Institute, 3412 Hillview Avenue, P.O. Box 10412, Palo Alto, CA 94303.

91. W. Radasky, Metatech Corporation, P.O. Box 1450, Goleta, CA 93116-1450.

92. J. J. Ray, Division of Syst. Planning, BPA, P.O. Box 3621, Portland, OR 97208.

93. T. W. Reddoch, Electrotek Concepts, Inc., 10305 Dutchtcwn Rd., Suite 103, Knoxville, TN 37932.

94. J. R. Rempel, Physicist, Defense Intelligence Agency, Washington, DC 20340-6761.

95. Dietrich J. Roesler, U.S. Department of Energy, CE-141, 1000 Independence Avenue SW, Washington, DC 20585.

96. F. Rosa, Division of System Intg., Nuclear Regulatory Commission, MS P1030, Washington, DC 20555.

97. J. E. Scalf, Florida Power \& Light Company, P. O. Box 14000, 700 Universe Blvd., Juno Beach, FL 33408.

98. W. J. Scott, Hq DNA/RAEE, 6801 Telegraph Road, Alexandria, VA 22310-3398.

99. Joe Sefcik, Nuclear Design, Lawrence Livermore National Lab, 2.O. Box 808, L-22, Livermore, CA 94550.

100. C. H. Shih, Manager, Electrical Research, American Electric Power Service Corp., 1 Riverside Plaza, Columbus, $\mathrm{OH} 43215$.

101. Jacqueline B. Shrago, Director, Office of Technology Transfer, Vanderbilt University, 405 Kirkland Hall, Nashville, TN 37240.

102. M. L. Sloan, Austin Research Associate, 1101 Capital of Texas Highway S., Building B, Suite 210, Austin, TX 78746.

103. P. Sullivan, Philadelphia Electric Co., 2301 Market Street (S10-1), Philadelphia, PA 19101. 
104. Dr. Robert L. Sullivan, Dean of Engineering, Florida Institute of Technology, 150 West University Boulevard, Melbourne, FL 32901.

105. E. R. Taylor, ABB Power Systems, Inc. , 777 Penn Center Blvd., Pittsburgh, PA 15235-5927.

106. R. L. Taylor, Director - Power Supply, Florida Power \& Light Co., 9250 W. Flagler, Miami, FL 33102.

107. F. M. Tesche, Consulting Scientist, 6921 Spanky Branch Dr., Dallas, TX 75248.

108. M. V. Thaden, Potomac Electric Power Co., 1900 Pennsylvania Ave., NW, Rm. 311, Washington, DC 20068.

109. James L. Thompson, 501 Barrington Road, Signal Mountain, TN 37377.

110. J. Towle, 3906 Bagley Ave. N., Suite 100, Seattle, WA 98103.

111. E. F. Vance, 6885 HWY 1187, Fort Worth, TX 76140.

112. D. R. Volzka, Senior Project Engineer, Wisconsin Electric Power Company, 333 West Everett Street, Milwaukee, WI 53201.

113. C. L. Wagner, 4933 Simmons Dr., Export, PA 15632.

114. R. Walling, General Electric Company, Building 2, Rm 507, One River Road, Schenectady, NY 12345.

115. R. C. Webb, Defense Nuclear Agency, RAEE, 6801 Telegraph Road, Alexandria, VA 22310.

116. E. P. Wigner, Consultant, 8 Ober Road, Princeton, NJ 08540.

117. M. W. Wik, Forsvarets Materielverk, Stockholm, S-11588, Sweden.

118. D. Woodford, Suite 400, 1619 Pembina Ave., Winnipeg, Manitoba, R-3T-2G5, Canada.

119. F. S. Young, Director, Electrical Systems Division, Electric Power Research Institute, P.O. Box 10412, Palo Alto, CA 94303.

120. R. W. Zwickl, Space Environment Laboratory, Mail Stop R/E/SE, Boulder, CO 80303.

121. Office of Assistant Manager for Energy, Research and Development, DOE-ORO, P.O. Box 2001.

122-123. OSTI, U.S. Department of Energy, P.O. Box 62, Oak Ridge, TN 37831. 

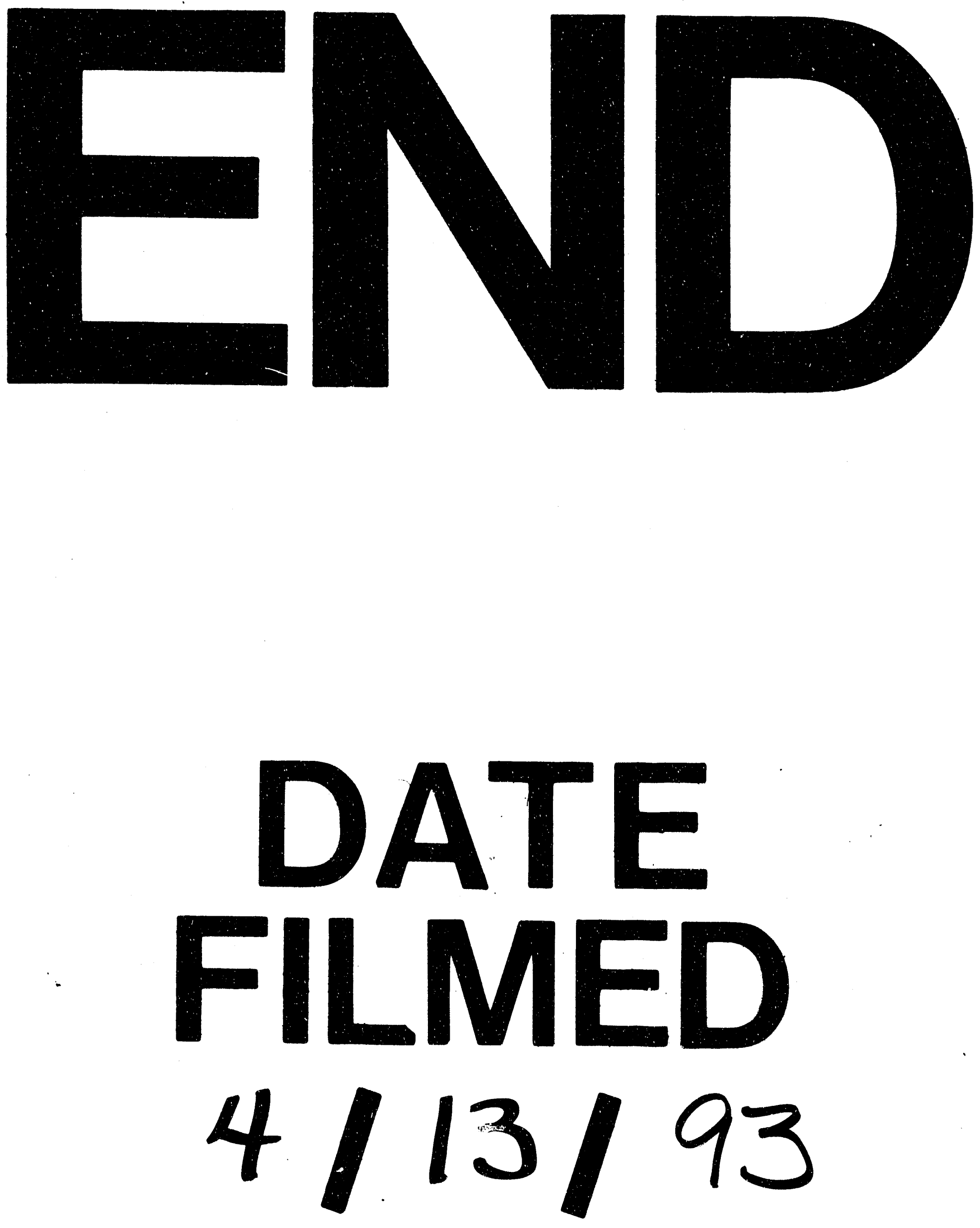
